\title{
Tribological Properties of Structural Ceramics
}

Donald H. Buckley and Kazuhisa Miyoshi Lewis Research Center

Cleveland, Ohio

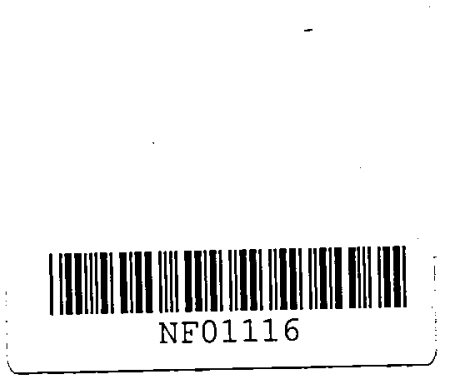

LERRRY ROPY

OCT 251985

LAIVGLEY RESEARCH CEIITER

LIERARY, NASA

HAMPTON, VIRGINII! 


\section{TRIBOLOGICAL PROPERTIES OF STRUCTURAL CERAMICS \\ Donald H. Buckley and Kazuhisa Miyoshi \\ National Aeronautics and Space Admintstration \\ Lewis Research Center \\ Cleve land, Ohio 44135}

\section{ABSTRACT}

The tribological and lubricated behavior of both oxide and non-oxide ceramics are reviewed in this chapter. Ceramics are examined in contact with themselves, other harder materials and metals. Elastic, plastic and fracture behavior of ceramics in solid state contact is discussed. The contact load necessary to initiate fracture in ceramics is shown to be appreciably reduced with tangential motion. Both friction and wear of ceramics are anisotropic and relate to crystal structure as has been observed with metals. Grit size effects in two- and three-body abrasive wear are observed for ceramics. Both free energy of oxide formation and the $d$ valence bond character of metals are related to the friction and wear characteristics for metals in contact with ceramics. Surface contaminants affect friction and adhesive wear. For example, carbon on silicon carbide and chlorine on aluminum oxide reduce friction while oxygen on metal surfaces in contact with ceramics increases friction. Lubrication increases the critical load necessary to initiate fracture of ceramics both in indentation and with sliding or rubbing. Ceramics compositions both as coatings and in composites are described for the high temperature lubrication of both alloys and ceramics.

\section{INTRODUCTION}

Tribology is the study of the adhesion, friction, wear, and lubricated behavior of materials in solid-state contact. The function of tribological research is to bring about a reduction in the adhesion, friction, and wear of mechanical components, to prevent their failure and provide long, reliable 
component life through the judicious selection of materials, operating parameters, and lubricants.

Mechanical systems such as bearings, gears, and seals are examples of components involving tribology. Wherever, however, two or more solid surfaces are in contact with relative motion between the surfaces, tribology is involved. Such mundane activities as a man's morning shave involve both friction and corrosive wear, and considerable tribological research has gone into increasing blade life and reducing friction and shaving discomfort. More complex tribological systems are gyro bearings and instrumentation gears requiring attention to many elements.

A notable amount of research effort has been put into fundamental studies of tribological behavior of metals. In recent years the increasing potential for the use of ceramics as components in mechanical systems has focused attention on these materials. Tribological studies have been conducted with ceramic materials to understand better those physical and chemical properties of ceramics which will affect their behavior when in contact with themseives, other ceramic or metals.

Metals readily deform plastically whereas ceramics, while having high strength, are normally brittle and fracture with little or no evidence of plastic flow. At the interface between two ceramics in solid state contact under load and relative motion, plastic flow has been observed in the surface layers of a number of ceramics. Plastic flow has been observed with magnesium. oxide (DuFrane et al., 1960), aluminum oxide (Steijn, 1961) and stlicon carbide (Miyoshi et al., 1979), for example, under relatively modest conditions of rubbing contact.

Factors which influence the mechanical behavior of materials when plastic flow occurs such as dislocations, vacancies, stacking faults and crystal structure will influence the friction and wear behavior of ceramics (e.g. 
$\mathrm{Al}_{2} \mathrm{O}_{3}$ ) (Kronberg, 1957) and comparisons can be made between the anisotropic friction behavior of ceramics and metals.

Surface films such as adsorbates markedly influences the adhesion, friction and wear behavior of ceramics. Further, with ceramics and other ionic solids, the presence of surface films such as water and surface-active organics can influence adhesion, friction and wear by altering the amount of plastic deformation that will occur during sliding or rubbing (Buckley, 1968 and 1969).

The objectives of this chapter are to review the adhesion, friction, wear and lubrication of ceramics, anisotropic friction and wear behavior and the effect of surface films and ceramics--metal interactions. Analogies with metals will be made where applicable. Both oxide and non-oxide ceramics will be discussed. Ceramics used as high temperature lubricants will also be described.

\section{TRIBOLOGICAL SURFACES}

The surfaces of all solids (in general) contain irregularities or hills and valleys. These surface irregularities, commonly called asperities, are indicated schematically in Fig. 1. The surfaces of most solids that are prepared either in the laboratory or in the machine shop have surfaces which contain these asperities. Figure $7(a)$ shows an exaggeration of the steepness of these surface irregularities. Typically surface irregularities have an angle of approximately $15^{\circ}$ from the surface. Thus, they are falrly flat hills or peaks which lie on the solid surface. These irregularities are found on ceramics, metals, polymers, and carbon bodies.

With ceramics, in addition to the presence of surface irregularities or asperities, the solid surface itself is covered with films. For example, on the outermost surface there may be a layer of adsorbate, which is frequently water vapor or hydrocarbons from the environment that may have condensed and 
become physically adsorbed to the solid surface. This is shown schematically in Fig. $1(b)$.

With ceramic materials an oxide layer made or may not be present. For example, on aluminum oxide, oxygen is an integral part of the structure so an oxide surface layer is not expected. For non-oxide ceramics such as silicon carbide an oxide layer may be present on the surface.

Beneath the adsorbed layer and for non-oxide ceramics possible oxide layers there may be a strained layer of material. This can result from the forming process when the ceramic surface was prepared. For example, in grinding, honing, machining, or polishing, the surface layers (the outermost layers of the solid surface) become highly strained. This strain is reflected in what is called the worked layer, which lies subsurface and is an integral part of the ceramic itself in the surface region. The amount of this material present and the degree of deformation that occurs are functions of two factors: (1) the amount of work or energy that was put into the deformation process, and (2) the nature of the ceramic. Some ceramics are much more prone to deformation than are others. This, of course, would be reflected in these surface layers.

With ceramics these finishing processes can also produce surface and subsurface originated microcracks and other defects. These also then exist in the surfictal layers.

These layers are extremely important because their properties, from a surface chemistry point of view, can be entirely different from the bulk ceramic. Likewise, their mechanical behavior is also influenced by the amount and the depth of deformation of the surface layers and the concentration of surface and subsurface microcracks.

When two solid surfaces are placed in contact, the actual contact takes place over a very small area, actually at the tips of the asperities or 
surface irregularities, as indicated in $\mathrm{Fig} . \mathrm{I}(\mathrm{c})$. These asperity regions initially deform elastically, and, if the load is sufficiently high, they deform plasticaliy until the load can be supported; that is, the real contact area continues to increase with deformation until the contact area is suffictent to support the load applied to the two surfaces in solid-state contact. With deformation of the surfaces, the adsorbed layers, oxides, and strained layers generally deform with the material. In some cases, depending on the mechanical properties of the surface films, they are completely compliant with the surface and deform with it. In other cases, they become disrupted or dislodged, and solid-state clean material contact can occur at the asperity junctions through the films because of the breakup of these surface flims. When that occurs, clean, solid-state contact occurs. At this point the basic material properties of the solids themselves become extremely important in the adhesion, friction, and wear behavior of the materiais.

The surface irregularities or asperities indicated in Fig. 1 are gross surface geometric characteristics of solids. In addition to these there are many other minor or smaller surface irregularities that can occur on the surface of solids. For example, it was mentioned earlier that most practical solid surfaces contain these irregularities or asperities. There are, however, situations where the surface is free of these surface defects. For example, although brittle inorganic crystals which are cleaved have atomically smooth surfaces, they contain surface cleavage steps. Between the cleavage steps are atomically smooth or flat surfaces; in other words, a complete absence of surface asperities. This occurs, for example, in the cleavage of a brittle materfal-like aluminum oxide along cleavage planes. In addition, some metals can be cleaved in this fashion at cryogenic temperatures; for example, zinc can be cleaved along the basal plane at liquid nitrogen temperatures. 
In addition to cleavage steps, other small alterations in surface geometry can occur. These include, for example, growth steps that develop during the growth of crystalline solids. They can also develop when materials solidify from the liquid state. There are deposits that may form a solid surface that serve as surface geometric irregularities. These could include deposits of solid wear particles, particles that adhere in a particular manner to the surface, and deposits of materials to the surface from the environment. With all crystalline materials there are also grain boundaries. Grain boundaries are high energy sites on a solid surface; they generally contain or act as an irregularity in the surface because of a cusp that usually forms at the region where the two adjacent grains meet in the boundary. The resulting cusp at the surface, then, is a defect or alteration in the surface geometry. Almost all surfaces that are prepared by mechanical techniques contain scratches in addition to the foregoing. Scratches can be generated by the rubbing of one hard surface particle against a softer surface or by the entrapment of sma11, hard particles between two solid surfaces.

Another type of surface defect that can be found is the etch pit when the environment or a constituent of a lubricant interacts with the surface in a reactive manner. The high energy sites (e.g., grain boundaries and dislocation sites) react chemically much more rapidly than the bulk of the surface. This can result in surface defects which are commonly called etch pits. The minor defects can then be superimposed on the larger surface defects or asperities so that, in any real surface, there may be a combination of these particular geometric irregularities. That is, there may be asperities in addition to, for example, growth steps, scratches, or etch pits. The presence of all of these then comprise the real surface geometry of a solid. When examining a surface it thus becomes apparent that a number of considerations are important. Surface chemistry is important from the 
viewpoint of the surface films that are adsorbed on the solid surface. Bulk material properties are important from the standpoint of the layers that may develop as a result of deformation in the surface layers. Physics is important because of the nature of the bonding or adhesion of the solid surfaces in solid-state contact. Similarly, mechanics is important to understand the deformation mechanisms when two solid surfaces are brought into solid-state contact.

\section{CERAMIC CONTACT}

Ceramics behave much like metals when they are brought into contact with themselves or other solids. For example, when a silicon carbide surface is placed in contact with a diamond under relatively low contact pressure, elastic deformation can occur in both the silicon carbide and the diamond. With the initiation of tangential motion sifding occurs at the interface. No groove formation due to plastic flow and no cracking of silicon carbide with sliding are observed (Mfyoshi and Buckley, 1979).

Under the foregoing condition, friction is a function of the shear strength of the elastic contact area, as indicated in Fig. 2(a). That is, the relation between coefficient of friction $\mu$ and load $W$ is given by an expression of the form:

$$
\mu=k W^{-1 / 3}
$$

The exponent arises from an adhesion mechanism for the surfaces in solid state contact and the area of contact being determined by the elastic deformation. Over the entire load range, the mean contact pressure is $1.5 \times 10^{3}$ to $3.5 \times 10^{3} \mathrm{~N} \mathrm{~mm}^{-2}$. The maximum pressure at the center of the contact area according to Hertz will be $2.3 \times 10^{3}$ to $4.9 \times 10^{3} \mathrm{~N} \mathrm{~mm}^{2}$. A similar contact and friction characteristic for diamond on diamond was also found by Bowden and Tabor (1964). 
A large increase in applied contact pressure, however, results in a complete reversal in friction characteristic with an applied load. Fig. 2 (b) reveals an entirely different mode of deformation and energy dissipation with an estimated maximum hertzian contact stress ranging from $1.4 \times 10^{4}$ to $3.0 \times 10^{4} \mathrm{~N} \mathrm{~mm}^{-2}$ in the contact area. Plastic deformation occurs in the silicon carbide, causing permanent grooves during sliding with very small cracks being generated in the silicon carbide. The diamond itself indents the silicon carbide without suffering any permanent deformation. The frictional energy dissipated during sliding following solid state contact is due to shearing at the interface and plastic deformation of the silicon carbide, 1.e. plowing of silicon carbide by the diamond. The relation between coefficient of friction $\mu$ and load $W$ now takes the form $\mu=k w^{0.3-0.4}$. The exponent depends on the crystallographic orientation of the silicon carbide. When a much higher contact pressure due to high concentrated stress in the contact area is provided, the sliding action produces gross surface and subsurface cracking as well as plastic deformation (Miyoshi and Buckley, 1979). Under such conditions wear debris particles and large fracture pits due to cleavage are observed. The area of a fracture pit is a few times larger than that of the plastically deformed groove. In this case, the coefficient of friction is much higher (four times or more) than those in elastic and plastic contacts, as indicated in Fig. 2. Although fracture and plastic deformation in silicon carbide are responsible for the friction behavior observed, most of the frictional energy dissipated during sliding is due to fracturing of the silicon carbide. The coefficient of friction is strongly influenced by the bulk properties of the silicon carbide such as crystallographic orientation and the presence of grain boundaries (Miyoshi and Buckley, 1979 and 1983). 


\section{ADHESION AND FRICTION}

Ceramics, like metals. when in the atomically clean state, will exhibit strong bonds of adhesion when brought into solid state contact. This will occur for ceramics in contact with themselves and other materials. There are a number of bulk and surface properties of ceramics that will affect the nature and magnitude of the adhesive bond forces that develop for ceramics. Surface properties include electronic surface states, fonic species present at the surface, chemistry of the contacting material and the nature of surface contaminants present. Bulk properties include crystallography, cohesive binding energy and the presence or absence of defects.

When two solids are brought into contact and adhesion occurs there are a variety of methods which can be employed to quantify the bonding forces. Some involve tensile type puling on the interface. Others are based upon tangential shearing of the junction. Friction force measurements are based upon the latter method. The stronger the interfaclal bond strength the greater is the resistance to move one surface relative to the other tangentially. Such measurements are sufficiently sensitive that the effects of various fractions of an adsorbed monolayer on interfacial adhesion can be readily quantified (Buckley, 1983).

\section{Oxide Ceramics}

oxide ceramics such as aluminum oxide, nirconium oxide, titanium oxide (rutile), and magnesium oxide have been considered for tribological applications. With these materials, both structure and surface chemistry are extremely important to adhesion behavior.

In order to determine if friction and accordingly adhesion characteristics of the oxide ceramic sapphire were anisotropic, experiments in vacuum were conducted with two orientations of a sapphire ball. The first orientation involved the plane $(0001)$ and the direction [11 20$]$ and the second 
the $(10 \overline{0} 0)$ plane [0001] direction in adhesive contact and sliding against a disk of sapphire with its basal plane essentially parallel (within $4^{\circ}$ ) to the interface. The results obtained in these experiments are presented in Fig. 3 together with data for the (0001) plane and [11 $\overline{2} 0]$ direction orientation examined in air to demonstrate the influence of adsorbed films.

The data of Fig. 3 indicate that the adhesion and friction characteristics of sapphire are highly anisotropic. At a moderate load of $0.25 \mathrm{~N}$, the friction coefficient for the basal orientation was less than half that obtained for the prismatic orientation. As load is increased to $1.0 \mathrm{~N}$ both orientations show a decrease in friction coefficient. The marked differences in adhesion and friction for the two orientations are, however, maintained.

With metals, experiments conducted in vacuum serve to reduce the presence of adsorbed films and surface oxides. Sapphire has a layer of surface oxygen atoms as an inherent part of its structure, however adsorbed films may be removed on vacuum degassing. The differences in friction coefficients for the basal orientation of sapphire in air and at $10^{-8} \mathrm{~Pa}$ (Fig. 3) may be related to the influence of these films on the adhesion characteristics of sapphire.

The influence of crystallographic direction for both prismatic and basal orientations were determined, and the results obtained are presented in Table 1. With the basal orientation, less adhesion and a lower coefficlent of friction was observed in the preferred sip direction [1120]. This orientation dependence is simflar to that observed for the hexagonal metal beryllium (Buckley, 1983).

The crystallographic direction of movement on a surface, reflecting changes in atomic orientation, also affect adhesion and friction force. This is demonstrated in the data of Table 1 for the prismatic and basal orientation of sapphire in contact with sapphire. 
The results of Fig. 3 and Table 1 indicate that the adhesion and friction characteristics of sapphire are highly anisotropic. There is further, marked evidence for plastic deformation at the contacting interface of the crystals as revealed by etching of sapphire crystals after friction experiments. The adhesion and friction behavior of sapphire in the figure and table is very analogous to that observed with hexagonal metals in general (Buckley, 1965 and 1966). With hexagonal metals in sliding friction experiments the friction coefficient is always less on preferred slip planes in preferred slip directions than for other silp systems. Similar results are obtained with ceramics. The easy glide or slip plane for sapphire is the basal plane under deformation. Further, the preferred slip direction is the [1120] direction when the crystal is deformed plastically. With plastic deformation occurring at the contacting interface under an applied load it might be anticipated that the prismatic orientation of sapphire would exhibit stronger adhesion and higher coefficients of friction than the basal orientation. There are a number of prismatic planes which can slip in the deformation process while, with the basal plane oriented paraliel to the sliding interface, only a single set of planes are involved.

When plastic deformation occurs at the sliding interface and a larger number of slip planes are involved, applied stresses in the form of the load may be distributed over a number of equivalent planes. With the basal plane parallel to the sliding interface, any applied normal load can only tend to compress basal planes. Even with metals such as beryllium, this orientation will support tremendous loads to the point where it will literally explode with no evidence of slip occurring on other slip planes. A larger true contact area can then occur in the sliding process with prismatic rather than with basal orientation. Further, when a number of prismatic planes undergo slip, there exists the possible interaction of such slip planes to produce 
locks similar to the Lomer-Cottrell locks observed in the face centered cubic metals. Such locks can produce marked increases in shear strength.

With sapphire the yield point for the prismatic orientation is different than that for the basal orientation. For the latter orientation the yield stress is ten times less at elevated temperatures (Wachtman et al., 1979).

The shear strength for sapphire calculated from adhesion and friction measurements together with bulk shear strength data obtained from King et al. (1954) are presented in Table 2. The surface shear strength is from twenty to thirty times that of the bulk shear strength. Simflar results have been observed with a number of inorganic crystals by king et al. (1954). A possible explanation for this increase may be that indicated by Wachtman, et a1. (1959). Microscopic plastic deformation occurring at the sliding interface permits relief of stresses in the sapphire resulting in an increase in shear strength.

Steijn (1961), Duwe 11 (1962 and 1964), Brown et a1. (1964) and King (1964) were all concerned with the influence of orientation on adhesion and friction of aluminum oxide. The experiments of these investigators were all conducted at higher speeds than reported in this chapter. Loads, however, in many instances were lighter than in the data presented herein. It should be indicated that interface temperatures in a vacuum environment may be considerably higher than those encountered in air under equivalent conditions of load and speed because of poor heat dissipation. Further, higher coefficients of friction in vacuum for sapphire (Fig. 3) will further increase interface temperatures. For example, increases in adhesion and friction observed in this study at $500^{\circ} \mathrm{C}$ was not observed in shear strength measurements of Scheuplein and Gibbs (1962) until temperatures of approximately $1000^{\circ} \mathrm{C}$. Some surface contaminants such as chlorine are not fully removed below $1000^{\circ} \mathrm{C}$. 
The data of Buckley (1965) showed the recrystallization of titanfum metal at a $500 \mathrm{~g}$ load and the same speed as employed here for aluminum oxide. Titanium would normally recrystallize in the temperature ranges of plastic deformation discussed here for sapphire. It is therefore reasonable to assume plastic deformation for aluminum oxide under similar load conditions.

The lower coefficient of friction measured for the basal orientation of sapphire sliding on sapphire in Fig. 3 are as might be predicted from observed slip behavior. In plastic deformation experiments of Scheuplein and Gibbs (1962) very little resolved shear stress was necessary to initiate slip on basal planes while the shearing stress for prismatic slip was at the maximum.

The data presented in Fig. 3 indicate adhesion at the siliding interface with the prismatic orientations resulting in prismatic slip. With hexagonal metals such as cobalt, orientation of single crystals for prismatic siip results in slip plane and slip plane dislocation interaction, strain hardening and consequently increase in measured friction. Cross slip mechanisms which can account for strain hardening in metals must be modified for sapphire since only two slip systems operate. Cross slip on the same system may not be possible but prismatic plane dislocations can interact with stacking faults of the basal planes producing strain-hardening. Scheuplein and Gibbs (1962) referred to strain hardening for prismatic slip in sapphire. This interaction of basal stacking faults cannot occur for the basal slip mechanism because the basal dislocations and stacking faults lie in the same plane. The adhesion and friction data presented for aluminum oxide (sapphire) indicate, that plastic deformation dictates the adhesion and sliding behavior.

If oxide ceramics are in solid state contact with softer materials such as metals the marked difference in elastic and plastic deformation of the two materials can result in considerable plastic deformation of the softer material. This can contribute to the adhesion of the materials because it 
increases real contact area. In Fig. 4 a rider (hemisphere) of sapphire slid on a single crystal flat of copper. The specimen materials were then reversed so that a single crystal copper rider slid on a sapphire flat. The coefficient of friction for the sapphire silding on copper was 1.5. With copper sliding on sapphire, it was 0.2 . In both instances, adhesion of copper to sapphire occurred. The difference in friction coefficient for the two experiments is due to the effects of plowing or plastic deformation of the copper. Plowing of the copper disk, which did not occur with the sapphire disk contributed heavily to measured friction.

In both experiments the sapphire adhered to the copper as indicated in the photomicrographs of Fig. 4. The wear on the sapphire flat was occasioned by fracture along (0001) planes, subsurface and parallel to the sliding interface.

When metals contact oxide ceramics, surface chemistry plays a very important role in the observed adhesion and friction behavior. Various metals were siid on a flat of sapphire with the basal orientation in the sapphire parallel to the sliding interface. With the metals which form stable oxides such as copper, aluminum, nickel, rhenium, cobalt and beryllium, adhesion of the metal occurred to the oxygen ions in the outermost atomic layer of the sapphire. The manner of bonding is shown in Fig. 5 .

If the same sifding experiments are conducted with metals that do not form stable oxides in vacuum (gold and silver) strong chemical bonding does not occur at the interface, adhesion is weak and wear to the hard oxide ceramic is absent. This is demonstrated in the data of Fig. 6 for gold and silver sliding on the basal orientation of sapphire.

The photomicrographs of Fig. 6 indicate an absence of any wear to the sapphire such as observed in $\mathrm{Fig}$. 4 with copper. The only surface markings in Fig. 6 were polishing scratches. The coefficients of friction were also 
one-half in Fig. 6 of that observed with copper in contact with sapphire in Fig. 4. In Fig. 4 fracture occurred with adhesion in the sapphire because the interfacial metal to the sapphire bond strength is greater than the cleavage or fracture strength in the sapphire and accordingly sapphire fracture occurs. With gold and silver in Fig. 6, the weakest region is the interface, and simple shear takes places at this location with bond strength no stronger than found with lubricant molecules as evidence by the friction coefficient of 0.1 which is comparable to that experienced with effective boundary Tubrication.

Experiments by other investigators confirmed a chemical bond between metals and the oxygen fons indicated in Fig. 5 (Pepper, 1976). The shear strength of the metal to sapphire contact were correlated with the free energy of formation of the metal oxide by Pepper (1976).

Attempts have been made to explain in a more fundamental manner the metal to sapphire bonding. This could assist in understanding the wear of hard ceramic oxides in general. Molecular-orbital energies have been examined for clusters in bulk sapphire and the metal-sapphire interface by Johnson and Pepper (1982).

The primary interaction at the metal-sapphire interface, as revealed herein, occurs between the metal $d$ orbitals and otherwise nonbonding $p$ orbitals of the oxygen ions at the surface of the sapphire crystal, 1.e., the nonbonding $p$ orbitals at the top of the valence band. It will be noticed in Fig. 7 that the d-orbital energies of the isolated metal atoms, as determined by this method, are in close proximity to the sapphire valence band, and the position of the atomic level relative to the top of the valance band changes systematically through the series $\mathrm{Fe}, \mathrm{Ni}, \mathrm{Cu}$, and $\mathrm{Ag}$. The metal-sapphire contact interaction produces at the interface sites of spatially localized occupied metal (d)-oxygen(p) bonding molecular orbitals of energies near the 
bottom of the sapphire valence band and metal (d)-oxygen( $p$ ) antibonding molecular orbitals of energies near the top of the sapphire valence band. This is exemplified for $\mathrm{Fe}$ by the bonding and antibonding orbital wave-function contour maps in Figs. $8(a)$ and (b), respectively. For Fe and Ni, the antibonding orbitals are only partially occupied and are located well above the valence band within the band gap, as shown in Fig. 7. For example, the antibonding $\mathrm{Fe}(\mathrm{d})-\mathrm{O}(\mathrm{p})$ orbital mapped in $\mathrm{Fig} .8(\mathrm{~b})$ is unoccupled. For $\mathrm{Cu}$ and $\mathrm{Ag}$, the antibonding orbitals are fully occupied and are located close to the top of the valence band. In addition to this covalent bonding and antibonding interactions between the metal and sapphire substrate, there is an ionic component associated with metal-to-oxygen charge transfer at the metal-sapphire interface. These results on covalent and ionic interactions Indicate that a chemical bond is in fact established between metal atoms and the oxygen anions on the sapphire surface, and that the ionic component of bonding is proportional to the metal(d) and oxygen(p) orbital electronegativity difference.

Relative to the strength of this bond, it is well known from the most elementary principles of quantum chemistry that the occupation of antibonding molecular orbitals tends to cancel the effects of occupled bonding orbitals, and reduces the net chemical bond strength in comparison to the situation where only bonding orbitals are occupied. Therefore, the increase in occupancy of the metal-sapphire antibonding orbitals through the series of fe, $\mathrm{Ni}, \mathrm{Cu}$, and $\mathrm{Ag}$ should tend to lower the net metal-sapphire chemical bond strength, which correlates with the significant reduction in metal-sapphire contact strength measured in adhesion, friction and wear experiments. The decrease of the friction coefficient from 0.2 for $\mathrm{Cu}$ to 0.1 for $\mathrm{Au}$ or $\mathrm{Ag}$ is explained qualitatively by the combined effects of increasing antibonding orbital occupancy and decreasing metal-to-oxygen charge transfer. The 
relatively small friction coefficlents and shear strengths of $\mathrm{AU}(0.1)$ and $\mathrm{Ag}$ $(0.1)$ are consistent with the fact that the fully occupied antibonding orbitals shown in Fig. 4 essentially cancel the covalent contributions of the bonding orbitals, leaving only small residual ionic and van der Waals contributions.

Similar studies should be conducted on other oxide ceramics to determine if a general relationship between interfacial bonding and fracture can be developed. This could lead to a better understanding of friction.

With other oxide ceramic materials such as $\mathrm{Mn}-\mathrm{Zn}$ and $\mathrm{N} \mathbf{H}-\mathrm{Zn}$ ferrites adsorbates are present on the surface from the environment, and these include water vapor and carbon, the latter as typically shown in Fig. 9. With metals, in addition to the presence of adsorbate films, beneath this layer of adsorbate is generally a layer of metal oxide.

The adsorbed films on ferrites and metals as well as oxides on metals can generally be removed by sputtering or heating. For example, in Fig. 9 the adsorbates have disappeared from the spectrum taken after sputter-cleaning. In addition to oxygen and iron, which are associated with the composition of Mn-Zn ferrite, the XPS peaks obtained from the sputter cleaned surface indicate manganese and zinc, but there is no adsorbate.

The adsorbates play a very large role in adhesion, mechanical and chemical behavior of ferrite surfaces in tribological systems. Experiments carried out in two environments, vacuum and argon at atmospheric pressure, Indicate the effects of adsorbate and environment on adhesion and friction properties of ferrites. The removal of adsorbed films from the surfaces results in very strong interfacial adhesion and high friction.

The data obtained from the experiments in vacuum are to be anticipated from chemical interactions and the important role they play in the adhesion 
and friction of clean ferrite-to-metal couples. The behavior is analogous to that observed for aluminum oxide.

The coefficients of friction reflecting interfactal adhesion for varfous metals sliding on ferrites measured in argon atmosphere were all neariy 0.1 to 0.2. The chemical activity or inactivity of metal does not appear to play a role as to adhesion and friction in argon as the argon is only physically adsorbed. A prerequisite for this sameness in friction is that the metals form a stable metal oxide, and the environment is responsible for providing the adsorbates on the surface.

Experiments of a similar nature with ferrites contacting polymeric magnetic materials indicate that adsorbed nitrogen will appreciably reduce adhesion and accordingly friction. oxygen conversely increases adhesion and friction.

The adhesion and accordingly coefficients of friction for polycrystalline $N_{1}-Z n$ and Mn-Zn ferrite in contact with metals can be correlated with the free energy of formation of the lowest metal oxides, as shown in Fig. 10. The correlation shown in Fig. 10 clearly indicates that the metal-ferrite adhesive bond at the interface is primarily a chemical bond between the metal atoms and the large oxygen anions in the ferrite surface, and the strength of this bond is related to oxygen to metal bond strength in the metal oxide (Miyoshi and Buck ley, 1984).

All metals indicated in Fig. 10 adhered and transferred to the surface of the ferrites. In general the less active the metal, the less adhesion and transfer there is to the ferrite. Titanium, having a much stronger chemical affinity to the elements of the ferrite, exhibited the greatest amount of transfer (Miyoshi and Buckley, 1981).

The relative chemical activity of the transition metals (metals with partially filled $d$ shells) as a group can be ascertained from their percentage 
d-bond character, as established by Pauling (1949). The frictional properties of metal-metal and metal-nonmental contacts have been shown to be related to this character (Buckley and Miyosh1, 1984). The greater the percentage of d-bond character, the less active is the metal, and the lower is the adhesion and friction. Conversely, the more active the metal, the greater is the adhesion.

The coefficients of friction for various metals in contact with $\mathrm{Ni}-\mathrm{Zn}$ ferrites are replotted with solid symbols in Fig. 11 as a function of the d-bond character of the transition metal. Titanium, which is a chemically very active metal, exhibits a considerably higher coefficient of friction in contact with ferrite than does rhodium, which is a metal of lesser activfty.

Figure 11. also presents the coefficient of friction for various metals in contact with the ferrites, in which both metal and ferrite specimens were exposed to $\mathrm{O}_{2}$ gas (99.99 percent pure). The data reveal increases in adhesion and the coefficients of friction for $\mathrm{Ni}-\mathrm{Zn}$ ferrite-to-metal interface. The enhanced bond of the metal oxide to ferrite may be due to the formation of complex oxides on establishing contacts.

Non-0xide Ceramics

The high strength and excellent oxidation and creep resistance of non-oxide ceramics such as silicon carbide make them extremely important materials for high-temperature mechanical and electronic applications in severe environments. Materials such as silicon carbide are used for example, in stable high-temperature semiconductors, in gas turbine blades, in turbine ceramic seals, and as an abrasive for grinding (0'Connor and Smiltens (1960) and Marshal and Faust (1973)).

In grinding, as a result of the extremely small chip size and the high wheel speed involved, the instantaneous temperatures and pressures at the tip of a silicon carbide abrasive particle are extremely high (Komanduri and Shaw, 
1976). The temperature and pressure may reach the meiting point and the yield pressure of the metal workpiece. In addition, the freshly formed surfaces of silicon carbide are highly reactive with metals. The fundamentals of the surface chemistry involved in adhesion, and friction of silicon carbide are not clearly understood.

Experimental work has been conducted at room temperature to gain an understanding of the surface of sllicon carbide and its adhesion and friction properties (Miyoshi and Buckley, 1978 and 1979). These properties depend strongly on the surface characteristics of silicon carbide. In turn the surface characteristics of silicon carbide are strongly affected by temperature. For example, an increase in temperature in vacuum can cause graphitization of the carbon and depletion (by evaporation) of the silicon. The adhesion and friction behavior of silicon carbide at high temperatures in vacuum is therefore important. The knowledge gained from such studies can assist in achieving a better understanding of the surfaces characteristics of silicon carbide when in solid state contact with other materials.

Properties of interest with silicon carbide involve the adhesion, friction and wear, and the metal transfer to the silicon carbide. Surfaces of silicon carbide were heated to $1500^{\circ} \mathrm{C}$ in a vacuum at a pressure of $10 \mathrm{nPa}$ by resistance heating, and then the surfaces were analyzed at room temperature. The surface chemistry of silicon carbide crystals was analyzed by $X$-ray Photoelectron Spectroscopy (XPS) as well as Auger Electron Spectroscopy (AES). AES analysis of silicon carbide preheated above $1200^{\circ} \mathrm{C}$ indicate that the silicon AES peak almost disappears and is nearly undetectable by AES, and the carbon peak is only of the graphite form at the surface. XPS analysis, however, clearly indicates evidence for sllicon and carbide being present as well as graphite on the silicon carbide surface preheated above $1200{ }^{\circ} \mathrm{C}$. The 
XPS spectra of the silicon carbide surface is unaffected by preheating in the temperature range of from 1200 to $1500{ }^{\circ} \mathrm{C}$.

A depth profile into the surface layers for elements present in silicon carbide surface preheated to $1500{ }^{\circ} \mathrm{C}$ obtained as a function of sputtering time is presented in Fig. 12. The graphite peak decreases rapidiy in the first 30 min of sputtering, and thereafter it gradually decreases with an increase in the sputtering time to about $18 \mathrm{hr}$. After $18 \mathrm{hr}$ the graphite peak does not change much with sputtering time. On the otherhand, the silicon and carbide-carbon peaks increase gradually with increasing sputtering time to $20 \mathrm{hr}$.

Ellipsometric measurements have been conducted with two different $(0001)$ faces of the silicon carbide crystals, one which consisted of silicon atoms $(0001)$ and the other which consisted of carbon atoms (0001) at temperatures above $1200{ }^{\circ} \mathrm{C}$ (Meyer and Loyen, 1975). In $1 \mathrm{hr}$ of heating at $1300{ }^{\circ} \mathrm{C}$ the layer, which consists of carbon (graphite), on the C-face grows to about $100 \mathrm{~nm}$, whereas the layer on the St-face does not grow thicker than $10 \mathrm{~nm}$ even with longer heating.

The silicon carbide $\{0001\}$ surfaces consisted of both silicon atoms and carbon atoms, and etching silicon carbide surface in molten salt $1 \mathrm{NaF}+2 \mathrm{KCO}_{2}$ gives both a smooth surface for the si-face and a rough one for the C-face. The apparent thickness of the layer, which consists of graphite at the surface and is produced by heating above $1200^{\circ} \mathrm{C}$ for $1 \mathrm{hr}$, is about $100 \mathrm{~nm}(1000 \mathrm{~A})$, is equivalent to a depth of a layer sputter etched for about $18 \mathrm{hr}$ shown in Fig. 12 .

The graphitization of the outermost surficial layer of silicon carbide is believed to be as follows. The analysis depth with AES is of the order of $1 \mathrm{~nm}$ or less, and an elemental concentration as low as 0.1 percent of a monolayer can be detected and identified. Therefore, the outermost surficial 
layer, which consists of mostly graphite and very little silicon, on the silicon carbide surface is concluded to be of the order of $1 \mathrm{~nm}$. This estimation is consistent with the proposition of Bommel et a 1 (1975), that is, the collapse of the carbon of three successive silicon carbide layers is the most probable mechanism for the initial stages of the graphitization of silicon carbide basal planes.

Adhesion and sliding friction experiments were conducted with single-crystal silicon carbide in contact with iron in vacuum. Friction-force traces resulting from such sliding were generally characterized by strong adhesion and a stick-silp behavior. All the coefficients of friction reported in Fig. 13 are static values reflecting adhesion forces at the interface. The coefficient of static friction is defined as: $\mu_{S}=F_{7} / W$, where $F_{7}$ is the friction force at which the first break, in adhesion occurs, that is, the first motion is observed in the friction-force trace, and $W$ is the normal load.

The coefficient of friction of the silicon carbide $\{0001\}$ surfaces in contact with iron as a function of sliding temperatures is indicated in Fig. 13. The iron rider was sputter cleaned with argon ions. The silicon carbide was in the as-received state after it had been baked out in the vacuum system. The specimen was then heated to the sliding temperature before the friction experiment was initiated. The coefficient of friction increased slightly with increasing temperature at temperatures below $400{ }^{\circ} \mathrm{C}$. Above $400{ }^{\circ} \mathrm{C}$, the coefficient of friction decreased with an increase in temperature in the range of 400 to $600{ }^{\circ} \mathrm{C}$. The general decrease in friction at these temperatures is due to the gradual removal of the contaminants of carbon and oxygen from the surface. This is in contrast to metals where removal of surface films increases friction. The coefficient of friction increased with increasing temperature in the range of 600 to $800{ }^{\circ} \mathrm{C}$. The increase in friction at the temperature can be associated with increased adhesion and 
increased plastic flow in the area of contact. Above $800^{\circ} \mathrm{C}$ the coefficient of friction decreases rapidly with an increase of temperature. The rapid decrease in friction above $800{ }^{\circ} \mathrm{C}$ correlated with the graphitization of the silicon carbide surface.

Inspection of the single-crystal silicon carbide surface after sliding contact with iron revealed adhesion and transfer of iron to silicon carbide. Fig. 14 presents scanning electron micrographs at the beginning of wear tracks on the as-received and treated surfaces of stlicon carbide generated by a single pass of the iron at sliding temperatures of room, $800^{\circ}$ and $1200^{\circ} \mathrm{C}$. It is obvious from Fig. 14 the copious amount of iron adhered and transferred to the silicon carbide. The increase in friction at these higher temperatures can be associated with increased adhesion and increased plastic flow in the area of contact. Above $800{ }^{\circ} \mathrm{C}$ the coefficient of friction decreases rapidly with an increase of temperature. The rapid decrease in friction above $800{ }^{\circ} \mathrm{C}$ correlated with the graphitization of the silicon carbide surface.

Iron undergoes the crystal transformation from $B C C$ to $F C C$ at $912{ }^{\circ} \mathrm{C}$ but this does not account for observed friction behavior. Similar experiments. with rhodium metal, where a transformation does not occur, gave similar friction.

As may be seen in Fig. $14(\mathrm{a})$, sliding at $800^{\circ} \mathrm{C}$ produces more transfer than does sliding at room temperature. In general, a very thin transfer film and very small.particles are seen in the contact area. The higher the sliding temperature, the more adhesive transfer produced. Above $800{ }^{\circ} \mathrm{C}$, there was very littie evidence for a smooth and continuous adhered transfer film on the wear track, as typically seen in Fig. 14(c). There was rather transfer that was rough, and discontinuous in nature. The appearance of iron transfer may be related to the graphite layer, of the order of to $7 \mathrm{~nm}$, on the silicon carbide surface. 
The adhesion and sliding of iron on a silicon carbide surface at elevated temperatures results in formation of cracks and fracture pits in the silicon carbide surface. The fracture wear occurs very locally and in very small areas in the sliding contact region.

Studies have also been conducted with polycrystalline silicon carbide to examine its abrasion and friction characteristics at various temperatures by the authors of this chapter.

Figure 15 indicates the coefficients of friction for polycrystalline sliticon carbide surface in contact with iron as a function of siding temperatures. The iron rider was sputter-cleaned with argon fons. At temperatures below $400^{\circ} \mathrm{C}$, after the specimen was heated to the sliding temperature, the coefficient of friction increased sightly with further increases in temperature. The coefficient of friction increased sightly with increasing temperature in range 400 to $800{ }^{\circ} \mathrm{C}$ and was due to the removal of the contaminants carbon and oxygen from the surface as will be seen in a discussion of XPS results. The increase in friction at these temperatures was associated with increased adhesion and plastic flow in the area of contact. Above $800{ }^{\circ} \mathrm{C}$ the coefficlent of friction decreased rapidly with an increase of temperature. The rapid decrease in friction above $800{ }^{\circ} \mathrm{C}$ correlated with the graphitization of the silicon carbide surface.

Figures 16 and 17 present the surface chemistry of polycrystalline sllicon carbide analyzed by XPS. The as-received crystal was heated at various temperatures in a vacuum.

The XPS survey spectra of the polycrystalline SiC surfaces obtained before sputter cleaning revealed oxygen peaks, in addition to slificon and carbon peaks. The crystals were in the as-received state after they had been baked out at a temperature of $800{ }^{\circ} \mathrm{C}$ in a vacuum system of $30 \mathrm{nPa}$. The XPS spectra of $\mathrm{Si}_{2 p}, \mathrm{C}_{1 s}$ and $\mathrm{O}_{1 s}$ obtained from narrow scans on the 
polycrystalline SiC surfaces are presented in Fig. 16. The crystals were heated at various temperatures in a $30 \mathrm{nPa}$ vacuum. The temperatures given in Fig. 17 were the highest temperatures to which the specimen had been heated. All the XPS spectra were taken at room temperature after bake out and heating. The results of Fig. 16 indicate a significant influence of temperature on the SIC surface characteristics.

The photoelectron emission lines for $\mathrm{Si}_{2 \mathrm{p}}$ of the SiC are primarily split asymmetrically into doublet peaks at temperatures from room to $600{ }^{\circ} \mathrm{C}$ (Fig. 16(a)). The doublet peaks at 100.4 and $103.4 \mathrm{eV}$ are due to distinguishable kinds of silicon compounds, which are $\mathrm{SiC}$ and $\mathrm{SiO}_{2}$, respectively. Above $600^{\circ} \mathrm{C}$, the $\mathrm{Si}_{2 \mathrm{p}}$ photoelectron peak associated with SiC is seen exclusively in the spectra.

The $c_{15}$ photoelectron emission lines of the SiC at temperatures from room to $400{ }^{\circ} \mathrm{C}$ include primarily three distinguishable kinds of peaks assoclated with: (1) adsorbed carbon contaminant, (2) graphite, and (3) SiC (Fig. $16(b)$ ). The $c_{15}$ photoelectron emission lines at temperatures from 600 to $1200^{\circ} \mathrm{C}$ are split asymmetrically into doublet peaks associated with graphite and SIC.

The $0_{1 \mathrm{~s}}$ photoelectron emission lines primarily include $\mathrm{SiO}_{2}{ }^{-0}$ is peaks as well as small concentrations of adsorbed oxygen contaminants at temperatures from room to $800^{\circ} \mathrm{C}$. At temperatures of 1000 and $1200^{\circ} \mathrm{C}$ the $0,1 \mathrm{~s}$ peaks are negligible.

In addition, a change in the vertical height of the peaks is observed in Fig. 16. There are distinct influences of temperature on the $\mathrm{Si}_{2 p}, \mathrm{C}_{15}$, and $0_{1 s}$ concentrations. The heights of the $\mathrm{St}_{2 \mathrm{p}}$ ( $\mathrm{SiC}$ and $\mathrm{SiO}_{2}$ ), $\mathrm{C}_{1 \mathrm{~s}}$ (adsorbed carbon contaminant, graphite, and $S i C$ ), and $0_{15}$ (adsorbed oxygen contaminant and $\mathrm{SiO}_{2}$ ) on the SiC surfaces are plotted as a function of temperature in $\mathrm{Fig} .17$. The trend of concentration of the $\mathrm{Si}_{2 p}$ related to 
the SIC is similar to that of $C_{15}$ related to carbide over the entire temperature range of from room to $1200^{\circ} \mathrm{C}$, as shown in $\mathrm{Fig} .17(\mathrm{a})$. The heights of $\mathrm{Si}_{2 p}$ and $\mathrm{C}_{1 s}$, which are related to the $\mathrm{SiC}$, increase linearly with increasing temperature to $800{ }^{\circ} \mathrm{C}$, and then decrease with increasing temperature above $800^{\circ} \mathrm{C}$. The carbon contaminant $C_{15}$ peak height decreases rapidly with increasing temperature to $400^{\circ} \mathrm{C}$, as shown in $\mathrm{Fig} .17(\mathrm{~b})$. The graphite $C_{1 s}$ peak is present even on the as-received (before any cleaning) SiC surface. This is a distinguishing feature of the sintered polycrystalline SiC, because the graphite $C_{15}$ peak is absent on the as-received single crystal SiC.

In Fig. $17(b)$, the graphite $C_{15}$ peak height is relatively constant at temperatures to $400^{\circ} \mathrm{C}$. Above $400^{\circ} \mathrm{C}$ the graphite $C_{15}$ peak height increases with increasing temperature. Large graphite peaks are observed at temperatures of $1000^{\circ} \mathrm{C}$ and $1200^{\circ} \mathrm{C}$. In other words, the surface of SiC is covered with a graphite layer.

The trend of the height of $0_{15}$ peak related to $\mathrm{SiO}_{2}$ is similar to that of $\mathrm{Si}_{2 \mathrm{p}}$ associated with $\mathrm{SiO}_{2}$, as shown in $\mathrm{Fig} .17(\mathrm{c})$. The peak heights of $\mathrm{SiO}_{2}-\mathrm{Si}_{2 \mathrm{p}}$ and $\mathrm{O}_{1 \mathrm{~s}}$ obtained from the SiC surface increase with increasing temperature to $600{ }^{\circ} \mathrm{C}$. Above $600{ }^{\circ} \mathrm{C}$ they decrease rapidly with increasing temperature. The amount of $\mathrm{SiO}_{2}$ present on the polycrystalline SiC was nearly three times more than that on the single crystal sic.

The XPS data of Figs. 12, 16 and 17 explain the friction data of Fig. 13 for single crystal silicon carbide and Fig. 15 for polycrystalline silicon carbide. For both forms of silicon carbide, surface graphitization markedly alters friction behavior. 


\section{ANISOTROPY}

Both oxide and non-oxide ceramics indicate anisotropic adhesion and friction behavior. The coefficient of friction and width of the permanent grooves, involving plastic flow and surface cracking, were measured as functions of the crystallographic direction of sliding on the $\{0001\}$, $\{10 \overline{0} 0\}$, and $\{11 \overline{2} 0\}$ planes of silicon carbide using a diamond rider in mineral o1l (Buckley and Miyosh1, 1984). The widths of the permanent grooves were obtained by average measurements of 20 samples from seven to ten scanning electron micrographs. The results presented in Fig. 18 indicate that the coefficient of friction and the groove width are influenced by the crystallographic orientation. The $\langle 11 \overline{2} 0\rangle$ direction on the basal $\{0001\}$ plane has the larger groove, primarily resulting from plastic flow, and is the direction of high friction for this plane. The $<0001\rangle$ directions on the $\{10 \overline{1} 0\}$ and $\{11 \overline{2} 0\}$ planes have the greater groove width and are the directions of high friction when compared with $\langle 11 \overline{2} 0\rangle$ on $\{10 \overline{1} 0\}$ and $\langle 10 \overline{0} 0\rangle$ on the $\{11 \overline{2} 0\}$ planes. The anisotropies of friction are $\mu<11 \overline{2} 0>/ \mu<10 \overline{1} 0\rangle=$ 1.2 on $\{0001\}, \mu<0001>/ \mu<17 \overline{2} 0\rangle=1.3$ on $\{10 \overline{1} 0\}$, and $\mu<0001>/ \mu<10 \overline{1} 0\rangle=$ 1.3 on $\{11 \overline{2} 0\}$.

Figure 18 also represents the contact pressure calculated from the data of the groove width in Fig. 18(b) and the Knoop hardness obtained by Shaffer (1964). The anisotropies of the contact pressure during sliding and the knoop hardness clearly correlate with each other.

Several siip systems have been observed in hexagonal silicon carbide, such as $\{0001\}<11 \overline{2} 0\rangle,\{3301\}<11 \overline{2} 0>$, and $\{10 \overline{1} 0\}<11 \overline{2} 0>$. The $\{10 \bar{T} 0\}<11 \overline{2} 0>$ slip system observed on the sliding surface was responsible for the anisotropic friction and deformation behavior of silicon carbide during sliding in the $\langle 10 \bar{T} 0\rangle$ and $\langle 11 \overline{2} 0\rangle$ directions on a $\{0001\}$ silicon 
carbide surface. The experimental results on the $\{0001\}$ plane generally agreed with Daniel and Dunn's (1949) resolved shear stress analysis based on the slip system $\{1010\}<11 \overline{2} 0>$. The minimum and maxima of the resolved shear stress for the $\{0001\}$ plane of hexagonal crystal match the hard and soft directions on that plane, that is, the $\langle 1010\rangle$ and $\langle 11 \overline{2} 0\rangle$ directions, respectively. These experimental results can not be explained by the Brookes, O'Neill, and Redfern's (1971) resolved shear stress analysis based on the $\{0001\}<11 \overline{2} 0>$ slip system. Thus, the anisotropies of friction and hardness on the $\{0001\}$ plane strongly correlate with the resolved shear stress, based on the slip system $\{1010\}<11 \overline{2} 0>$.

The anisotropies of friction, contact pressure (groove width), and Knoop hardness on the $\{10 \overline{1} 0\}$ and $\{11 \overline{2} 0\}$ planes were correlated with Daniels and Dunn (1949) resolved shear stress based on the $\{10 \overline{1} 0\}<0001>$ and $\{10 \overline{1} 0\}<11 \overline{2} 0>$ sip systems. They were also correlated with Brookes et a 1 . (1971) resolved shear stress based on the $\{12 \overline{1} 0\}<10 \overline{1} 0>$ sip system. However, the slip system actually observed in hexagonal sliticon carbide, the $\{10 \overline{1} 0\}<11 \overline{2} 0\rangle$ silp system, may be responsible for those anisotropies on the $\{10 \overline{1} 0\}$ and $\{11 \overline{2} 0\}$ planes.

Similar data for Knoop hardness anisotropy of tungsten carbide $\{0001\}$ and $\{10 \overline{1} 0\}$ surfaces have been reported by French and Thomas (1965) who used a resolved shear-stress calculation involving the $\{10 \overline{1} 0\}<0001>$ and $\{10 \overline{0} 0\}<11 \overline{2} 0>$ slip systems to explain the data. Thus, the anisotropies of friction, contact pressure, and Knoop hardness on the $\{0001\},\{10 \overline{10}\}$, and $\{11 \overline{2} 0\}$ planes of silicon carbide are primarily controlled by the slip system $\{10 \overline{0} 0\}<11 \overline{2} 0\rangle$. The data of $\mathrm{Fig} .18$ also suggests that the $\langle 10 \overline{0} 0\rangle$ direction on the basal plane of silicon carbide would exhibit the lowest coefficient of friction. 
Anisotropy results can be of two kinds. First, there is the observed vartation in friction and wear when the sliding surface is changed from one crystal plane to another for a given material. Secondly, there is the variation in friction and wear observed when the orientation of the sliding surface is changed with respect to a specific crystallographic direction on a given crystal plane. For example, the differences in the coefficients of friction with respect to the mating crystallographic planes and directions are significant under adhesive conditions as indicated in Table 3, Miyoshi and Buckley (1981). The data of Table 3 were obtained in vacuum with clean ferrite-ferrite oxide ceramics. The mating of preferred sipp plane and highest atomic density plane and direction, such as $\{110\}<1 \overline{1} 0>$ and $\{111\}<170>$ for Mn-Zn ferrite, gives the lowest coefficients of friction. In other words, the lowest coefficients of friction were obtained on the preferred slip plane when sliding in the preferred slip direction. Similar results have been obtained with sllicon carbide and aluminum oxide (sapphire). Their anisotropic friction is shown in Table 4. Again, the lowest coefficients of friction with silicon carbide and aluminum oxide were obtained on the preferred basal slip plane when sliding in the preferred $\langle 11 \overline{2} 0\rangle$ slip direction. The coefficient of friction reflects the force required to shear at the interface with the basal planes of the sflicon carbide or aluminum oxide parallel to the interface. The results presented in Table 4 indicate that the force required to resist the shearing fracture of the adhesion bond at the interface is lower in the preferred crystallographic $\langle 11 \overline{2} 0\rangle$ direction than it is in the $\langle 10 \overline{0} 0\rangle$ direction.

The frictional properties of the silicon carbide $\{0001\}$ surface in contact with iron at temperatures to $800{ }^{\circ} \mathrm{C}$ in vacuum indicated that the coefficient of friction was lower in the $\langle 11 \overline{2} 0\rangle$ direction than it was in the 
$<10 \overline{10} 0$ direction over the entire temperature range from room temperature to $800{ }^{\circ} \mathrm{C}$ (Miyosht and Buckley, 1982).

Under abrasion just as under adhesive conditions the differences in the coefficients of friction with respect to the crystallographic plane and direction were also significant. In this case, plowing was extremely important and influenced the friction and wear when ceramics contacted hard materials. With silicon carbide the <1010> directions on the basal $\{0001\}$ plane exhibited the lowest coefficient of friction and the greatest resistance to abrasion resulting from plastic deformation, as indicated in Table 5 . The anisotropic friction and wear on the $\{0001\},\{10 \overline{0} 0\}$ and $\{11 \overline{2} 0\}$ planes of silicon carbide were primarily controlled by the silp system $\{10 \overline{10}\}<11 \overline{2} 0\rangle$ and can be explained by a resolved shear stress calculation.

The abrasive wear of $M n-Z n$ ferrite sliding against a tape impregnated with $7 \mu \mathrm{m} \mathrm{Al}_{2} \mathrm{O}_{3}$ abrasive (the two-body condition) decreased in the order $\{211\}>\{111\}>\{100\}>\{1 \overline{1} 0\}$. The s1ip planes $\{1 \overline{10}\}$ (the most closely packed planes) of Mn-Zn ferrite exhibited the highest resistance to abrasion. Crystallographic direction effects on the wear of sapphire were also found (see Table 1 and Buckley 1972).

FRACTURE BEHAVIOR IN INDENTATION AND SLIDING

When two solid surfaces are placed in contact, high pressures are developed in the regions where real contact occurs at the interface. If a hard particle or a hard asperity of approximately spherical shape is in contact with a ceramic under load, the ceramic initially deforms locally according to the well-known Hertzian elastic equation (Hertz, 1881). Fractures with ring cracks have been produced in flat-surfaced ceramics critically loaded, either staticaliy or dynamically with hard spheres (Averbach, 1891), (Johnson, 1966), (Powell and Tabor, 1970), (Frank and Lawn, 1967), (Lawn, 1968) and (Lawn and Swain 1975). Hemispherical diamond 
indenters with radil characteristic of asperities or wear particles have been used to simulate real contact conditions (Buckley and Miyoshi, 1984).

Indenting with a hemispherical diamond indenter on a silicon carbide \{0001\} surface also results in the formation of circular (ring) cracks as well as in plastic deformation. Figure 19 presents scanning electron photomicrographs of the permanent indentations and the surrounding circular cracks generated by $0.1,0.02-$, and $0.008-\mathrm{mm}$-radius hemispherical diamond indenters. It becomes obvious from an examination of $\mathrm{Fig}$. 19 that the plastic deformation is accompanied by nearly perfect circular cracking in the silicon carbide.

It is very interesting that, as shown in Fig. 19, the crystallinity of the solid does not influence the geometry of the cracks. In other words, for anistropic solids such as a single crystal, some orientation dependence of the circular cracks produced in crystals with strong cleavage tendencies might be expected. Figure 19, however, reveals nearly circular cracks that were not crystallographically oriented.

Figures 19 (b) and (c) also reveal cracks propagating and expanding radially from the center of the contact circle. The cracks form preferentially on the planes of easy cleavage in the silicon carbide. These photomicrographs clearly show several slip lines, accompanying plastic deformation, in the indentations. The slip lines are crystallographicaliy oriented and are in the $\langle 11 \overline{2} 0\rangle$ directions. To summarize, the indenting experiments generally revealed (1) a plastically deformed indentation, (2) circular cracks produced around the indentation without cleavage tendencies of a given crystal, and (3) radial cracks with strong cleavage tendencies for the given crystals.

Figure $20(a)$ is a scanning electron photomicrograph of an indentation on the single-crystal silicon carbide surface accompanied by an exceptionally 
large fracture pit. The deformation and fracture made by the hemispherical indenter are also shown schematically in Fig. 20(b). There does not exist confirmed criteria or reasonable data to explain what conditions can produce this exceptionaliy large fracture pit. The pit is, however, found in the indenting experiments which were conducted with a $0.008-\mathrm{mm}-\mathrm{radius}$ hemispherical diamond indenter as a load of $10 \mathrm{~N}$. There was a discharge of fragments that were displaced from the surface of the silicon carbide. The fracture pit is like a volcanic crater. The crater forms a wide basin with steeply sloping sides. The fracture pit (crater) contains a plasticaliy deformed indentation in the center of the crater with small fracture pits. The crater is much larger than the indentation. The partially spherical surface in the crater and on the sides of the basin are all produced by the indenting and unloading actions of the diamond hemispherical indenter. There are many fracture steps on the surfaces of the spherical hillsides and on the sides of the basin. These steps may be due to sequential rupture of cohesive bonds along easy fracture planes such as the cleavage and quasicleavage planes. There are also many radial cracks on the nearly spherical fracture surface. The radial cracks are similar to those shown in Figs. 19 (b) and (c).

Figure 21 presents scanning electron photomicrographs of indentations on a single-crystal magnesium oxide $\{001\}$ surface (99.99 percent pure). The indenting experiments were conducted with the magnesium oxide in contact with

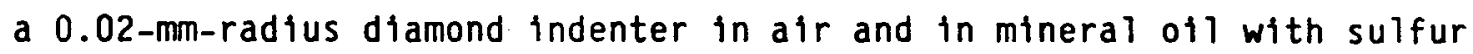
additive at a load of $0.25 \mathrm{~N}$. The observed patterns of nearly circular cracks and crystallographically oriented cracks are much like those previously mentioned for silicon carbide.

The most prominent features of all of the crack patterns presented in Figs. 19 to 21 may be plausibly explained by reference to Fig. 22 . When two solid surfaces are on contact, the stress concentration at the contact area 
may produce a small zone of plastic deformation in the solid, as shown in Fig. 22. Cracks will subsequently be initiated in the solid. The cracks develop a stable growth pattern in a subsurface region and on the surface around the plastic deformation zone during the loading and unloading processes. The cracks, which are generally circular, spherical, and radial, are schematically shown in Fig. 22 with a model. As suggested by this schematic diagram, spherical cracks appear to develop along the spherical stress trajectories (Miyoshi and Buckley, 1981 and 1982). Although crystalinity, is imposed on the crack geometries of anisotropic materials such as silicon carbide, it is possible that the cracks may grow and pile up in atomistic terms by the sequential rupture of cohesive bonds along the circular or the spherical stress trajectories shown in Fig. 22.

If a tangential force is applied to the normally loaded hemisphere, the additional tangential stress compresses the ceramic and opposes the tensile tangential stress due to the normal load on the leading edge of the rider. Conversely, at the trailing edge, the tensile tangential stress is augmented. As a result, cracking will be restricted to the rear of the contact region and suppressed at the leading edge. Cracks of this type have long been observed when a hard hemisphere slides over the surface of a brittle solid (Preston, 1922), (B11linghurst et a1., 1967), (Tanaka et a1., 1976), and (Sugita and Hashikawa, 1981).

sliding friction experiments have been conducted with a hemispherical diamond $(0.02 \mathrm{~mm}$ radius) in contact with a flat either of silicon carbide or of $\mathrm{Mn}-\mathrm{Zn}$ ferrite a non-oxide and oxide ceramic respectively. Figure 23 presents scanning electron photomicrographs of wear tracks on these surfaces. As shown in these photomicrographs, plastic deformation occurs in both the silicon carbide and the Mn-Zn ferrite. Two kinds of cracks are observed. One occurs in the wear tracks and propagates perpendicular to the sliding 
direction. The other is primarily observed on both sides of the wear track, propagating outward from the wear track. Two effects of potential importance for sliding contact are to be noted.

(1) The deformation and fracture behavior of ceramic materials may be very dependent on crystallographic orientation already discussed in reference to friction.

(2) The cracks may grow easily by the application of shearing force during sliding.

In 1891, Auerbach demonstrated that the load for Hertzian cone crack initiation varies linearly with the radius of the indenting sphere. This relationship, known as Auerbach's law, is of special interest to fracture theorists, (1) because it predicts a size effect, i.e., the smaller the indenter, the higher the stress required to initiate fracture, (2) because of its implications concerning the validity of certain brittle fracture criteria, and (3) because of its potential use as a means for measuring fracture surface energies. The theoretical justification of Auerbach's law has consequently been the object of many treatments of Hertzian fracture mechanics.

With a 0.02-mm-radius diamond hemisphere, circular cracks formed on the silicon carbide $\{0001\}$ surface, when the normal load exceeded $2 \mathrm{~N}$ in the indentation process. However, if a tangential force was applied, cracking occurred at the rear of the contact region for a normal load of $0.4 \mathrm{~N}$. Therefore, relatively small tangential stresses are very potent in producing conditions for fracture at the surface.

Figure 24 indicates the critical normal load of fracture of $\mathrm{Mn}-\mathrm{Zn}$ ferrite as a function of radius for both indenter and rider in indentation and in sliding contact. The load to fracture is directly proportional to the radius of the indenter and rider. The tangential force introduced by sliding plays an important role in the generation of surface fracture. With indentation, 
the cracks produced in the single-crystal Mn-Zn ferrite surfaces were not circular (ring) cracks, but rather extended in radial directions from the indentation. The cracks generated in sliding propagated perpendicular to the sliding direction in the wear tracks.

The removal of adsorbed films (usually water vapor, carbon monoxide, carbon dioxide, and oxide layers) from the surfaces of ceramics and metals results in very strong interfacial adhesion when two such solids are brought into contact. For example, when an atomically clean silicon carbide surface is brought into contact with a clean metal surface, the adhesive bonds formed at the silicon carbide-to-metal interface are sufficiently strong that fracture of cohesive bonds in the metal and transfer of metal to the silicon carbide surface results, as already discussed. This is observed in the scanning electron microscope.

Figure 25 presents scanning electron photomicrographs of the wear tracks generated by ten passes of rhodium and titanium riders on the SiC $\{0001\}$ surface along the $\langle 10 \bar{T} 0\rangle$ direction. Metal transfer is evident in the sliding contact. The sliding of a metal on a silicon carbide surface also results in local cracks along cleavage planes. The cracks, which are observed in the wear tracks, primarlily propagate along cleavage planes of the $\{10 \overline{1} 0\}$ orientation. In Fig. 25(a), the hexagonal light area is the beginning of a wear track. There is a large track where cracks primarliy along the $\{10 \overline{1} 0\}$ planes were generated, propagated, and then intersected during loading and sliding of the rhodium rider on the SiC surface. It is postulated from Fig. 25(a) that subsurface cleavage cracking of the $\{0001\}$ planes, which are parallel to the sliding surface, also occurs. Figure 25 (b) reveals a hexagonal pit and a copious amount of thin titanium film around the pit. The hexagonal fracturing is primarily due to cleavage cracking along $\{10 \overline{1} 0\}$ planes and subsurface cleavage cracking along the $\{0001\}$ plane. 
Similar fracture pit and multiangular wear debris, having crystallographically oriented sharp edges, have been previously observed with single-crystal Mn-Zn ferrite in contact with itself or a metal. The fracture behavior of the ferrite crystal during sliding was similarly found to be significantly dependent on the cleavage systems of the $\{110\}$ planes.

Figure 26 presents a scanning electron photomicrograph of the wear track on the silicon carbide $\{0001\}$ surface generated by single-pass sliding of an iron rider at $800^{\circ} \mathrm{C}$ in a vacuum of $10^{-8} \mathrm{~Pa}$. The wear track contains microfracture pits in very small areas in the sliding contact region. Under adhesive conditions then, the same two kinds of fracture pits were generally clearly observed as under the abrasive condtitions described earlier (figs. 20 and 23); namely: (1) pits with spherically fractured surfaces and (2) pits with polyhedrally fractured surfaces that are nearly of a hexagonal platelet shape. These results reconfirm that spherical fracture may occur even in single-crystal silicon carbide during sliding. Figure 27 presents a scanning electron photomicrograph of another spherical fracture, showing that a nearly spherfcally fractured surface can exist in the fracture pit in a very local area of the wear track.

The experimental evidence assembled in this section then allows the conclusion that substantially the same mechanisms operate to produce fracture under adhesive conditions as those described earlier under abrasive conditions.

\section{WEAR}

In general there are two types of wear encountered with ceramics. These are adhesive and abrasive wear. Adhesive wear occurs when adhesion takes place across an interface between two ceramic surfaces or a ceramic surface and another material. With tangential motion, that is silding or rubbing one surface over the other, if fracture occurs in the ceramic as discussed in the previous section, adhesive wear has taken place. In order for this type of 
wear to exist, adhesion must first occur. Secondly, the fracture strength of one of the two materials in contact must be less than that of the interfacial junction. If bonding in the interfaclar junctions is less than that in either of the two materials, fracture will occur at the interface with theoretically no wear occurring.

The presence and location of subsurface defects such as dislocations, vacancies, impurfties, and microcracks in the surfictal layers of the materials in contact will generally dictate the zones from which wear particles are generated. The extent and distribution of such defects will also to a large extent determine the size of the wear particles generated. Generally, the adhesive wear rate of ceramics such as aluminum oxide in air or when lubricated is extremely low. The excellent wear resistance of such materials make them extremely useful in mechanical applications requiring a minimum in wear, such as bearing surfaces in instruments and watches.

Abrasive wear occurs when two surfaces are brought into contact and one of the two surfaces is considerably harder than the other. Where free particles of the harder materials are generated and imposed at the interface between the two surfaces, these particles can cut into and remove material from the softer surface.

Abrasive wear can also occur when a third particle harder than one or both of the surfaces in contact becomes trapped in the interface. It can then operate to remove material from one or both surfaces.

Much like metals, ceramics exhibit anisotropic behavior in their wear properties. Wear behavior of ceramics just as in friction is also anisotropic. Frictional anisotropy of ceramics has already been discussed and wear to a lesser degree. 


\section{Oxide Ceramics}

The wear of oxide ceramics, as with friction, is highty anisotropic. This behavior has been measured for a number of oxide ceramics but in greatest detail for titanium dioxide (rutile) and aluminum oxide. The wear of these two oxides will therefore now be discussed in greater detall.

The wear rate of rutile is anisotropic both with respect to atomic plane and sliding direction (Duwe 11,1969 ). The variation of wear rate with plane can be seen from the data of Fig. 28. A seven fold difference in wear rate exists with a change in plane from that exhibiting the minimum wear to that having the highest rate of wear.

In Fig. 29 the effect of changing direction on the (001) plane is seen to influence wear rate. The least amount of wear occurs when sliding in the $<100>$ directions.

The wear rate of sapphire also varies with changes in crystallographic direction (Duwe11, 1967). The schematic of Fig. 30(a) shows the direction of sliding on the sapphire surface. The angle between the basal sheets and the crystal axis is indicated by the angle $\theta$. Wear rate is shown in Fig. $30(b)$ as a function of two sliding directions and variations in the angle $\theta$.

In Fig. 30 (b) the wear rate is higher when sliding along the direction of than when sliding against the basal sheet edges. When silding against the edges a difference in wear rate exists with a change in $\theta$. The differences in wear rates are, however, even greater with changes in $\theta$ when sliding is with the direction of the basal edges. This edge effect is not normally seen with metals.

The ferrites, particulariy the $\mathrm{Mn}-\mathrm{Zn}$ and $\mathrm{Ni}-\mathrm{Zn}$ ferrites, are ceramics widely used in magnetic heads for magnetic recording and playback devices. These ceramics are in sliding or intermittent contact with a tape. 
Magnetic tapes normally consist of $\mathrm{r}_{-} \mathrm{Fe}_{2} \mathrm{O}_{3}$ or $\mathrm{CrO}_{2}$ powder (small particies $1 \mu \mathrm{m}$ or less in size) held in a polymeric binder. Composed largely of oxide particles, the magnetic layer bears a certain resemblance to emery paper, a familiar abrasive.

The sliding of magnetic tape on a ferrite generates abrasion. Figure 31 presents electron micrograph and diffraction pattern of the $\{110\}$ plane of a Mn-Zn ferrite simulated head sliding against the magnetic tape.

The wear surface of ferrite revealed a large number of plastically deformed grooves formed primarily by the plowing actions of oxide particles held in the magnetic tape. The grooves are formed in the silding direction of the head. The width of the grooves formed on the wear surface was almost the same as the diameter of oxide particles (less than $0.1 \mu \mathrm{m}$ ). The electron diffraction pattern of the wear surface (Fig. 31(a)) indicates that the. surficial layer was nearly amorphous, but contained fine grains of approximately a few nanometers in diameter. The surface after etching at a depth of a few hundred angstroms from the wear surface had an enlarged streak spot pattern, as shown in Fig. 31(b). The streaking indicates the imposition of a large amount of plastic deformation. The amount of line defects can lead and give rise to streaking in diffraction patterns.

The surface etched to $0.3 \mu \mathrm{m}$ in depth had a sharp spot pattern without streaking. Further, the surface etched to a depth of $0.6 \mu \mathrm{m}$ from the wear surface had Kikuchi lines conststing of pairs of black and white parallel lines, which are an indication of the bulk crystalline structure of the ferrite specimen.

The abrasiveness of a magnetic tape containing needlelike ferric oxide $\mathrm{Y}-\mathrm{Fe}_{2} \mathrm{O}_{3}$ particles $(0.7-\mu \mathrm{m}$ long and $0.07 \mu \mathrm{m}$ diameter) was almost the same as that for lapping-tape, which is an abrasive impregnated tape containing 1.5-4m silicon carbide abrasives (mesh no. 6000), as presented in Fig. 32. 
Note that lapping-tapes normally use silicon carbide (SiC), aluminum oxide $\left(\mathrm{A}_{2} \mathrm{O}_{3}\right)$ or chromium oxide $\left(\mathrm{CrO}_{2}\right)$ powder of varlous grit sized held in a nonmetallic binder.

The lapping-tapes are very similar to the magnetic tapes and both tapes are very flexible. The specific wear rates shown in Fig. 32 were strongly dependent upon abrasive grit size. The specific wear rate is variable and depends on the kind of abrasive grit. The specific wear rates for grits of the same kind decreased rapidly with a decrease in grit size. A decrease in the specific wear rate for lapping-tapes with SiC was almost the same as that for lapping with tapes containing $\mathrm{Al}_{2} \mathrm{O}_{3}$ with the exception of $1.5 \mathrm{\mu m}$ SiC. Another interesting point to be observed from Fig. 32 is that, in spite of the nearly same grit size, of $7.1 \mu \mathrm{m}$ for $\mathrm{Al}_{2} \mathrm{O}_{3}$ and $6.3 \mu \mathrm{m}$ for $\mathrm{SiC}$, the abrasiveness of $\mathrm{Al}_{2} \mathrm{O}_{3}$ is approximately five times higher than that of the SiC. This may be related to the shape of particles and their distribution on the tape as well as the degree of enclosure of the particles by the binder. Thus, abrasion can occur when a magnetic tape slides against a ferrite surface. The abrasion and groove formation on the ferrite surface strongly depends on the nature of the surface, the tribological properties, bulk properties of both the ferrite and the tape, and on the environment.

Figure 33 presents wear volume for four crystallographic planes of ferrite $\{100\},\{110\},\{111\}$, and $\{211\}$ sliding against an abrasive impregnated lapping-tape, as a function of Vickers hardness of wear surfaces. A modffied commercial two-headed helical scan video tape recording system was used for wear experiments. The wear is influenced by the crystallographic orientation and vickers hardness. The wear of the ferrite surfaces was lower in the order $\{211\}>\{111\}>\{100\}>$ $\{110\}$. The slip planes (most closely packed planes) of $M n-Z n$ ferrite $\{110\}$ exhibits the highest resistance to the abrasion. 
Khrushchov and Babichev (1960-61) found that the resistance of metals to abrasive wear are related to their static hardness under two-body conditions, that is, the inverse of the abrasive wear rate is proportional to the hardness for a large number of annealed pure metals. Avient et a1. (1960) have theoretically and experimentally indicated that the resistance of metals to abrasive wear is inversely proportional to the vickers hardness of the fully work-hardened surface region on the abraded metal. Similar results have been obtained by Rabinowitcz et al. (1961) for three-body conditions. In Fig. 33 the wear volume is inversely proportional to the vickers hardness of the wear surface region on the abraded ferrites. It therefore appears that a similar relationship exists with ceramics.

Three body abrasion is a commonly encountered form of wear. It is also a necessary form of wear for the finish preparation of ceramic surfaces. For example, ferrite surfaces are prepared by abrasively wearing away at surface layers with silicon carbide grit.

Figure 34 presents replication electron photomicrographs and reflection electron diffraction patterns of wear surfaces of Mn-Zn ferrite abraded by 15 and 4 um silicon carbide grits in the three-body condition. The abrasion with $15 \mu \mathrm{m}$ silicon carbide grits results in brittle fractured facets on the Mn- $\mathrm{Zn}$ ferrite surface due to cleavage and quasi-cleavage, while 4 um silicon carbide grits mostly produced a large number of plastically deformed indentations and grooves. These were formed primarily by plowing and microcutting processes. A very few brittle fractured facets were observed on the surface abraded by the $4 \mu m$ silicon carbide grits.

Electron diffraction patterns taken on both abraded surfaces of single-crystal Mn-Zn ferrite contained continuous arcs extending over nearly a semicircle. The rest were blocked out by the shadow of the solid specimen. The arcs for the abraded surface generated by the $15 \mu \mathrm{m}$ silicon carbide grits 
are much sharper than those by $4 \mu \mathrm{m}$ stlicon carbide grits. The broad arcs indicate a large extent of plastic deformation on the abraded surface by $4 \mu \mathrm{m}$ silicon carbide grits. Thus, there is a drastic change in abrasion mechanism of the ferrite oxide ceramic.

\section{Non-Oxide Ceramics}

As discussed earlier in this chapter, plastic deformation occurs in silicon carbide components sliding in rubbing contact. The experimental evidence establishes that permanent grooves in sllicon carbide are formed during the sliding process and these can be seen in Fig. 35 . Figure 35 presents surface replication electron micrographs of a wear track generated by the diamond spherical rider with a radius of $0.02 \mathrm{~mm}$ and at 1 oads 30 and $40 \mathrm{~g}$. It is obvious from Fig. 35 that plastic deformation occurs in silicon carbide. The calculated mean contact pressure, at the load of $50 \mathrm{~g}$ with the rider of a radius $0.02 \mathrm{~mm}$, is about $2000 \mathrm{~kg} / \mathrm{mm}^{2}$. The maximum pressure at the center would be $3000 \mathrm{~kg} / \mathrm{mm}^{2}$ (yield pressure of silicon carbide). When a rider having a radius of $0.15 \mathrm{~mm}$ was used in these same experiments, small permanent grooves in silicon carbide were formed during sliding at the load of $50 \mathrm{~g}$. These observations with a diamond rider in sliding contact with silicon carbide indicate that silicon carbide can deform both elastically and plastically over the contact area. Thus, with diamond riders of radif of 0.15 and $0.02 \mathrm{~mm}$ the sliding truly occurred at the interface with plowing resulting in the silicon carbide.

Figures $35(a)$ and (b) also indicates surface cracking observed at loads of 30 and $40 \mathrm{~g}$. At $40 \mathrm{~g} \mathrm{load}$, however, two types of cracks are observed. One type is characterized by being very small in size, is observed in the wear track and propagates perpendicular to the sliding direction, indicated by $P$ - in Fig. 35(b). 
The second type is a crack, primarily observed on both sides of the wear track, propagating outward from the wear track indicated by $S$ in Fig. 35(b). These small cracks zig-zag along cleavage planes of $\{10 \overline{0} 0\}$ (see the $Z$ in $\mathrm{Fig} .35(\mathrm{~b})$ ). With a rider having a radius of $0.02 \mathrm{~mm}$, and with a load of less than 20 grams no cracks were observed. Similarly with a rider having a radius of $0.15 \mathrm{~mm}$ no visible cracks were observed over the entire load range. When, however, a rider having a radius of $0.02 \mathrm{~mm}$, was used and the load was above $30 \mathrm{~g}$, visible cracks were observed as indicated in Fig. 35(a). The first sign of cracking was the formation of a crack in the wear track $(P)$. Thus, the critical load for crack formation and for initiation of wear during sliding was $30 \mathrm{~g}$. Figure 36 presents a scanning electron micrograph of a wear track generated by the diamond conical rider. The specimen surface was lightly etched with molten salt $\left(1 \mathrm{NaF}+2 \mathrm{KCO}_{3}\right)$ at 700 to $800{ }^{\circ} \mathrm{C}$. In Fig. 35 , surface crack $P$ in the wear track, $S$ at the both sides of the wear track, and $L$ in the central portion of the wear track are observed. Most of the cracks of the. $S$ type are observed on both sides of the wear track and propagate outward from the wear track along $\{10 \overline{1} 0\}$ planes.

The fracturing of the silicon carbide surface is the result of cracks being generated, propagating and then intersecting. Figure $37(a)$ presents a scanning electron micrograph of the wear track and wear debris before gross sliding. In this case, both the loading and tangential force were applied to the specimen, but no gross sliding was observed.

In Fig. 37(a), a sector-shaped light area adjacent to and ahead of the wear track (plastic indentation) made by the rider is a large particle of wear debris which was generated during micro-sliding of the rider. A large number of small wear debris particles are also generated during loading and micro-siliding by the rider. It is anticipated from Fig. 37 (a) that gross 
fracturing is primarily due to cleavage-cracking along \{10T0\} planes and subsurface-cleavage-cracking made by micro-sliding of the rider. Further, Fig. 37 (b) presents a scanning electron micrograph of wear track and wear debris after gross sliding.

Figure 37 (b) reveals the wear debris has been divided (fractured) by gross-sliding of the rider, and the wear track is plastically deformed. The gross wear debris has sharp edges generated by cleavage cracking of $\{1010\}$ planes. Figure $37(\mathrm{c})$ presents the third stage of the fracturing process. One of the gross wear debris particles divided, fractured, and was ejected from the wear track. The track, where the wear debris particle was ejected reveals that the fracturing is the result of surface cracking as a result of cleavage of $\{10 \overline{10}\}$ planes and subsurface cracking as a result of cleavage along $\{10 \bar{T} 0\}$ planes. Dislodged gross wear particles could be observed near the wear track as shown in Fig. $37(\mathrm{c})$.

The sliding of an alloy rider on a silicon carbide surface results in the formation of cracks and fracture pits in and near the contact region of the silicon carbide surface as well as that on the metal rider. The cracks and fracture pits are similar to those observed for a diamond rider in contact with the silicon carbide surface.

Figure 38 presents a scanning electron micrograph of a wear track on a silicon carbide surface accompanied by an exceptionally large fracture pit. A large light area at the beginning of wear track is a fracture pit where the wear track was generated by 10 -pass sliding of a 18.2 atomic percent titanium-iron alloy rider across the surface. Most of the silicon carbide wear debris has already been efected from the wear track. The smooth surface at the bottom of the fracture pit is due to subsurface cleavage along \{0001\} planes. 
Figure 39 presents a scanning electron micrograph and an $x$-ray map of a wear scar of a 8.12 percent titanium-iron alloy rider after it sidd against the silicon carbide surface already shown in Fig. 38. The wear scar contains a large amount of silicon carbide wear debris which was produced in multipass sliding of the alloy rider and was embedded in the alloy rider. The concentration of white spots in Fig. 39(b) correspond to silicon carbide wear debris locations in Fig. $39(a)$ where silicon carbide transfer is evident. Figure 40 is a scanning electron micrograph at the beginning of the wear scar examined at high magnification (see the small rectangie in Fig. $39(a)$ ). Again, the copious amount of silicon carbide wear debris, having crystallographically oriented sharp edges, was seen on the wear scar of the alloy rider.

It is understandable that the fracturing of ceramic materials and the formation of wear debris may be characterized by crystallographic orientation as demonstrated in the former sections. However, more detalled examination of the wear track on the silicon carbide and the wear scar on the alloy riders revealed in addition evidence of spherical wear particles of silicon carbide. Figures 40 (a) and (b) are a scanning electron micrograph and an $x$-ray dispersive analysis map of a nearly spherical wear particle and a groove, produced in a plastic manner by the plowing action of the particle. This dislodged spherical wear particle could be observed near the wear scar of the 1.02 atomic percent titanium-iron alloy rider after 10-passes of sliding on the silicon carbide surface.

Figure 40 consists of scanning electron micrographs of rider wear scars after sliding against a silicon carbide surface. These figures reveal spherical indentations and straight grooves along the sliding direction on the rider surfaces formed by indenting and plowing the spherical wear debris. Such a spherical wear particle and its indentation and groove were primarily 
observed for the alloys with low solute concentrations. These results reveal that (1) a nearly spherical wear particle can be produced by sliding (2) the wear particle plows the surface of the alloy rider during sliding, that is, the hardness of the particle is much greater than that of the alloy rider surface, and (3) the wear particle includes the element of silicon, as shown by the $x$-ray map of Si $K_{\alpha}$.

\section{LUBRICATION}

Lubrication is extremely important to ceramic materials in tribological systems. Not only are adhesion and friction of ceramic materials reduced by the presence of lubricants, but also brittle fracture during sliding, which is one of the main limitations to a wider use of ceramic materials in tribological applications.

Figure 41 presents scanning electron photomicrographs of wear tracks for Mn-Zn ferrite oxide ceramic in sliding contact with a hemispherical (100 um-radius) diamond rider in dry sliding and under lubricated conditions. The lubricant was an olive 011, which is commonly used in fine lapping processes of ceramic materials and semiconductors. As shown in the photomicrographs, the fracture behavior of the oxide ceramic is very dependent on the lubricant. Cracks generate much more easlly in the dry sliding condition than with a lubricant present.

As mentioned earlier the tangential force introduced by silding plays an important role in the generation of surface fracture. The critical load to fracture in dry siliding was one-half of that observed with static indentation. However, under lubricated conditions the critical load to fracture was two times greater than that in dry siliding, and is almost the same as that in indentation. The critical load to fracture in lubricated sliding and in static indentation with a 100 um-diamond was $4 \mathrm{~N}$, while that in dry sliding was $1.5 \mathrm{~N}$ on the $\{100\}$ surfaces of the Mn-Zn ferrite. 
The lubrication of ceramics by liquids therefore affords the opportunity of not only reducing friction and wear but arresting crack formation as well. Ceramics are, however, being considered as mechanical components for such systems as heat engines where temperatures can be quite high and beyond the range of usefuiness of liquids. Figure 42 indicates the temperature limitations of those fluids that may be considered for liquid lubrication of ceramics (Loomis, 1984).

An examination of Fig. 42 reveals that in the list of fluids none are useful beyond $350^{\circ} \mathrm{C}$. Above these temperatures ceramics must be lubricated by solids.

Graphites and molybdenum disulfide $\left(\operatorname{MoS}_{2}\right)$ are two of the more commonly used solid film lubricating materials. As already mentioned in this chapter, heating of silicon carbide in the range of 800 and $1500{ }^{\circ} \mathrm{C}$ graphitized the silicon carbide surface as a result of segregation and evaporation of the silicon in the surficial region of the silicon carbide and, thereafter, reconstruction of the remained carbon at the silicon carbide surface to form graphite. The graphitization of the slificon carbide surface was demonstrated by XPS analysis (Fig. 43). Figure 43 presents the graphitized silicon carbide surface after heating to $1500{ }^{\circ} \mathrm{C}$.

After being cooled to room temperature, sliding friction experiments from room temperature to $1200{ }^{\circ} \mathrm{C}$ in vacuum were conducted on the preheated surface of the silicon carbide. The friction properties are presented in Fig. 43 . The silicon carbide specimens preheated to $1500{ }^{\circ} \mathrm{C}$ produced coefficients of friction lower, by one half, of those for the surfaces cleaned by argon-ion-sputtering. The marked difference in friction between graphitized and nongraphitized surfaces was observed even in air. Thus, the silicon carbide generates its own solid lubricant surface films in the form of the graphite. 
$\mathrm{MoS}_{2}$ is also an effective solid film lubricant for ceramics. It reduced the friction for aluminum oxide in approximately half as indicated in the data of Table 6 . Steijn (1969) indicates that even with a solid film lubricant present on the surface of a ceramic, anisotropic effects are still detected.

While both graphite and molybdenum disulfide are promising solid film lubricants for ceramic surfaces they too are limited in their temperature range of usefulness, particularly in an oxidizing atmosphere. They can not be usefully employed above $400{ }^{\circ} \mathrm{C}$ in air.

In a search for even higher temperature solid lubricants, much research has been performed on various soft oxides, and also the fluorides of alkali metals and alkaline earth metals. Oxides are obvious candidates for consideration when oxidation-resistant compounds are required. The hard oxides, typical of ceramic materials, such as alumina, silica and the silicates have good wear resistance but generaily high friction coefficients as already discussed. Further, unpolished surfaces or wear debris from hard oxides are abrasive to softer, counterface material when ceramics are in contact with other solids.

On the other hand, soft oxides such as lead monoxide ( $\mathrm{PbO}$ ) are relatively nonabrasive and have relatively low friction coefficients, especially at high temperatures where their shear strengths are reduced to the degree that deformation occurs by plastic flow rather than brittle fracture. Binary and ternary eutectic oxide systems are of interest because the melting point suppression, which is the primary characteristic of eutectic systems, tends to lower the shear strength relative to the individual oxides. If the second oxide is a vitrifying agent such as $51_{2}$, glaze (glass) formation is promoted at the sliding surface and this also tends to modify friction by introducing a viscous component of shear. This increases or decreases 
friction depending upon the viscosity of the glaze within the sliding contact. Therefore, the friction characteristics of an oxide coating are controlled by a mechanism involving either or both crystalinine shear and viscous drag.

Increasing the surface temperature reduces both crystalline shear strength and glass viscosity within the siliding contact and, therefore, tends to reduce the friction coefficlent of oxide surfaces. This is fllustrated in Fig. 44 (Siliney 1958) which shows the effect of ambient temperature and sliding velocity on the friction coefficients which are for a stainless steel alloy lubricated with a coating of $\mathrm{PbO}^{-\mathrm{SiO}_{2}}$. At low sliding velocities, the Pbo coating lubricated effectively over only a very small temperature range of 500 to $650{ }^{\circ} \mathrm{C}$. With increasing sliding velocity, frictional heating rates increase and low friction is achieved at ever lower ambient temperatures unt 11 at $6 \mathrm{~m} / \mathrm{s}$, friction coefficients of 0.2 or lower are observed from room temperature to $650^{\circ} \mathrm{C}$. Because of the narrow range of temperatures at which Pbo lubricates effectively at low velocities, its use has been limited to high speed, high-temperature application such as the lubrication of dies for high-speed wire drawing. Such a coating should lubricate a ceramic equally we 11 .

Other studies have demonstrated that chemically stable fluorides of some Group I and II metals, such as LiF, $\mathrm{CaF}_{2}$ and $\mathrm{BaF}_{2}$, also lubricate at high temperature but over a broader range of temperatures than $\mathrm{PbO}$. For example, coatings with compositions from the $\mathrm{CaF}_{2} / \mathrm{BaF}_{2}$ binary eutectic system lubricate from about $500^{\circ} \mathrm{C}$ to $950^{\circ} \mathrm{C}$. The tribological properties in air of a fused fluoride coating with the composition $62 \mathrm{BaF}_{2}-38 \mathrm{CaF}_{2}$ are given in Fig. 45 (Sliney et al., 1965). Data for uncoated specimens are given for comparison. 
The fluorides of the rare earth metals are another group of metal halides that are chemically stable and have shown promise as high-temperature solid lubricants. In an exploratory study of their lubricating properties, cerium trifluoride $\left(\mathrm{CeF}_{3}\right)$ and lanthanum trifluoride $\left(\mathrm{LaF}_{3}\right)$ were the best solid lubricants among the rare earth fluorides (Sliney, 1969). The individual $\mathrm{CeF}_{3}$ or $\mathrm{LaF}_{3}$ powders lubricated nickel base super alloys in afr to at least $100{ }^{\circ} \mathrm{C}$; friction coefficients were 0.3 to 0.4 from room temperature to $500{ }^{\circ} \mathrm{C}$, but averaged about 0.2 at higher temperature. These compounds have received little further attention, but should be considered where friction coefficients of 0.2 to 0.4 combined with good antiwear characteristics at high temperatures are required. Again, they offer promise as solid lubricating films for ceramic surfaces.

Coatings of oxide and fluoride compositions that melt at a lower temperature than the substrate metal can be applied by well known procedures for applying glass or porcelain enamel glazes. In brief, an aqueous slurry of the oxide or fluoride powders is sprayed on to the substrate, cured to dryness, then furnace-fired above the melting point of the coating composition. Upon cooling, a fusion bonded, dense coating is obtained. Good adhesion depends upon reasonably matched thermal expansion coefficient and other factors such as the nature of high-temperature interactions that take place between the coating and ceramic as well as the atmosphere during firing. Fusion bonded fluoride coatings can be applied by a similar procedure, but while oxide coatings are generally fired in air, inert or reducing atmospheres are generally used for fluorides to avoid contamination of the coatings with oxides of the substrate ceramic where oxide ceramics are to be lubricated on surface components of non-oxide ceramics.

Composite bearing materials in which the solid lubricant is dispersed throughout the structure are advantageous when long lubricant life is 
required. In some cases, a thin, bonded solid lubricant coating is used as an overlay on the self-lubricating composite material. This assures the minimum friction coefficient obtainable by enrichment of the composite surface with lubricant while providing long life due to the underlying, self-lubricating composite material. The friction and wear of a composite consisting of a porous sintered metal matrix infiltrated with barium fluoride-calcium fluoride eutectic have been examined (Siiney, 1966). Wear 1ife comparisons for composite coatings in air and hydrogen indicate that the composites have longer endurance than the coatings. However, these composites are difficult and time consuming to prepare. The process involves preparing a sintered porous metal matrix which is then infiltrated with molten fluorides at about $1000^{\circ} \mathrm{C}$, cooled, and finish machined. If an overlay is used, the coating material is next sprayed on from an aqueous slurry, then cured in an argon atmosphere at about $950^{\circ} \mathrm{C}$. Similar compositions can be prepared more conventently by plasma spraying.

Mixed powders of, for example, $\mathrm{CaF}_{2}$ and metal can be deposited by plasma arc spraying to form a composite coating on a wrought metal or ceramic substrate. Excess coating material is applied, and the coating is then surface ground to the desired thickness (usually 0.1 to $0.2 \mathrm{~mm}$ ) and a smooth surface finish. Two coatings of this type that have been successfully applied for application in extreme environments (Siliney, 1979).

\section{SUMMARY REMARKS}

Based upon fundamental studies conducted with both oxide and non-oxide ceramics the following remarks can be made. Ceramics, like metals, will deform elastically in the interfactal region between two solids in contact under load. Unlike metals, however, when the elastic limit is exceeded gross fracture, as well as plastic deformation can occur. With tangential motion 
the forces necessary to initiate brittle fracture in the ceramic is markedly less than that assoclated with normal loading.

The friction and wear characteristics of ceramics, again like metals, are anisotropic. In general the lowest coefficient of friction is observed when sliding on the preferred siip plane in the preferred slip direction on that plane. Adhesive wear behaves with respect to orientation as does friction. Likewise the high atomic density, most resistant to deformation atomic planes exhibited the greatest resistance to abrasive wear. In two and three body abrasion the grit size effect on abrasive wear holds for ceramics.

When ceramics are in contact with metals, surface chemistry is extremeiy important to friction and wear behavior. For oxide ceramics the free energy of oxide formation for the lowest metal oxide is directly correlated to metal shear properties which relates to friction. With the transition metals, the d valence bond character correlates directly with the coefficient of friction for both oxide and non-oxide ceramics. The higher the percent $d$ bond character the lower is the coefficient of friction.

Contaminants on the surface of ceramics affect their tribological behavior. For example, desorption of carbon contaminants from a sflicon carbide surface results in an appreciable increase in friction coefficient. With aluminum oxide in contact with metals, chloride as a surface contaminant decreases interfacial bond strengths and accordingly friction, while oxygen increases both adhesion and friction.

Lubrication of ceramic surfaces increases the critical load to initiate fracture of ceramics, under sliding or rubbing. Heating of a ceramic such as silicon carbide to high temperatures can result in the graphitization of the ceramic surface with the graphite functioning to reduce adhesion and friction. A lubricating film is therefore provided from the material itself. 
Ceramics themselves can be effectively used as high temperature Jubricants both as coatings and composite structures. At temperatures above $400{ }^{\circ} \mathrm{C}$ in air or oxidizing environments they are the only lubricants currentiy available. 


\section{REFERENCES}

Adewoye, 0.0., Sawyer, G.R., Edington, J.W. and Page, T.F. (1974).

"Structural Studies of Surface Deformation in $\mathrm{MgO}, \mathrm{SiC}$ and $\mathrm{Si}_{3} \mathrm{~N}_{4}$. Annual Technical Report, 1 Oct. 1973-30 Sep. 1974." Dept. of Metallurgy and Materials Science, Cambridge University, England. AD-A008993.

Auerbach, F. (1891). Ann. Phys. (Leipzig) 43, 61 .

Avient, B.W.E., Goddard, J., and Wilman, H. (1960). Proc. R. Soc. London A 258, 159-180.

Billinghurst, P.R., Brookes, C.A. and Tabor, D. (1967). "Physical Basis of Yield and Fracture; Proceedings, Oxford, September, 1966." (A.C. Strickland, ed.) Institute of Physics \& The Physical Society, London, 253-258.

Bowden, F.P., and Tabor, D. (1964). "The Friction and Lubrication of Solids, Part II." Clarendon Press, Oxford, 173.

Brookes, C.A., O'Nei1, J.B., and Redfern, B.A.W. (1971). Proc. ‥ Soc. London A 322, 73-88.

Brown, W.R., Eiss, N.S. Jr., and McAdams, H.T. (1964). ‥ Am. Ceram. Soc. 47. $157-162$. 
Buckley, D.H. (1965). "Infouence of Crystal Orientation of Friction

Characteristics of Titanium Single Crystals in Vacuum." NASA

Lewis Research Center, Cleveland. NASA TN D-2988.

Buckley, D.H. (1966). "Effect of Orientation on Friction Characteristics

of Single-Crystal Beryllium in Vacuum $\left(10^{-10}\right.$ TORR)." NASA Lewis

Research Center, Cleveland. NASA TN D-3485.

Buckley, D.H. (1968). "Influence of Surface Active Agents on Friction, Deformation, and Fracture of Lithium Fluoride." NASA Lewis Research Center, Cleveland. NASA TN D-4716.

Buckley, D.H. (1969). "Effect of Surface Active Media on Friction, Deformation, and Fracture of Calcium Fluoride." NASA Lewis Research Center, Cleveland. NASA TN D-5580.

Buckley, D.H. (1972). Am. Ceram. Soc. Bul1. 51, 884-890, 905.

Buckley, D.H. (1978). ASLE Trans. 21, 118-124.

Buckley, O.H. (1981). "Surface Effects in Adhesion, Friction, Wear, and Lubrication." Elsevier, Amsterdam.

Daniels, F.W., and Dunn, C.G. (1949). Trans. Am. Soc. Met. 41, 419-442. 
DuFrane, K.F., and Glaeser, W.A. (1967). "Study of Rolling-Contact Phenomena in Magnesium 0xide." NASA Lewis Research Center, Cleveland. NASA CR-72295.

Duwe 11, E.J. (1962). J. Appl. Phys. 33, 2691-2698. Duwe 11, E.J. (1967). ASLE Trans. 10, 143-144. Duwe 11, E.J. (1969). ASLE Trans. 12, 34 Duwe 11, E.J., and Butzke, H.C. (1964). ASLE Trans. I, 101-108. Duwell, E.J., and Butzke, H.C. (1964). ‥ Appl. Phys. 35, 3385-3390. Frank, F.C., and Lawn, B.R. (1967). Proc. R. Soc. London A 299, 291-306. French, D.N., and Thomas, D.A. (1965). Trans. Meta11. Soc. AIME 233, 950-952.

Hertz, H. (1881). Journal fur die Reine und Angewandte Mathematik (Berlin) 92, $156-171$. Johnson, O.W. (1966). ‥ Appl. Phys. 37, 2521-2526. Johnson, K.V., and Pepper, S.V. (1982). ‥ Appl. Phys. 53, 6634-6637. Khrushchov, M.M., and Babichev, M.A. (1960). Sov. Phys. Dokl. (Engl. Trans 1.) 5, 410-412.

King, A.G. (1964). Am. Ceram. Soc. Bull. $43,395-401$. King, R.F., and Tabor, D. (1954). Proc. R. Soc. London A 223, 225-238. 
Komanduri, R., and Shaw, M.C. (1976). ‥ Eng. Ind. 98, 1125-1134.

Kronberg, M.L. (1957). Acta Meta 11. 5, 507-524.

Lawn, B.R. (1968). ‥ Appl. Phys. 39, 4828-4836.

Lawn, B.R. and Swain, M.V. (1975). J. Mater. Sc1. 10, 113-122.

Loomis, W.R. (1984). "Solid and Liquid Lubricants for Extreme Environments

- Papers." American Society of Lubrication Engineers, Park Ridge, IL, 133-39.

Marsha11, R.C., Faust, J.W. Jr., and Ryan, C.E. (1974). "Silicon Carbide 1973: Proceedings of the Third International Conference." University of South Carolina Press, Columbia.

Meyer, F., and Loyen, G.J. (1975). Acta Electron. 18, 33-38.

Miyoshi, K., and Buckley, D.H. (1978). "Effect of Oxygen and Nitrogen Interactions on Friciton of Single-Crystal Silicon Carbide." NASA Lewis Research Center, Cleveland. .NASA TP-1265.

Miyoshi, K., and Buckley, D.H. (1979). ASLE Trans. 22, 79-90.

Miyoshi, K., and Buckley, D.H. (1979). ASLE Trans. 22, 245-256.

Miyoshi, K., and Buckley, D.H. (1981). Wear 66, 157-173.

Miyoshi, K., and Buckley, D.H. (1981). Wear 67, 303-319. 
Miyoshi, K., and Buckley, D.H. (1982). "Occurrence of Spherical Ceramic Debris in Indentation and sliding Contact." NASA Lewis Research Center, Cleveland. NASA TP-2048.

Miyoshi, K., and Buckley, D.H. (1983). Am. Ceram. Soc. Bul1. 62, 494-500.

Miyoshi, K., and Buckley, D.H. (1984). "Properties of Ferrites Important to Their Friction and Wear Behavior." NASA Lewis Research Center, Cleveland. NASA TM-83718.

Miyoshi, K., and Buckley, D.H. (1984). Wear 100, 333-353.

O'Connor, J.R., and Smiltens, J. (1960). "Silicon Carbide, A High Temperature Semiconductor." Pergamon, New York.

Pauling, L. (1949). Proc. R. Soc. London A 196, 343-362.

Pepper, S.V. (1976). ‥ Appl. Phys. 47, 801-808.

Powe 11, B.D., and Tabor, D. (1970). ‥ Phys. D 3 , 783-788.

Preston, F.W. (1921). Trans. Opt. Soc. London 23, 141-164.

Rabinowicz, E., Dunn, L.A., and Russe11, P.G. (1961). Wear 4, 345-355.

Scheuplein, R., and Gibbs, P. (1962). ‥ Am. Ceram. Soc. $45,439-452$.

Shaffer, P.T.B. (1964). ‥ Am. Ceram. Soc. 47,466 . 
Sliney, H.E. (1958). "Effect of Sliding Velocity on Friction Properties

and Endurance Life of Bonded Lead Monoxide Coatings at Temperatures

Up to $1250^{\circ} \mathrm{F} . "$ NACA RM-E58B11.

Siiney, H.E. (1966). ASLE Trans. 9, 336-347.

Siiney, H.E. (1979). Thin Solid Films 64, 211-217.

Sliney, H.E., Strom, T.N., and Allen, G.P. (1965). ASLE Trans. ㅁ, 307-322.

Steijn, R.P. (1969). ASLE Trans. 12, 21-23.

Steijn, R.P. (1969). ‥ Appl. Phys. 32, 1951-1958.

Steijn, R.P. (1969). ‥ Appl. Phys. 32, 1951-1958.

Sugita, T., and Hashikawa, A. (1981). Wear 72, 295-303.

Tanaka, K., et a1. (1976). "Proceedings of the JSLE-ASLE. International Lubrication Conference, Tokyo, Japan, June 9-11, 1975." (T. Sakurai, ed.) Elsevier, Amsterdam, 58-66.

Van Bomme1, A.J., Crombeen, J.E., and Von Tooren, A. (1975). Surf. Sc1. $48,463-472$.

Wachtman, J.B. Jr., and Maxwel1, L.H. (1959). ‥ Am. Ceram. Soc. 42, $432-433$. 
TABLE 1. - THE INFLUENCE OF CRYSTALLOGRAPHIC DIRECTION ON THE COEFFICIENT

OF FRICTION FOR SAPPHIRE SLIDING

ON SAPPHIRE IN VACUUM ( $30 \mathrm{nPa}$ )

[Load, $10 \mathrm{~N}$; sliding velocity, $0.013 \mathrm{~cm} / \mathrm{sec}$.]

\begin{tabular}{|c|c|c|}
\hline Plane & Direction & $\begin{array}{c}\text { Coefficient of } \\
\text { friction }\end{array}$ \\
\hline Prismatic & {$[11 \overline{2} 0]$} & 0.93 \\
$(1010)$ & {$[0001]$} & 1.00 \\
Basa $]$ & {$[11 \overline{2} 0]$} & .50 \\
$(0001)$ & {$[10 \overline{1} 0]$} & .96 \\
\hline
\end{tabular}

TABLE 2. - BULX AND SURFACE SHEAR STRENGTH DATA FOR SAPPHIRE ${ }^{\mathrm{a}}$

\begin{tabular}{|l|c|}
\hline \multicolumn{1}{|c|}{ Source } & $\begin{array}{c}\text { Shear strength } \\
1 \times 10^{6} \mathrm{~N} / \mathrm{m}^{2}\end{array}$ \\
\hline $\begin{array}{l}\text { Bulk shear strength } \\
\text { Surface shear strength } \\
\text { from friction }\end{array}$ & 34.0 \\
\hline$(0001)[11 \overline{2} 0]$ & 680.0 \\
$(10 \overline{0} 0)[0001]$ & 1020.0 \\
\hline
\end{tabular}

asurface shear strengths calculated from friction values. 
TABLE 3. - ANISOTROPIC FRICTION FOR Mn-Zn FERRITE ANO SILICON CARBIDE UNDER ADHESIVE CONDITIONS

[Load, 0.05 to $0.5 \mathrm{~N}$; sliding velocity, $3 \mathrm{~mm} \mathrm{~min}^{-1}$; vacuum pressure, $10^{-8} \mathrm{~N} \mathrm{~m}^{-2}$; room temperature.

\begin{tabular}{|c|c|c|c|}
\hline Mated plane & Mated direction & $\begin{array}{l}\text { sliding } \\
\text { direction }\end{array}$ & $\begin{array}{l}\text { Coefficient } \\
\text { of friction }\end{array}$ \\
\hline \multicolumn{4}{|c|}{ Effect of crystallographic plane } \\
\hline$\{110\}$ on $\{110\}$ & $\langle 110\rangle$ on $\langle 110\rangle$ & $\langle 110\rangle$ & 0.21 \\
\hline$\{111\}$ on $\{111\}$ & $\langle 110\rangle$ on $\langle 110\rangle$ & $\langle 110\rangle$ & .21 \\
\hline$\{100\}$ on $\{100\}$ & $\langle 110\rangle$ on $\langle 110\rangle$ & $\langle 110\rangle$ & .24 \\
\hline$\{110\}$ on $\{100\}$ & $\langle 110\rangle$ on $\langle 110\rangle$ & $\langle 110\rangle$ & .27 \\
\hline$\{110\}$ on $\{111\}$ & $\langle 110\rangle$ on $\langle 110\rangle$ & $<110\rangle$ & .29 \\
\hline$\{110\}$ on $\{211\}$ & $\langle 110\rangle$ on $\langle 110\rangle$ & $<110\rangle$ & .29 \\
\hline \multicolumn{4}{|c|}{ Effect of crystallographic direction } \\
\hline$\{110\}$ on $\{110\}$ & $\langle 110\rangle$ on $\langle 110\rangle$ & $\langle 110\rangle$ & 0.21 \\
\hline & $\langle 110\rangle$ on $\langle 100\rangle$ & $\langle 110\rangle$ & .43 \\
\hline
\end{tabular}

TABLE 4. - ANISTROPIC FRICTION FOR

SAPPHIRE-SAPPHIRE AND SILICON

CARBIDE-SILICON CARBIDE

CONTACTS UNDER ADHE-

SIVE CONDITIONS

\begin{tabular}{|c|c|c|}
\hline Plane & Direction & $\begin{array}{l}\text { Coefficient } \\
\text { of friction }\end{array}$ \\
\hline \multicolumn{3}{|c|}{ Sapphire sliding on sapphtrea } \\
\hline \multirow[t]{2}{*}{ Prismatic $\{1010\}$} & $\langle 11 \overline{2} 0\rangle$ & 0.93 \\
\hline & $<0001\rangle$ & 1.00 \\
\hline \multirow[t]{2}{*}{ Basal $\{0001\}$} & $\langle 11 \overline{20}\rangle$ & .53 \\
\hline & $\langle 10 \overline{10}\rangle$ & .96 \\
\hline \multicolumn{3}{|c|}{ Sic on $\mathrm{sic}^{\mathrm{b}}$} \\
\hline \multirow[t]{2}{*}{ Basal $\{0001\}$} & $\langle 11 \overline{2} 0\rangle$ & 0.54 \\
\hline & $\langle 10 \overline{10}\rangle$ & .68 \\
\hline
\end{tabular}

aLoad, $10 \mathrm{~N}$; sliding velocity, $7.8 \mathrm{~mm} \mathrm{~min}^{-1}$; vacuum pressure, $10^{-8} \mathrm{~N} \mathrm{~m}^{-2}$; room temperature.

bLoad, $0.3 \mathrm{~N}$; sliding velocity, $3 \mathrm{~mm} \mathrm{~min}^{-1}$; vacuum pressure, $10^{-8} \mathrm{~N} \mathrm{~m}^{-2}$; room temperature. 
TABLE 5. - ANISOTROPIC FRICTION AND WEAR FOR SILICON CARBIDE UNDER ABRASIVE CONDITIONS

[Conical diamond with an apical angle of $117^{\circ}$; load, $0.2 \mathrm{~N}$; sliding velocity, $3 \mathrm{~mm} \mathrm{~min}^{-1} ; \mathrm{mineral}$ o11; room temperature.]

\begin{tabular}{|c|c|c|c|}
\hline Plane & Direction & $\begin{array}{l}\text { Coefficient } \\
\text { of friction }\end{array}$ & $\begin{array}{l}\text { Width of permanent } \\
\text { groove corresponding } \\
\text { to plastic deformation, } \\
\mu \mathrm{m}\end{array}$ \\
\hline \multirow[t]{2}{*}{0001} & $\langle 10 \overline{10}\rangle$ & 0.19 & 2.6 \\
\hline & $\langle 11 \overline{2} 0\rangle$ & .21 & 2.7 \\
\hline \multirow[t]{2}{*}{$10 \overline{10}$} & $<0001>$ & .29 & 3.6 \\
\hline & $\langle 11 \overline{2} 0\rangle$ & .23 & 2.9 \\
\hline \multirow[t]{2}{*}{$11 \overline{2} 0$} & $<0001>$ & .31 & 3.5 \\
\hline & $\langle 10 \overline{0} 0\rangle$ & .24 & 3.1 \\
\hline
\end{tabular}

TABLE 6. - FRICTION ON DRY AND LUBRICATED ${ }^{a}$ (110) AND (010) PLANES 1/16-IN-DIAMETER RUBY SLIDER; $6000 \mathrm{~g}$ LOAD (Steijn, 1969)

\begin{tabular}{|l|c|c|c|}
\hline $\begin{array}{c}\text { Crystal } \\
\text { face }\end{array}$ & $\begin{array}{c}\text { Sliding } \\
\text { direction }\end{array}$ & \multicolumn{2}{|c|}{ Coefficient of friction } \\
\cline { 2 - 4 } & Dry & Lubricated \\
\hline \multirow{3}{*}{$(010)$} & {$[001]$} & 0.11 & 0.061 \\
& {$[001]$} & .11 & \\
& {$[100]$} & .10 & .069 \\
{$[100]$} & {$[001]$} & .10 & \\
& {$[001]$} & .12 & .052 \\
& {$[110]$} & .15 & .055 \\
& {$[110]$} & .16 & \\
\hline
\end{tabular}

aLubricated with commerclal resin-bonded $\mathrm{MoS}_{2}$ film. The film was applied by spraying the solid lubricant dispersion from an aerosol can followed by drying in alr for $18 \mathrm{hr}$. 


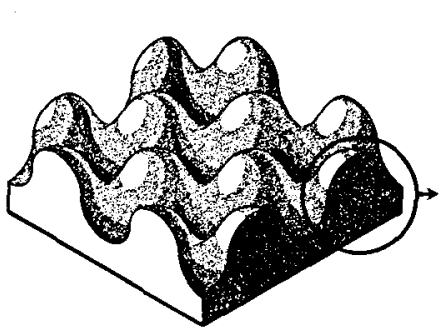

(a)

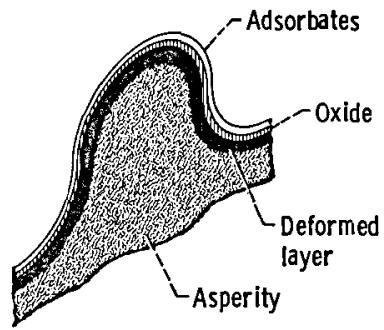

(b)

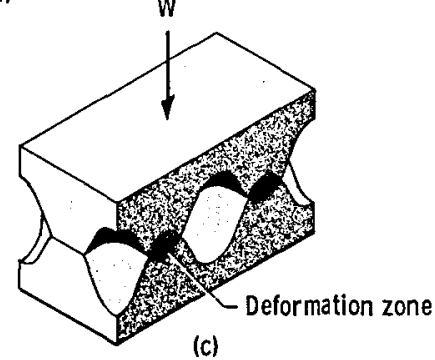

Figure 1. - Surface topography and contact.

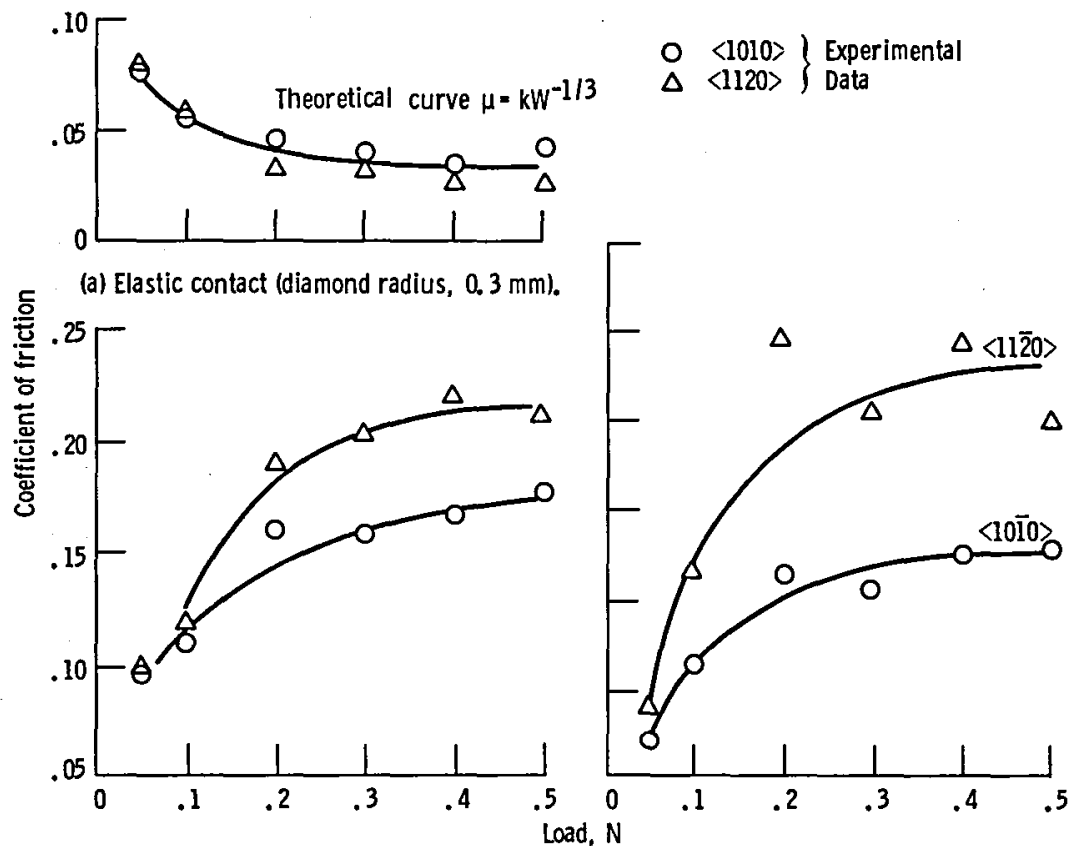

(b) Plastic contact (diamond radius, $0.02 \mathrm{~mm}$ ).

(c) Sliding accompanied by gross fracture (conical diamond with an apical angle of $117^{\circ}$.

Figure 2 - Coefficient of friction as a function of load for hemispherical diamond riders of different radii and a conical diamond rider sliding on a single-crystal silicon carbide \{0001\} surface (sliding velocity, $3 \mathrm{~mm} \mathrm{~min}^{-1}$; room temperature). 


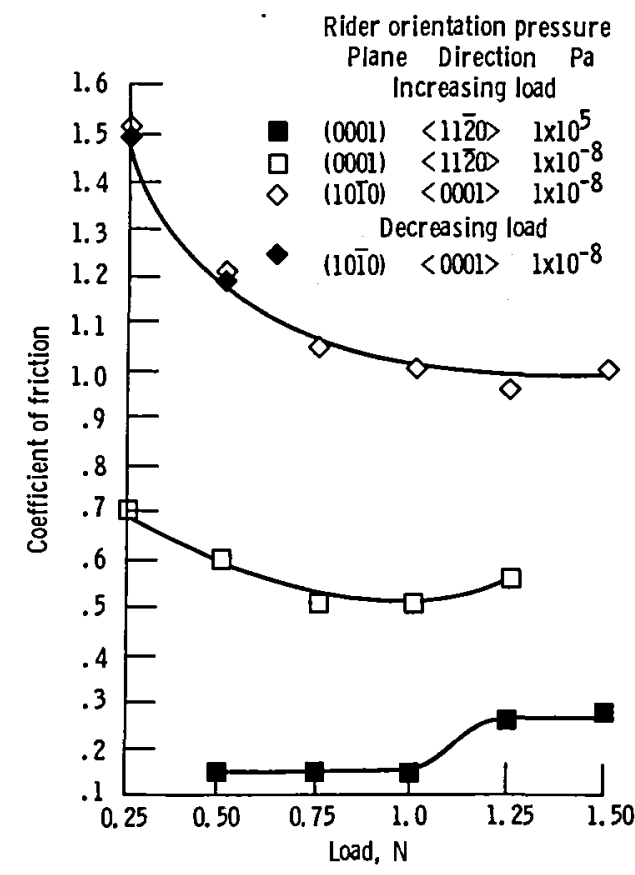

Figure 3. - Coefficient of friction as function of load for sapphire sliding on sapphire in vacuum, $30 \mathrm{nPa}$ and air, $1 \times 10^{5} \mathrm{~Pa}$. Sliding velocity, a. 13 centimeter per second; temperature, $298 \mathrm{~K}$; specimen outgassing with electron gun at $573 \mathrm{~K}$. Disk specimen was (0001) plane parallel to sliding interface. 

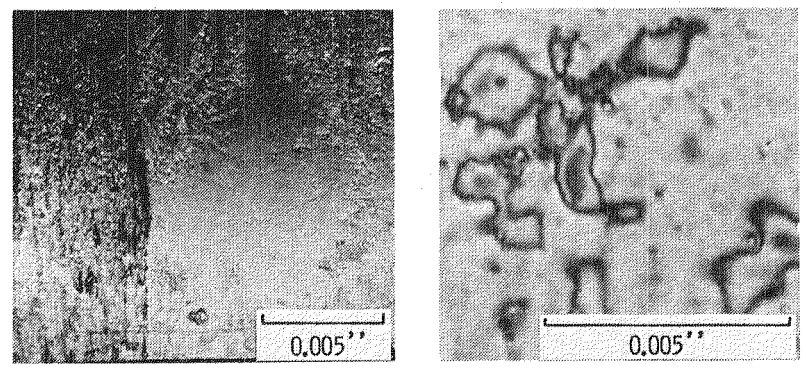

Sapphire surface scar

Sapphire contact surface

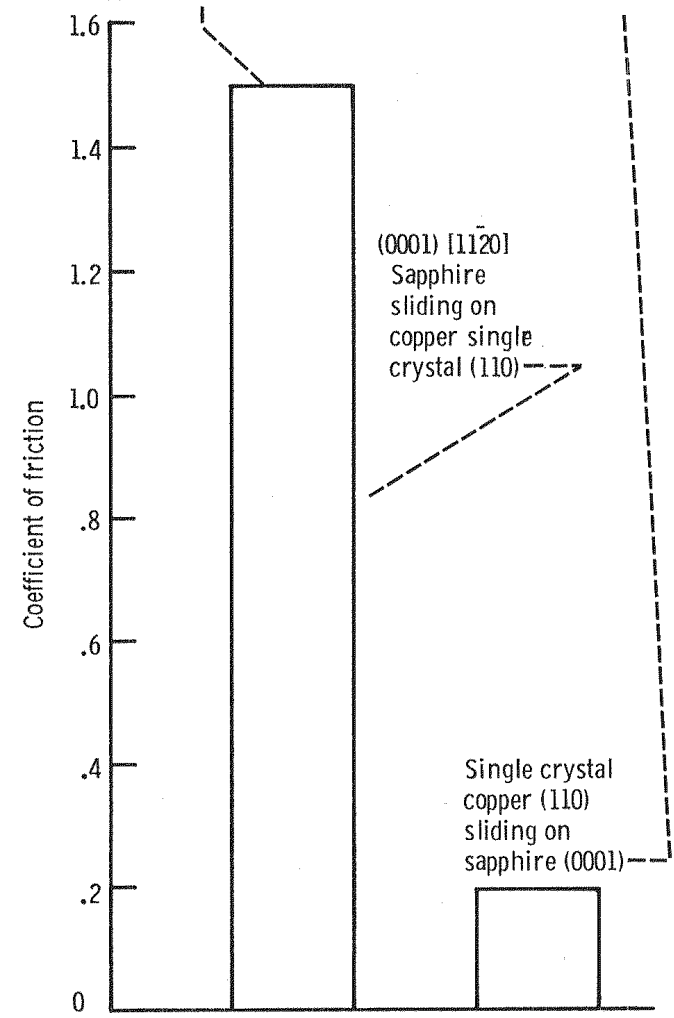

Figure 4. - Coefficient of friction for copper in sliding contact with sapphire in vacuum ( $30 \mathrm{nPa}$ ). Load, $0.5 \mathrm{~N}$, sliding velocity, 0.013 centimeter per second. 
S. $\mathrm{Al}^{+3}$ in first subsurface layer and arranged in octahedral array,

Surface covered by layer of $0^{-2}$

Sites for chemical bonding of metals with oxygen when in contact with surface

Sites for Van Der Waals interaction with metals sliding on surface

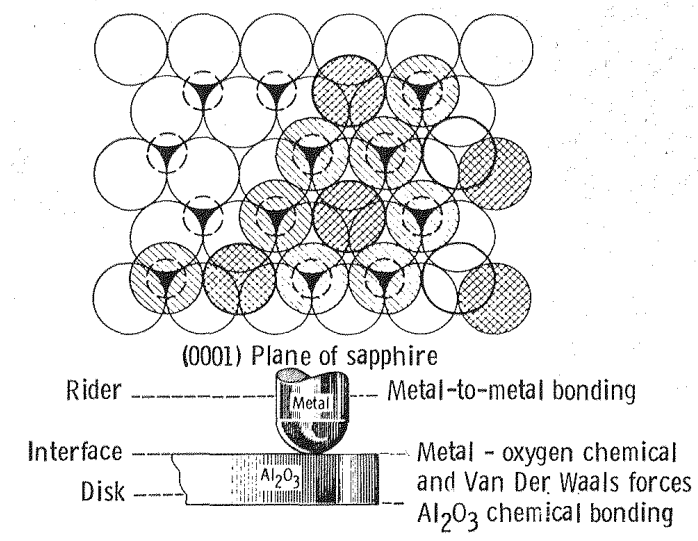

Figure 5. - Nature of surface interaction and bonding of metal to $\mathrm{Al}_{2} \mathrm{O}_{3}$.

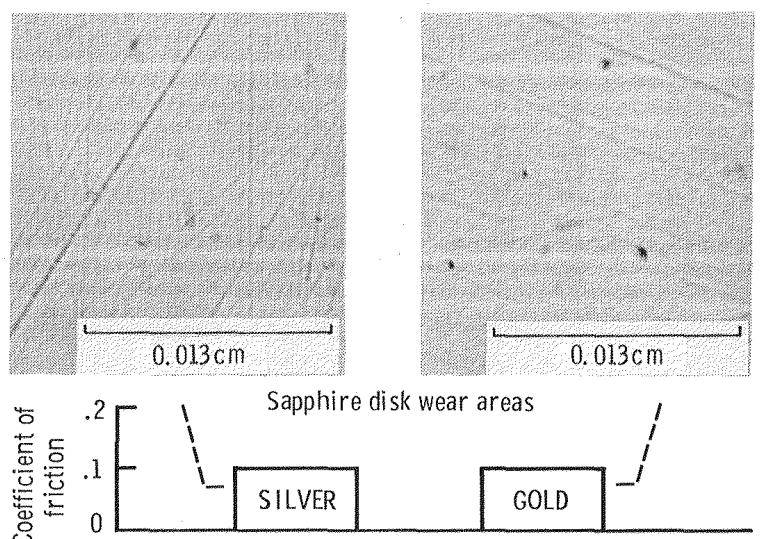

Figure 6. - Coefficient of friction for gold and silver riders sliding on sapphire in vacuum ( $30 \mathrm{nPa}$ ). Sliding velocity, 0.013 centimeter per second; ambient cemperature, $298^{\circ} \mathrm{K}$; duration, 1 hour. 


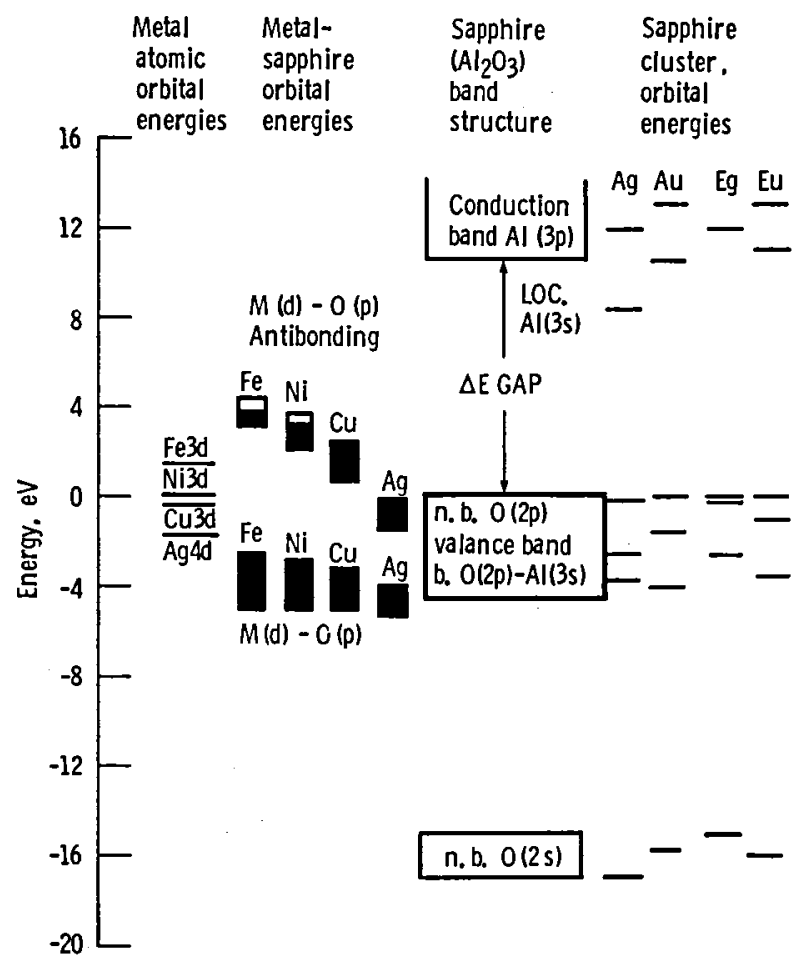

Figure 7. - Molecular-orbital energies, as determined by the self-consistent-field $X$-alpha scattered wave method, for clusters representing bulk sapphire and metal-sapphire interfaces. (Johnson and Pepper (1982).)

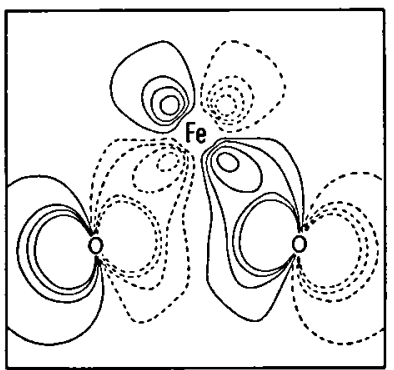

(a)

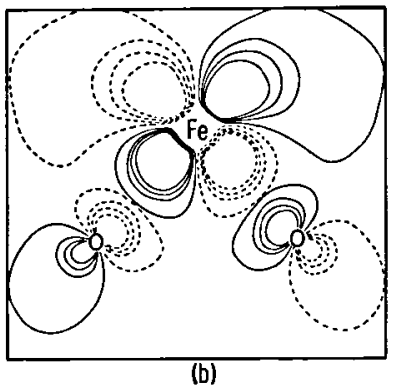

Figure 8. - Occupied bonding and unoccupied antibonding Fe(d) -0 (p) molecular-orbital wave function contour maps for and iron atom supported on sapphire, plotted in the plane of the iron atom and two surface oxygen atoms. The solid and dasted contours represent the positive and negative phases of the wave function. (Johnson and Pepper (1982). 


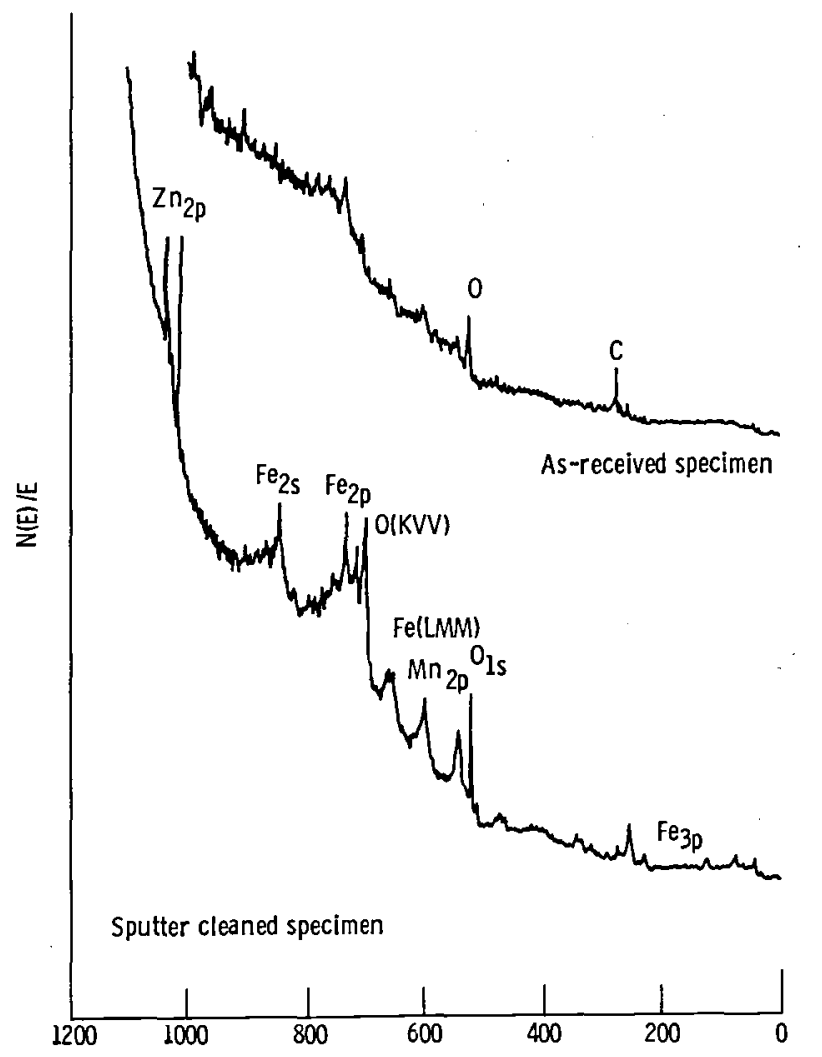

Figure 9. - XPS-survey spectra of the $M n-Z n$-ferrite surfaces. 

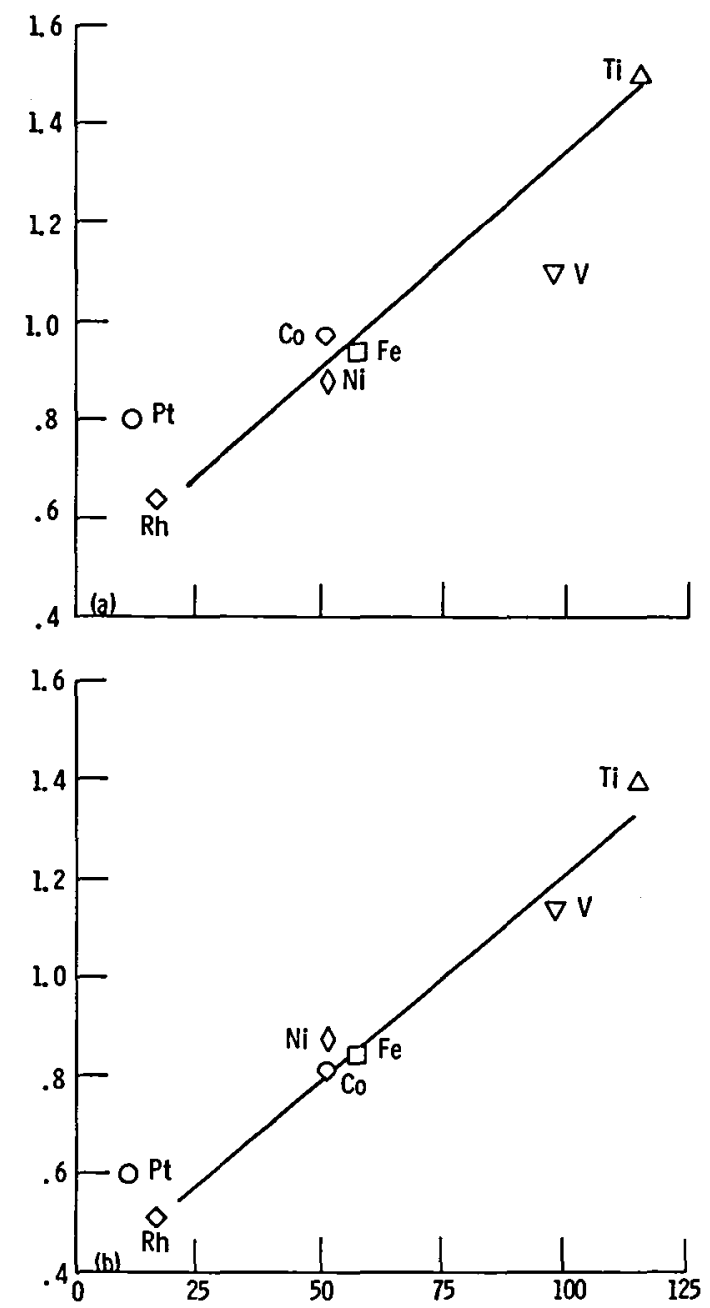

Figure 10 - Coefficients of friction for various metals in contact with (a) Ni-Zn and (b) Mn-Zn ferrites as a function of the free energy of formation of the lowest metal oxide. Single-pass sliding; sliding velocity. $3 \mathrm{~mm} / \mathrm{min}$; load, 0.05 to $0.2 \mathrm{~N}$; vacuum, $30 \mathrm{nPa}$; room temperature. 


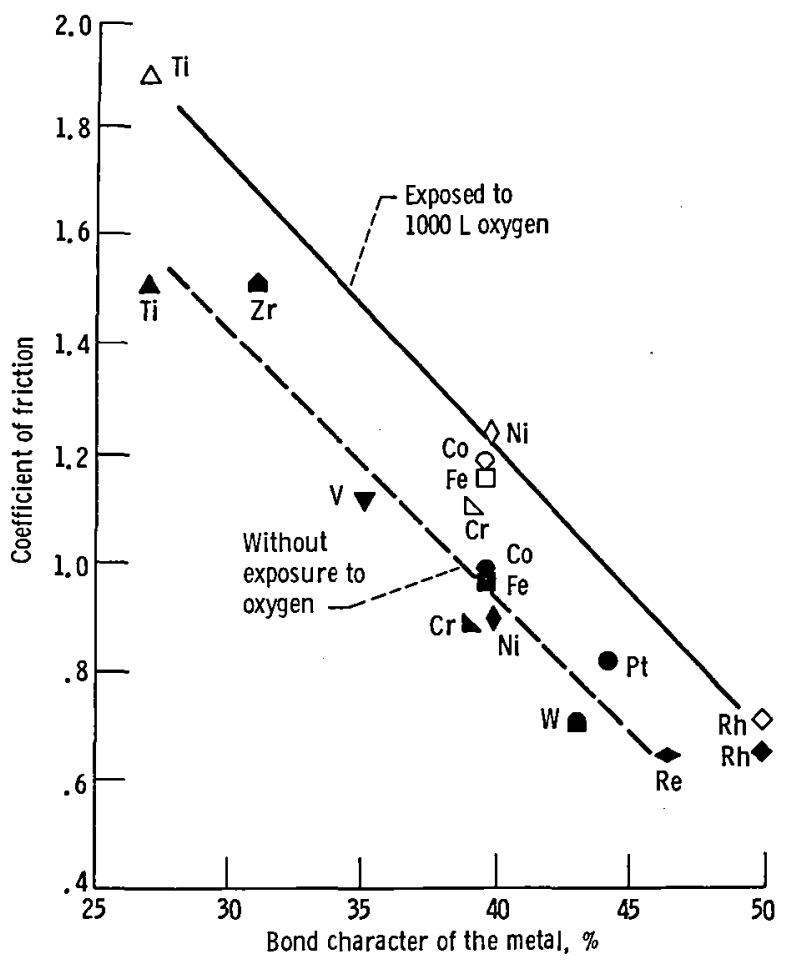

Figure 11. - Effect of adsorbed oxygen on the friction for various metals in contact with Ni-Zn ferrite. Exposure, $1000 \mathrm{~L}$ of oxygen gas; sliding velocity, $3 \mathrm{~mm} / \mathrm{min}$; load, 0.05 to $0.2 \mathrm{~N}$; vacuum, $30 \mathrm{nPa}$; room temperature.

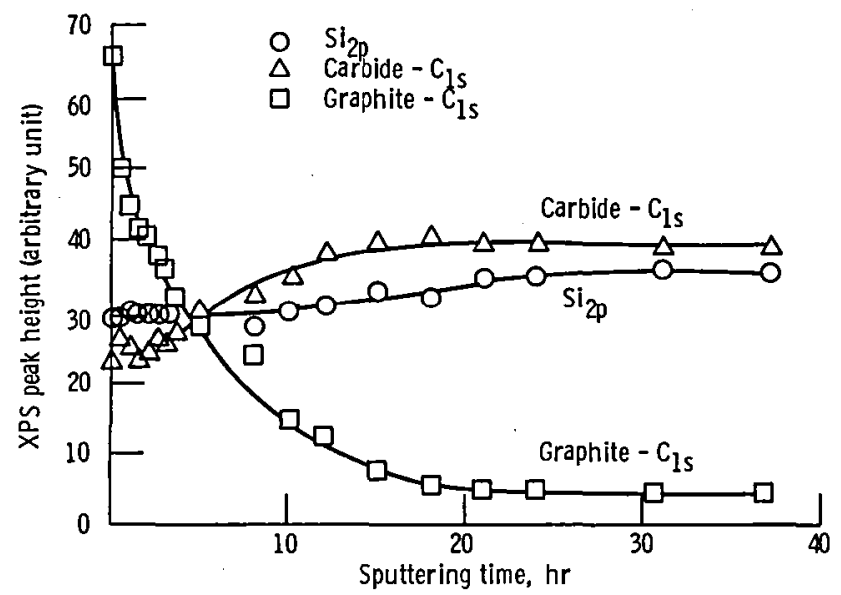

Figure 12 - Elemental depth profile of silicon carbide $\{0001\}$ surface preheated to a temperature of $1500^{\circ} \mathrm{C}$ for 1 hour. 


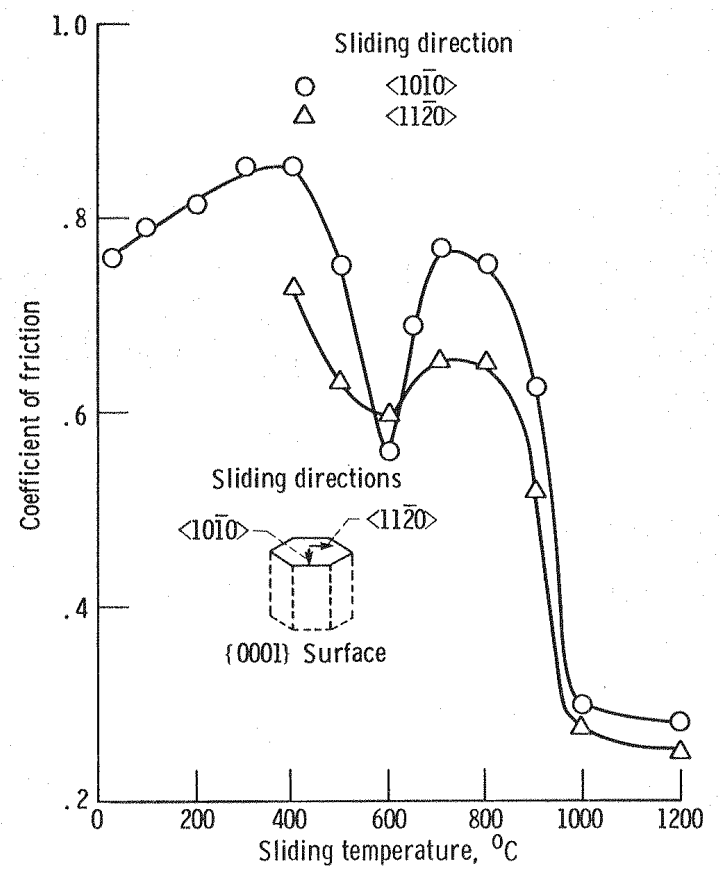

Figure 13. - Effect of temperature on coefficient of friction for silicon carbide $\{0001\}$ surface sliding against an iron rider. The iron rider was argon ion sputter cleaned before experiments. Normal load, $0.2 \mathrm{~N}$; vacuum, $10 \mathrm{n} \mathrm{Pa}$. 


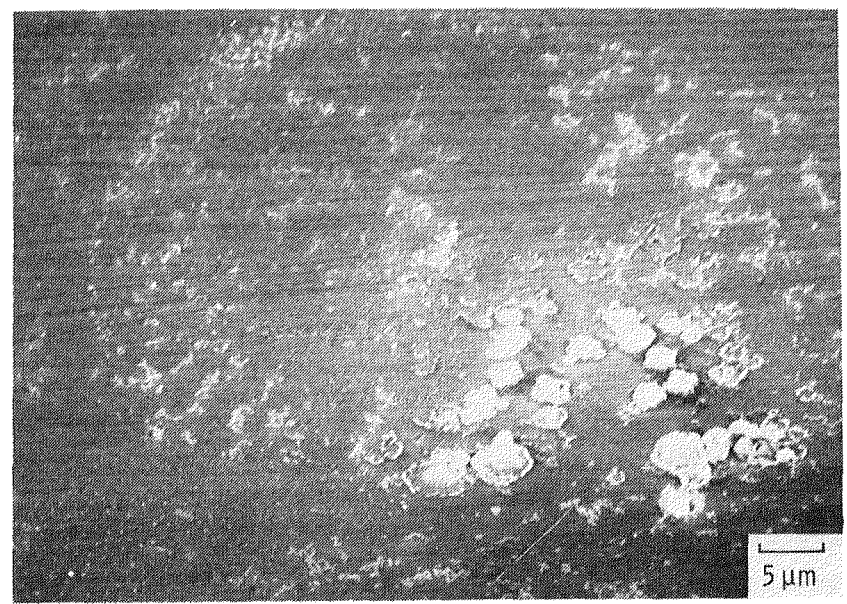

(a) Room temperature.

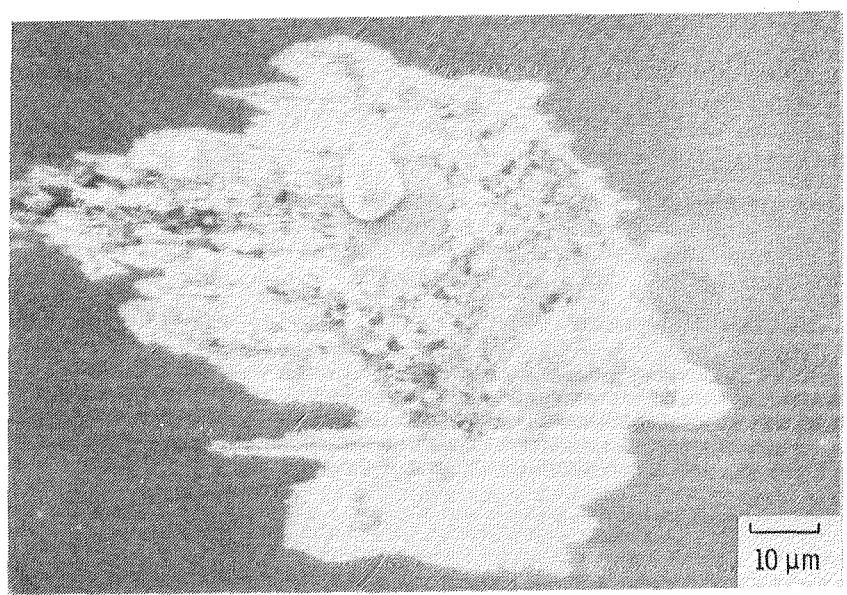

(b) $800^{\circ} \mathrm{C}$.

Figure 14. - Iron transferred to single-crystal silicon carbide at commencement of sliding as a result of single pass of rider at room temperature, $800^{\circ} \mathrm{C}$ and $1200^{\circ} \mathrm{C}$ in vacuum. Silicon carbide $\{0001\}$ surface; sliding direction $\langle 1010\rangle$; load, $0.2 \mathrm{~N}$; vacuum pressure, $10 \mathrm{n} \mathrm{Pa}$. 


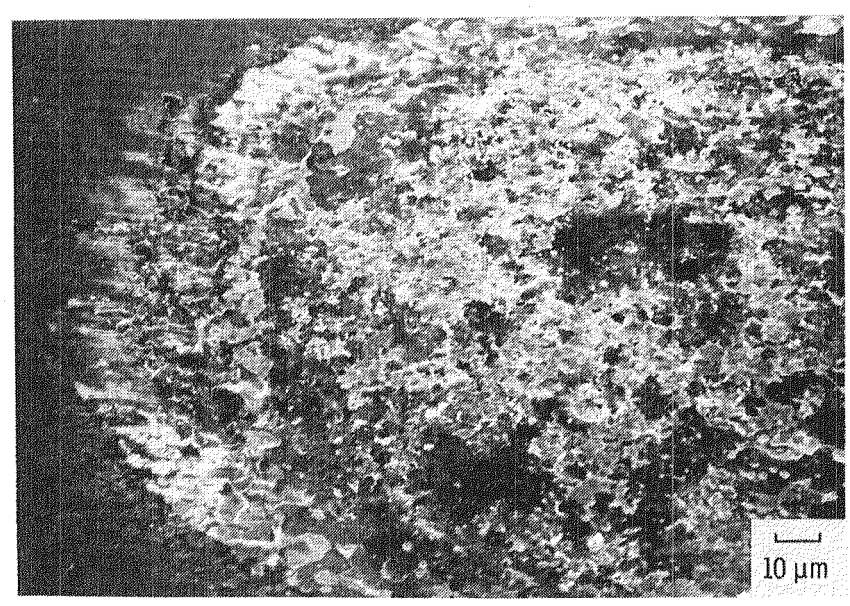

(c) $1200^{\circ} \mathrm{C}$.

Figure 14. - Concluded.

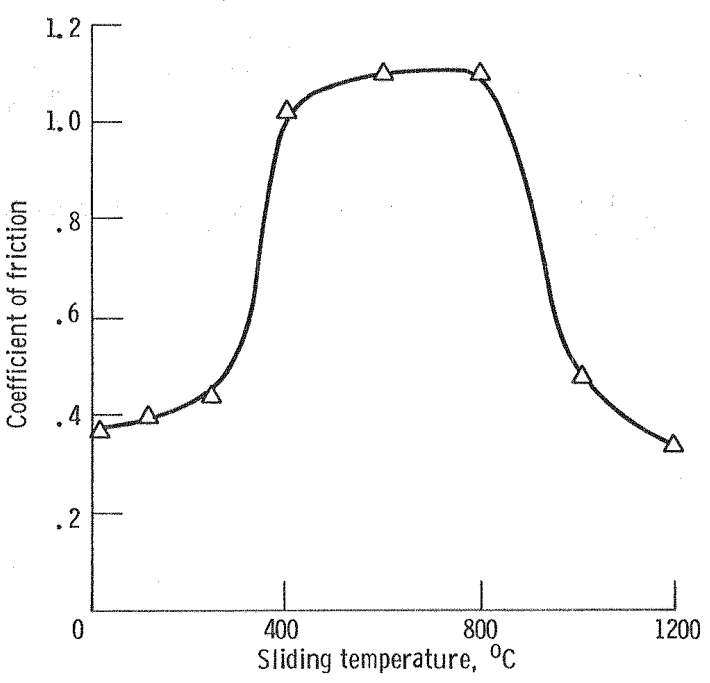

Figure 15. - Effect of temperature on coefficient of friction for sintered polycrystalline silicon carbide surface sliding against clean iron rider (which was argonion-sputter cleaned before experiments). Normal load, 0.1 to $0.2 \mathrm{~N}$; vacuum, $30 \mathrm{nPa}$. 
(a)

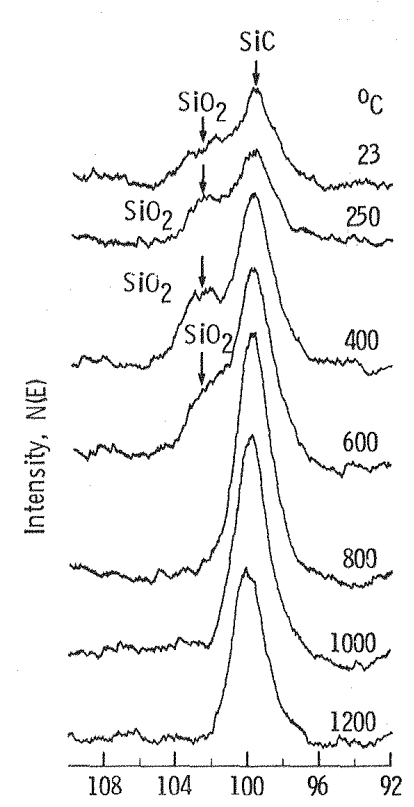

(b)

\section{Adsorbed carbon}

contaminant peak

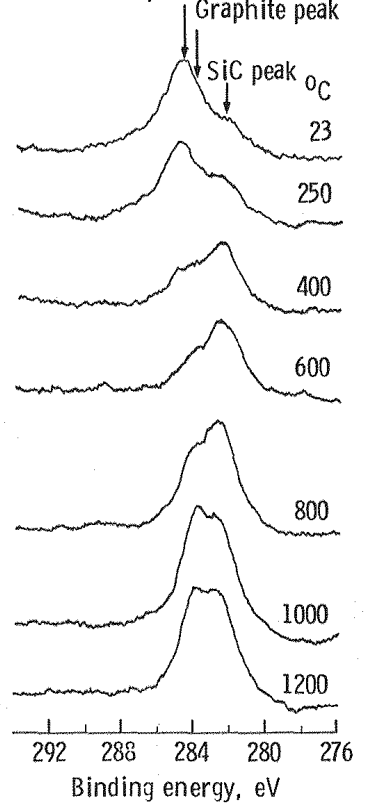

(c)
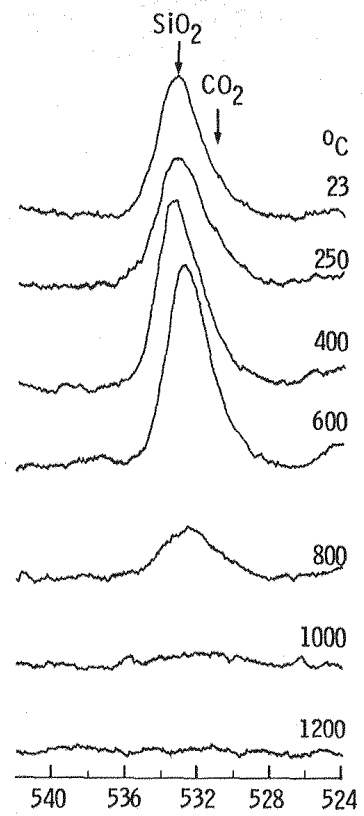

Figure 16. - Representative (a) $\mathrm{Si}_{2 \rho}$, (b) $\mathrm{C}_{1 \mathrm{~s}}$, and (c) $\mathrm{O}_{1 \mathrm{~S}}$ XPS peaks from sintered polycrystalline SiC surface preheated at temperatures indicated. 


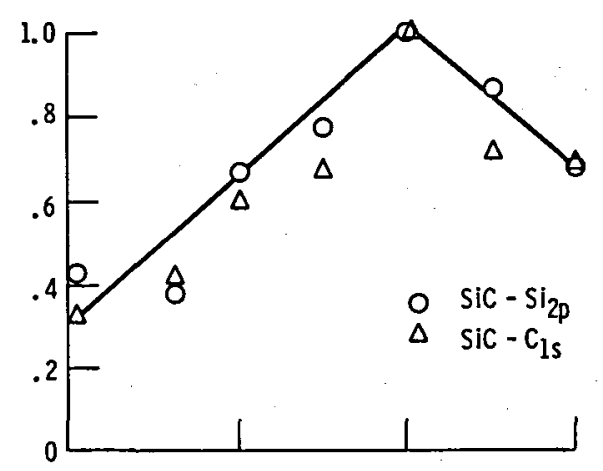

(a) $\mathrm{Si}_{2 p}$ and $\mathrm{C}_{1 \mathrm{~s}}$ peaks from $\mathrm{SiC}$.
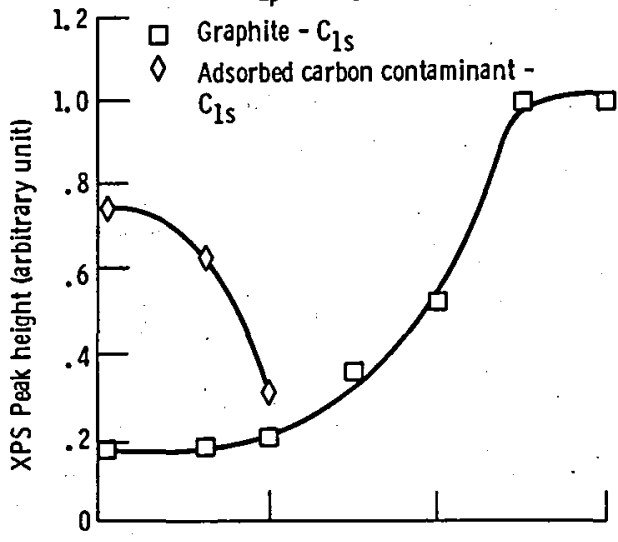

(b) $C_{1 s}$ peaks from graphite and adsorbed carbon contaminant.

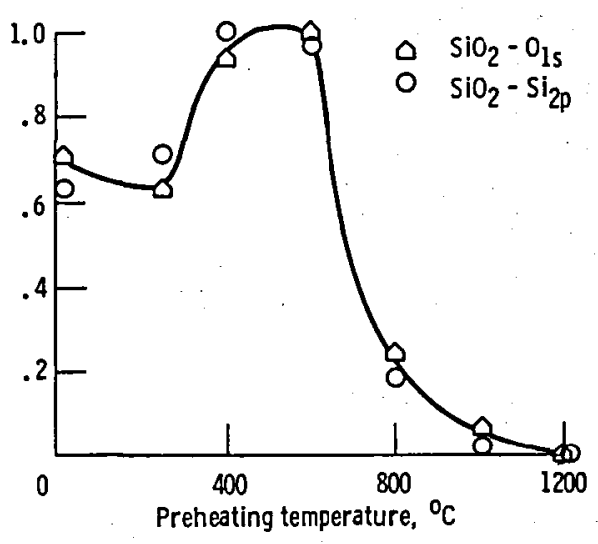

(c) $\mathrm{SI}_{2 p}$ and $\mathrm{O}_{1 \mathrm{~s}}$ peaks from $\mathrm{SiO}_{2}$

Figure 17. $-\mathrm{Si}_{2 p}, \mathrm{C}_{1 \mathrm{~s}}$, and $\mathrm{O}_{1 \mathrm{~s}}$ XPS peak heights from preheated sintered polycrystalline SiC surface. 


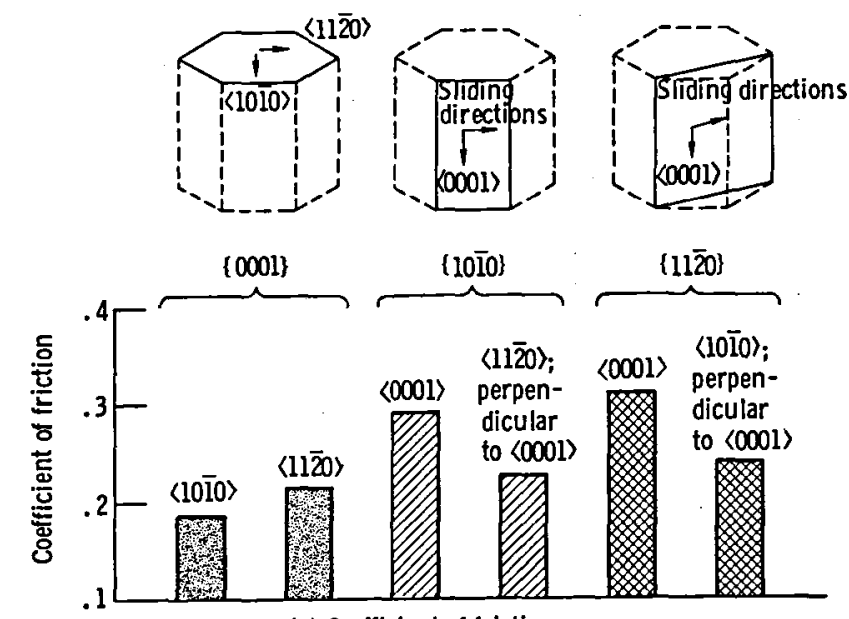

(a) Coefficient of friction.

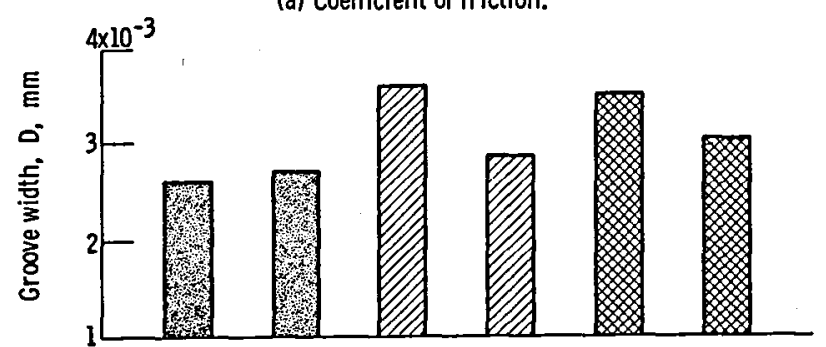

(b) Groove width.

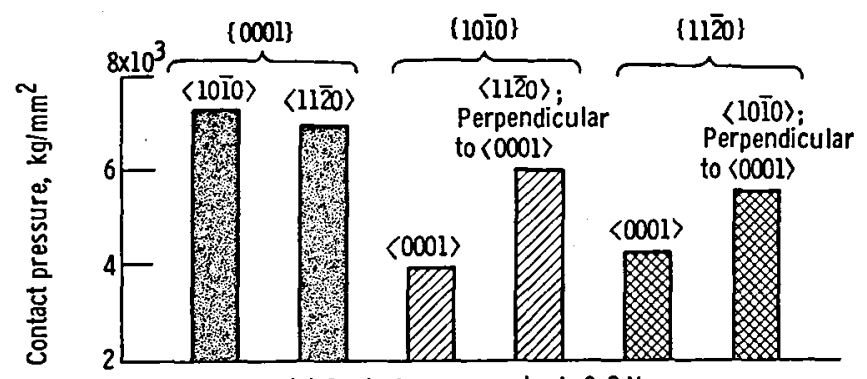

(c) Contact pressure; load, $0.2 \mathrm{~N}$.

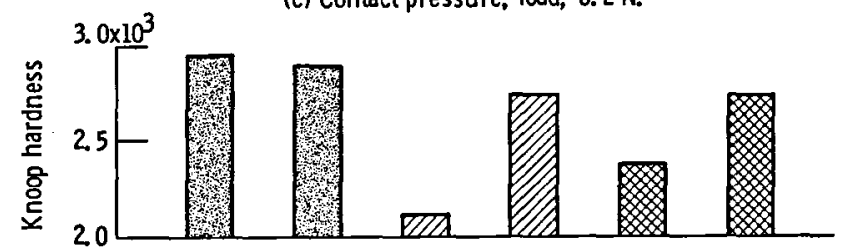

(d) Knoop hardness (Shaffer); load, $1 \mathrm{~N}$.

Figure 18 - Coefficients of friction, groove width, contact pressure. and Knoop hardness anisotropies on $\{0001\}$, $\{10 \overline{1} 0\}$, and $\{11 \overline{2} 0\}$ silicon carbide surfaces. 


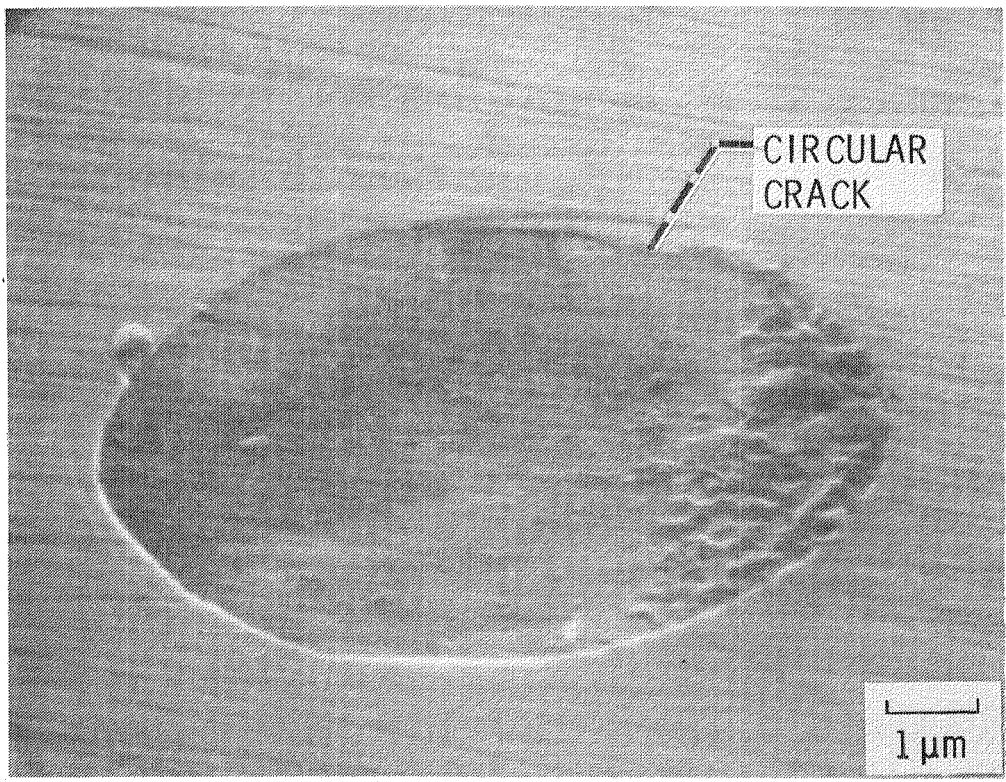

(a) Indentation generated by 0.1 -mm-radius hemispherical indenter. Load, $10 \mathrm{~N}$.

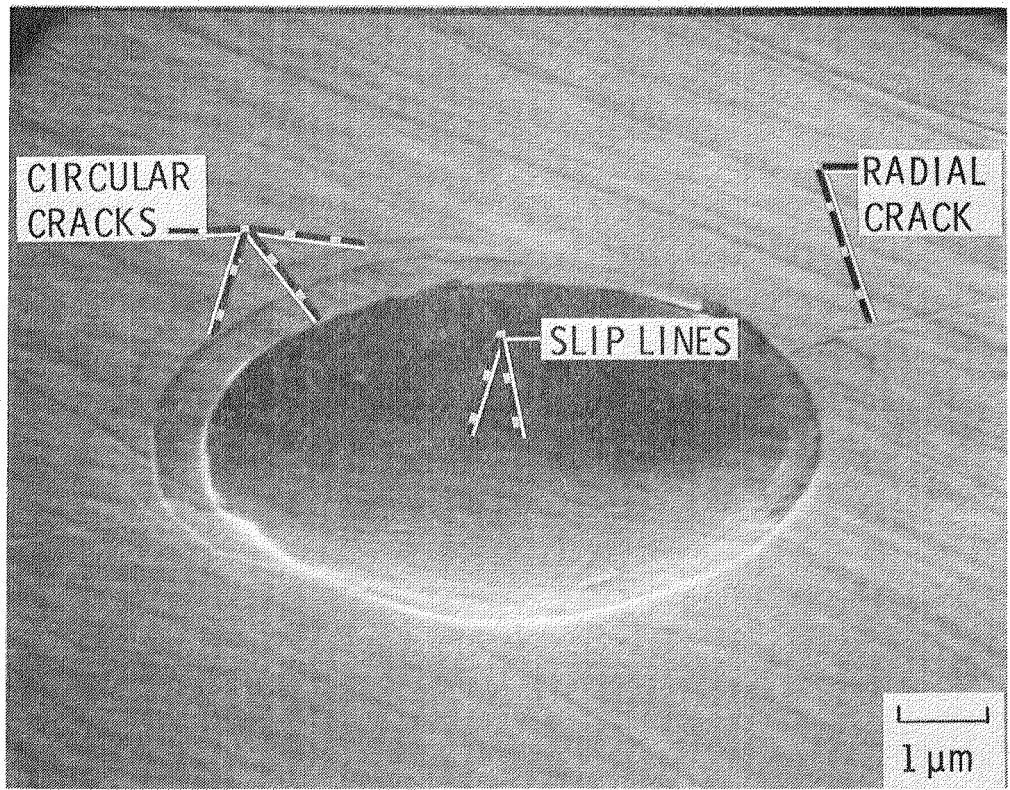

(b) Indentation generated by $0.02-$ mm-radius hemispherical indenter. Load, $5 \mathrm{~N}$.

Figure 19. - Scanning electron photomicrographs of indentation and cracks on silicon carbide \{0001\} surface generated by hemispherical indenter. 


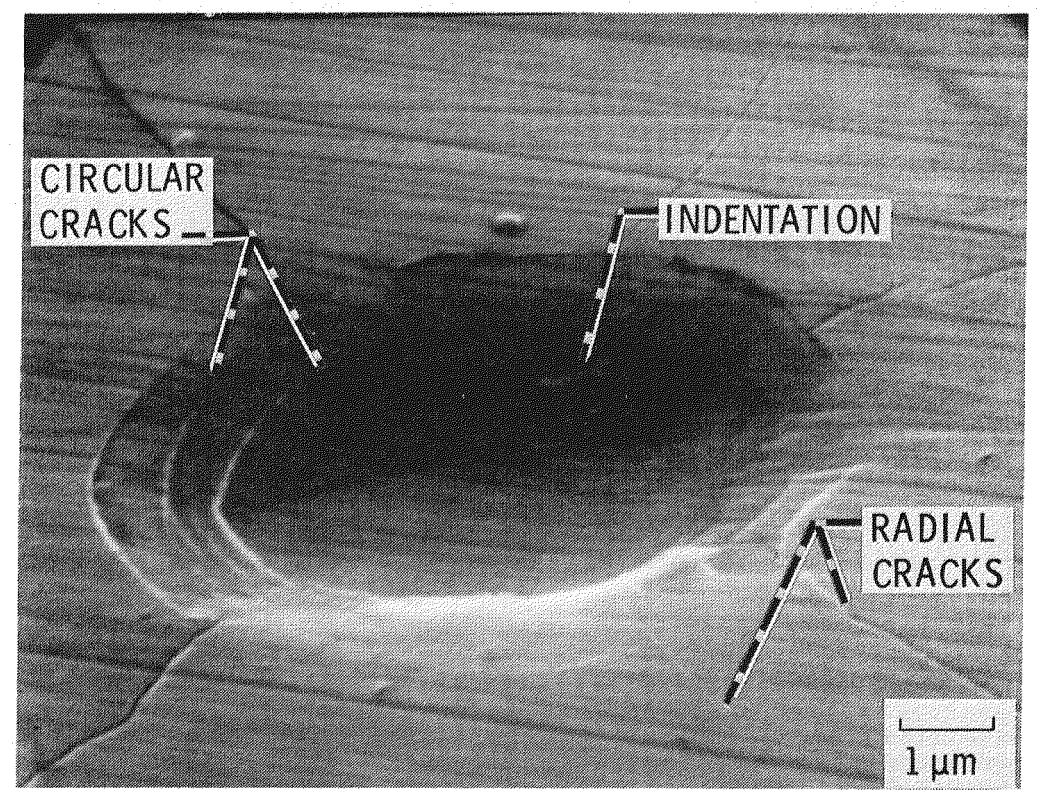

(c) Indentation generated by 0.008 -mm-radius hemispherical indenter. Load, $2 \mathrm{~N}$.

Figure 19. - Concluded. 


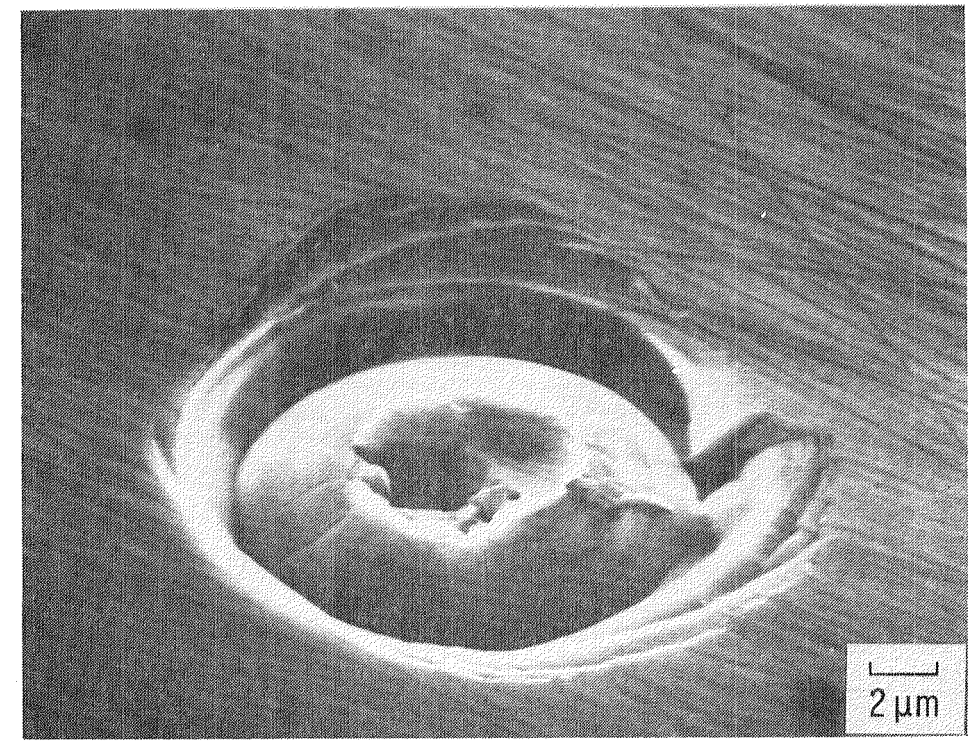

(a) Scanning electron photomicrograph.

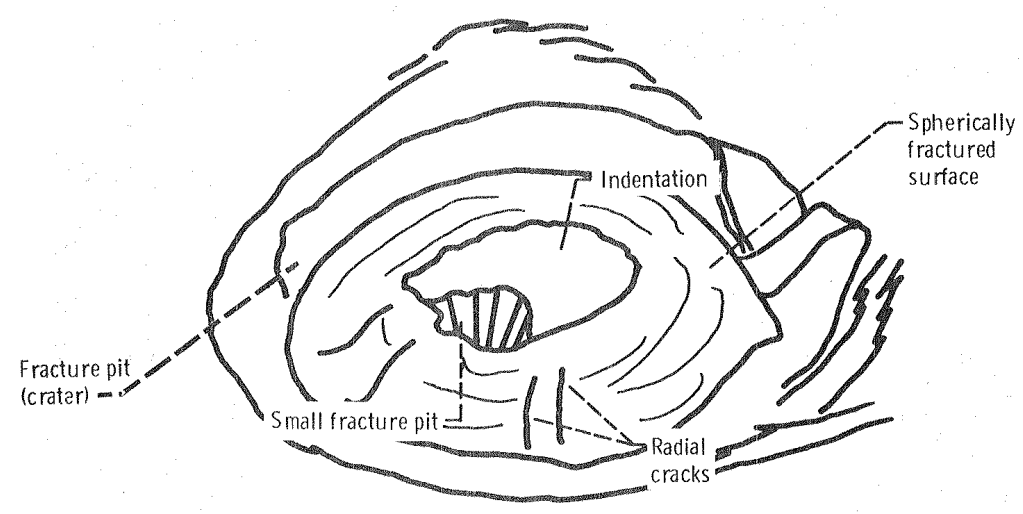

(b) Schematic.

Figure 20. - Indentation and fracture pit with a hemispherically fractured surface generated by 0.008 -mm-radius hemispherical indenter. Load, $10 \mathrm{~N}$. 


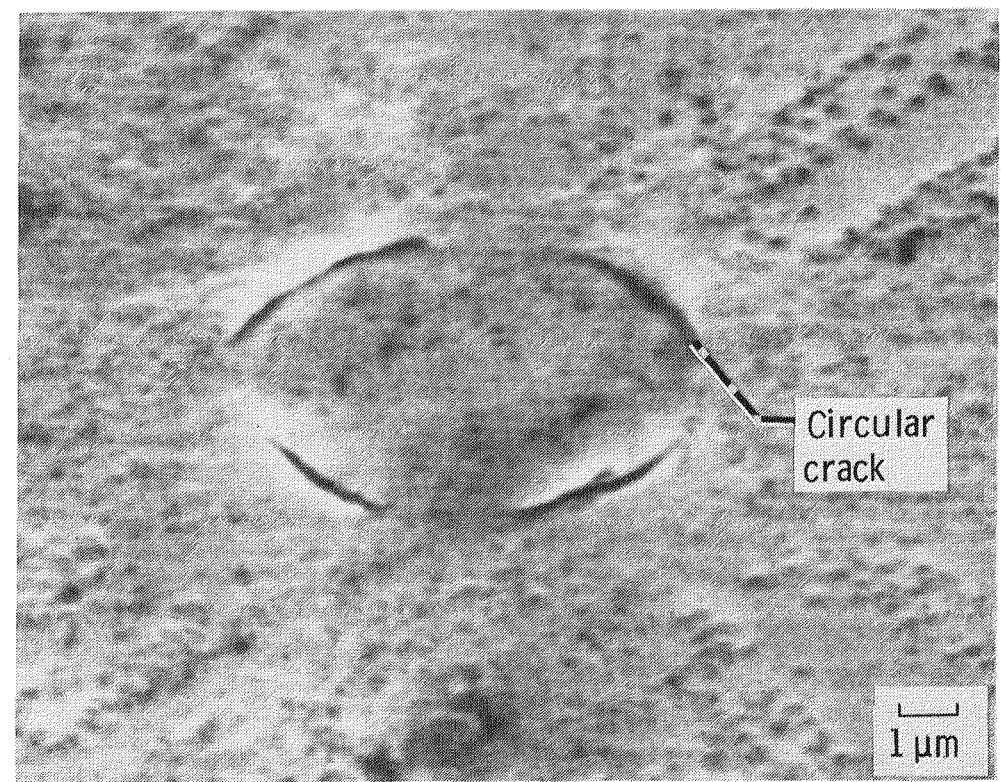

(a) In air.

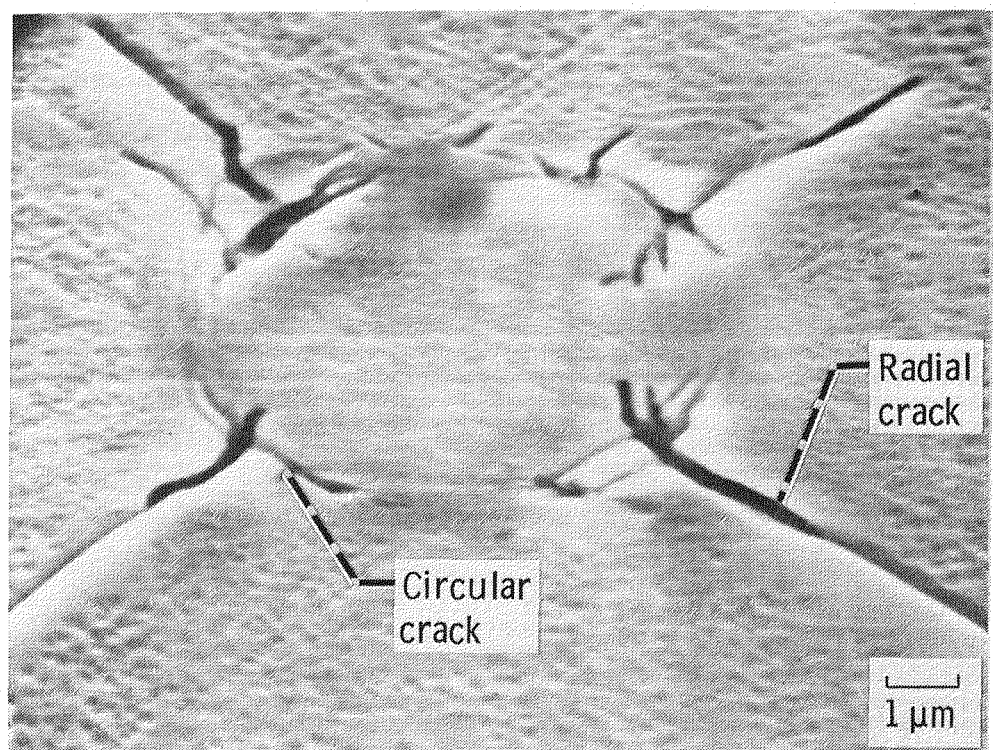

(b) In mineral oil with sulfur additive.

Figure 21. - Scanning electron photomicrographs of indentation and cracks on single-crystal magnesium oxide $\{001\}$ surface generated by 0.02 -mm-radius hemispherical diamond indenter. MgO crystals cleaved in air and in mineral oil with sulfur additive. Indentations made on surface in air or immersed in the oil. Load, $0.25 \mathrm{~N}$; room temperature. 


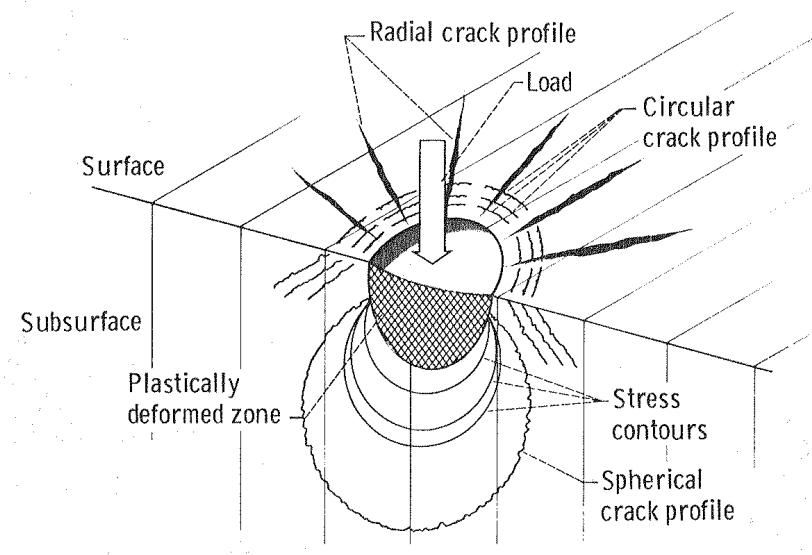

Figure 22. - Schematic of a hemispherical crack formation under a plastically deformed zone. 


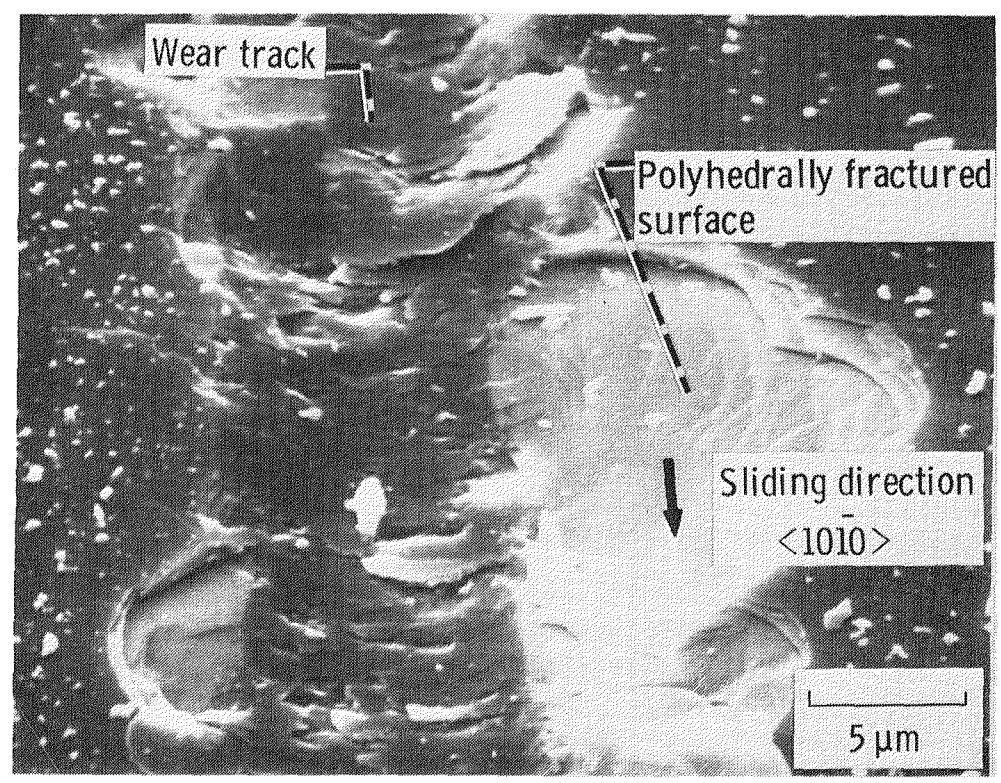

(a) Silicon carbide. Load, 2 N.

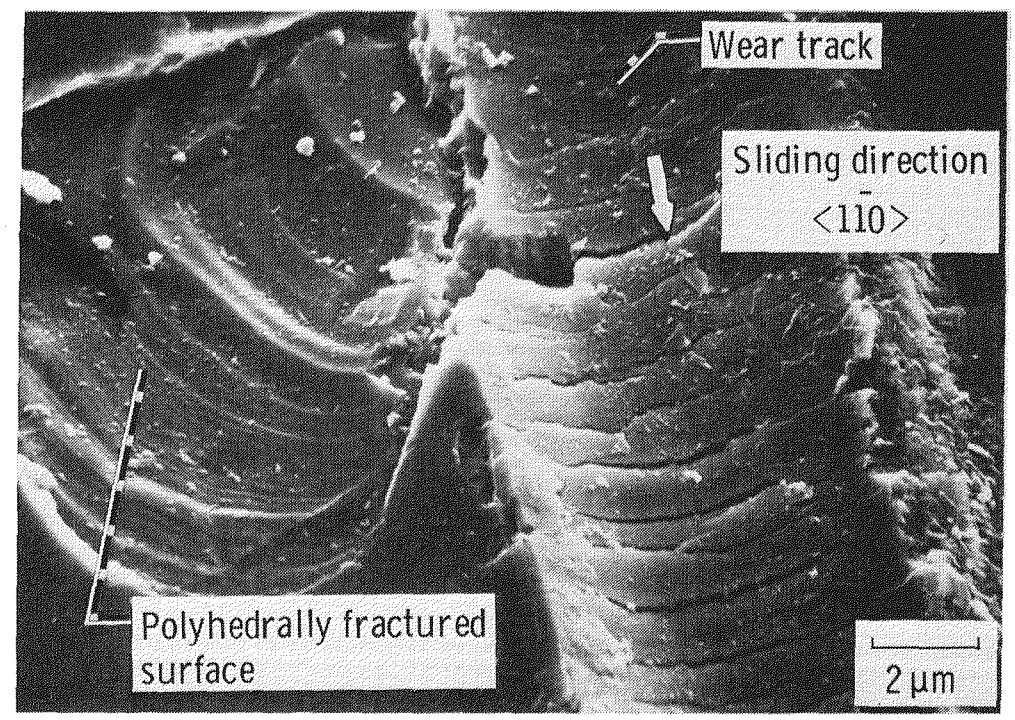

(b) Mn-Zn ferrite. Load, IN.

Figure 23. - Scanning electron photomicrographs of wear tracks on single-crystal silicon carbide $\{0001\}$ surface and manganese-zinc ferrite $\{110\}$ surface generated by 0.02 -mm-radius hemispherical riders. 


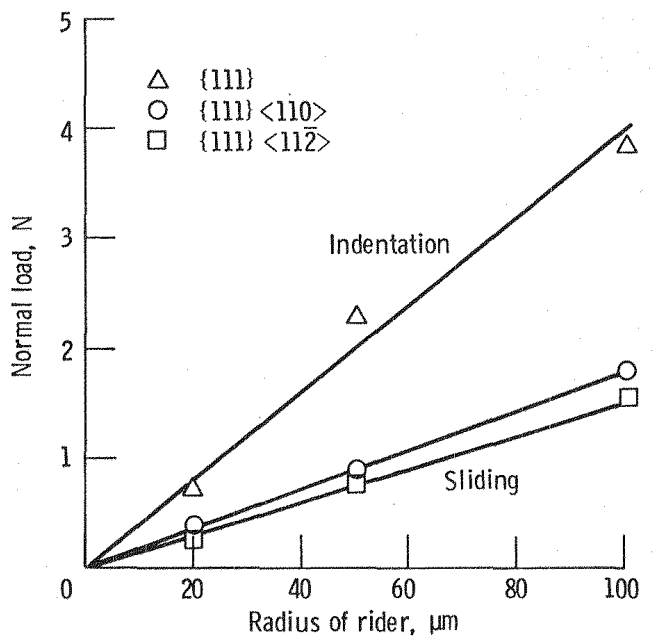

Figure 24. - Critical normal load to fracture Mn $\mathrm{Zn}$ ferrite as a function of radius of indenter and rider in indentation and in sliding contact. Indentation: \{111\} surfaces. Sliding: $\{111\}$ surface, $\langle 110\rangle$ direction: $\{111\}$ surface, $\langle 11 \overline{2}\rangle$ direction. 


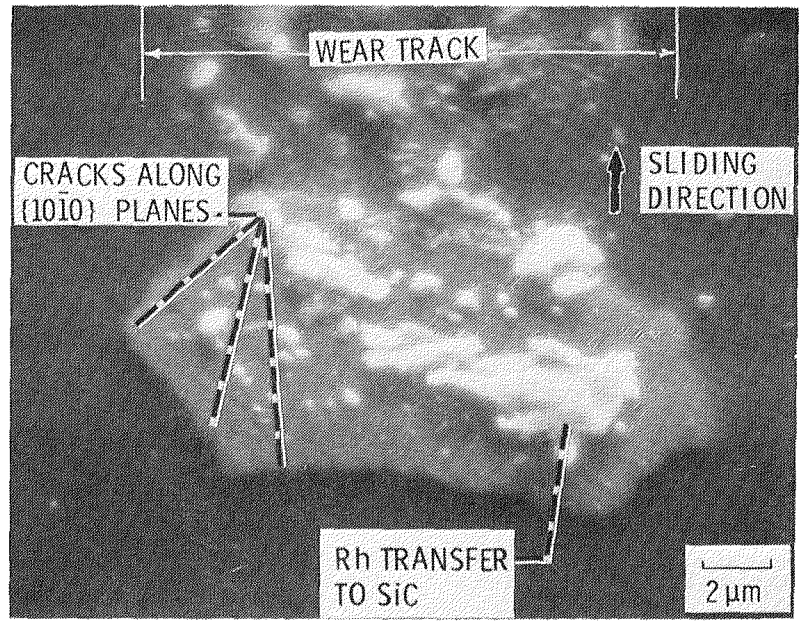

(a) Hexagonal cracking.

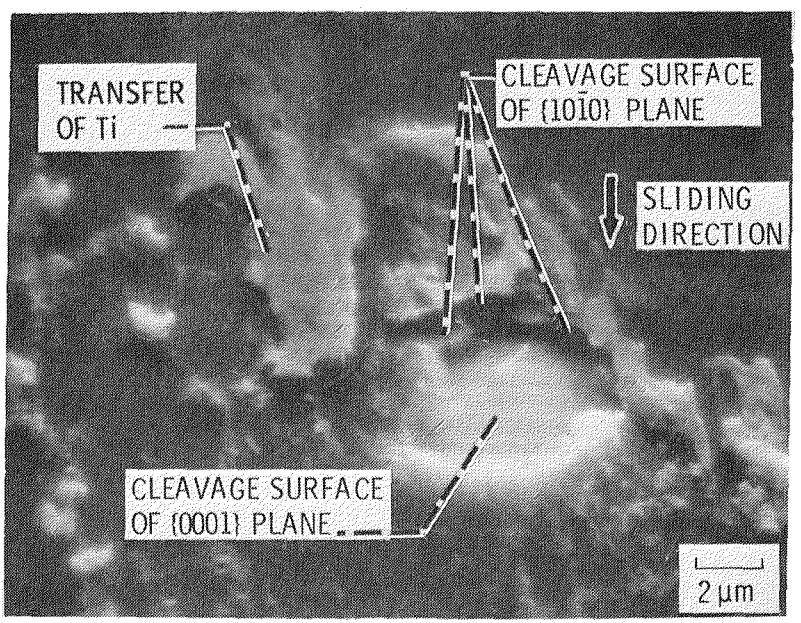

(b) Hexagonal pit.

Figure 25. - Scanning electron photomicrographs of wear tracks on the $\{0001\}$ surface of single-crystal SiC in contact with Rh and $\mathrm{Ti}$ as a result of ten passes of a rider in vacuum. Sliding direction, $\langle 1010\rangle$ : sliding velocity, $3 \mathrm{~mm} / \mathrm{min}^{-1} ; \operatorname{load}_{0} 0.3 \mathrm{~N}$ : room temperature; pressure, $30 \mathrm{nPa}$; metal pin rider, $0.79 \mathrm{~mm}$ radius. 


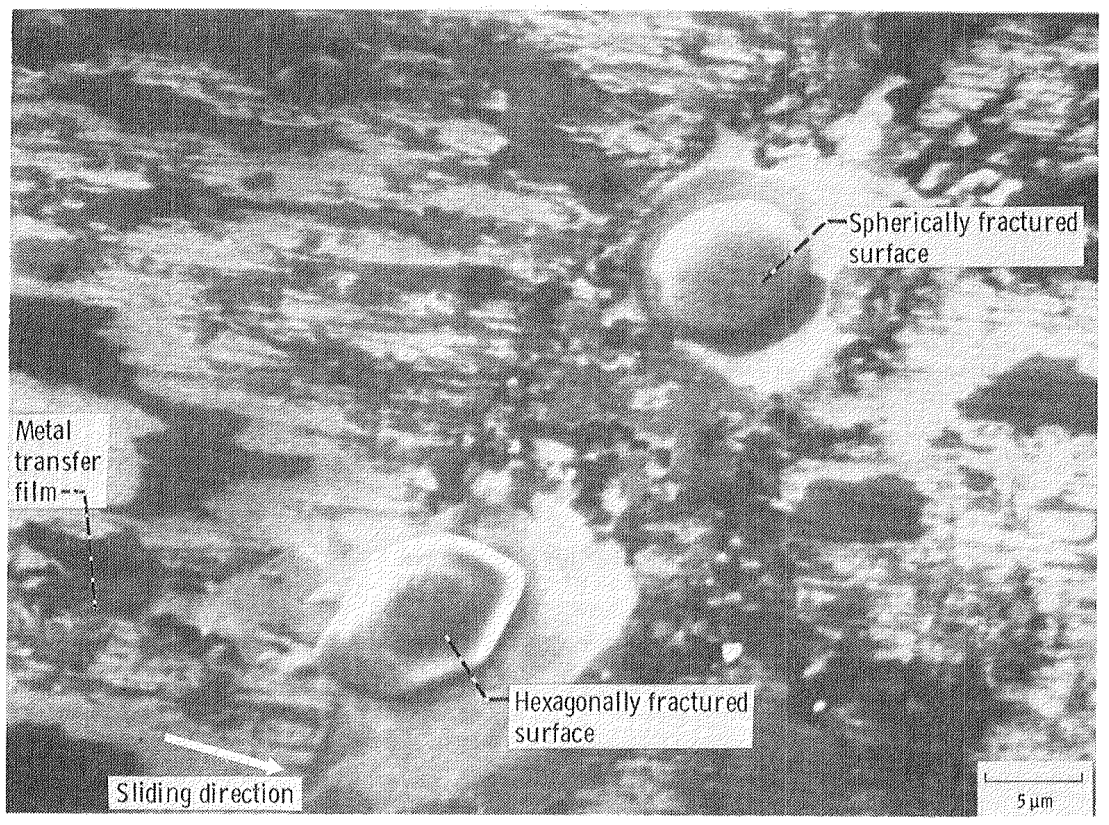

Figure 26. - Wear track with fracture pits on silicon carbide $\{0001\}$ surface as a result of a single-pass sliding of iron rider $\left(0.79 \mathrm{~mm}\right.$ radius). Sliding velocity, $3 \mathrm{~mm} / \mathrm{min}$; $10 a d, 0.2 \mathrm{~N}$; temperature, $800^{\circ} \mathrm{C}$; vacuum, $30 \mathrm{nPa}$.

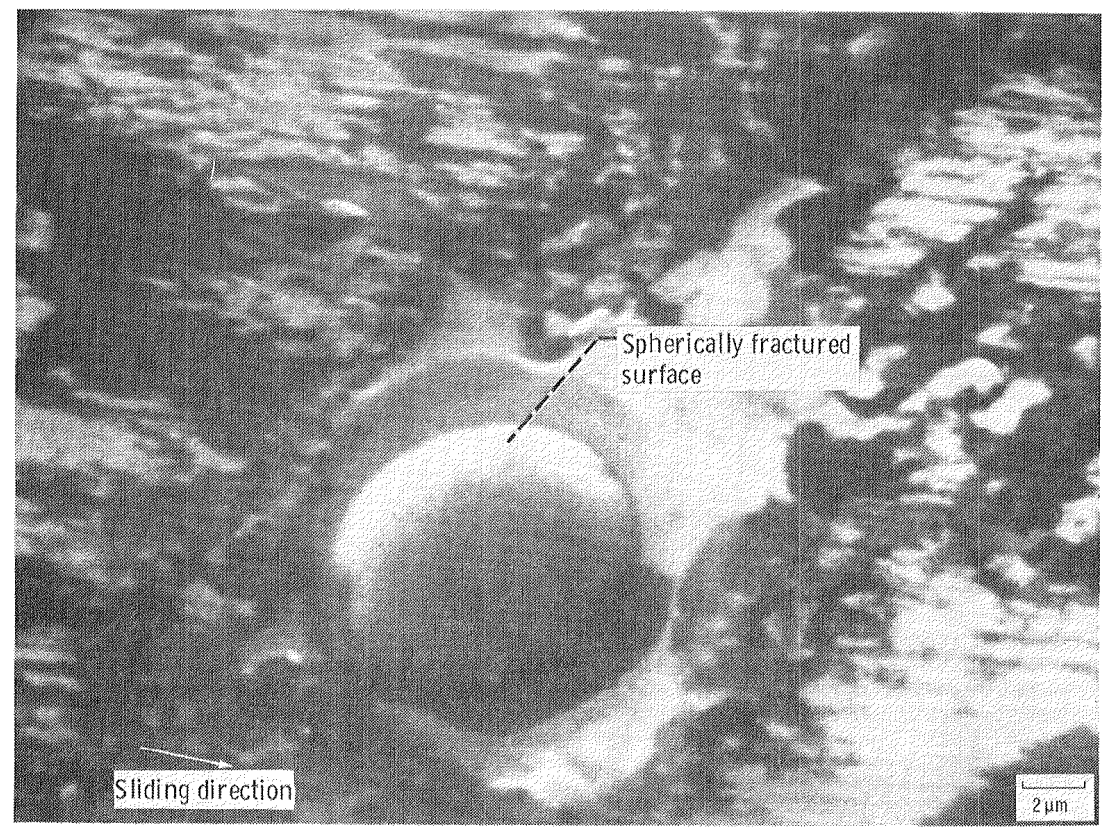

Figure 27. - Fracture pit on silicon carbide (0001) surface with spherically fractured surface as a result of single-pass sliding of iron rider $(0.79 \mathrm{~mm}$ radius). Sliding velocity, $3 \mathrm{~mm} / \mathrm{min}$; load, $0.2 \mathrm{~N}$; temperature, $800^{\circ} \mathrm{C}$; vacuum, $30 \mathrm{nPa}$. 


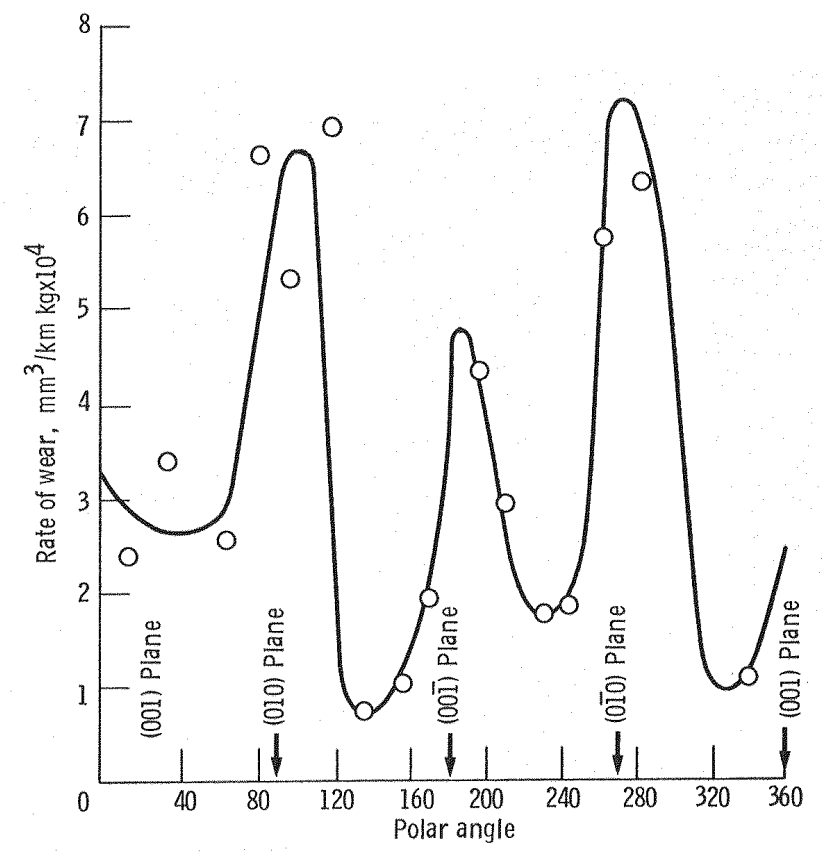

Figure 28. - Rate of wear of a rutile single crystal sphere on a great circle in the plane of the a and c-axes. The c-axis is normal to the plane of sliding at 0 and $180^{\circ}$. The slide direction was in the plane of the great circle (Duwell, 1969).

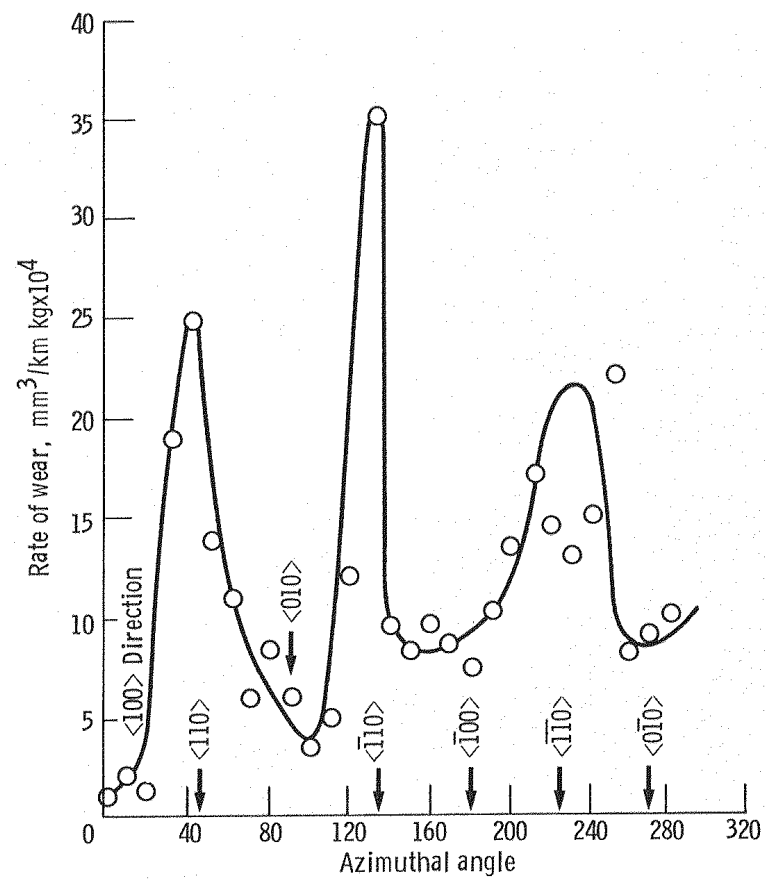

Figure 29. - Rate of wear of a rutile single crystal sphere as a function of slide direction on the (001) plane. The slide direction is parallel to an a-axis at $0,90,180$, and $270^{\circ}$ (Duwell, 1969). 


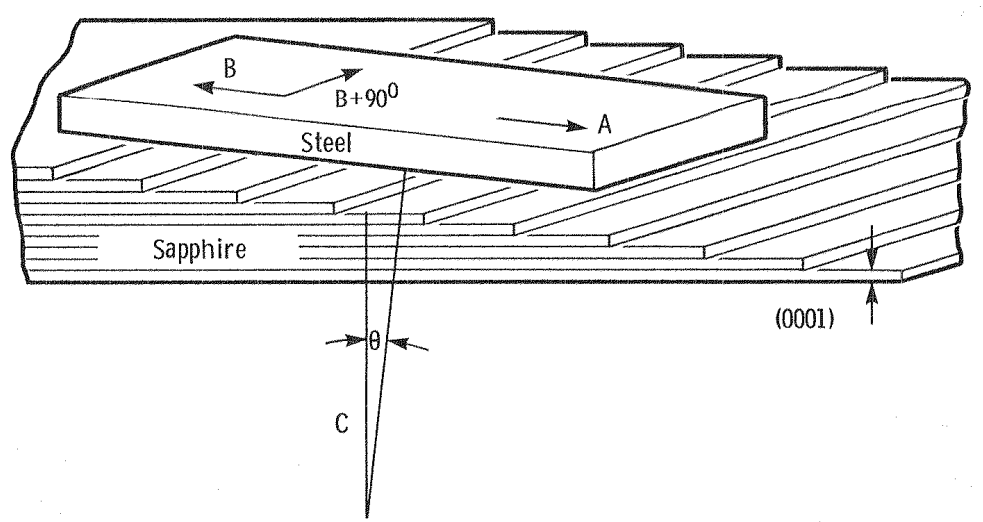

Figure 30(a). - Schematic diagram of $\mathrm{Al}_{2} \mathrm{O}_{3}$-Fe slide interface. The sapphire surface consists of successive emerging basat sheets (0001). The $c$-axis, which is normal to the basal sheets, makes an angle $\theta$ with the slide interface. Slide direction $A$ : high wear rate of sapphire; slide $B$ : low wear rate of sapphire; slide direction $\mathrm{B}+90^{\circ}$; intermediates wear rate. Slide directions $\mathrm{A}$ and $\mathrm{B}$ are in opposite directions and perpendicular to the edges of the basal sheets. (Duwell, 1967).

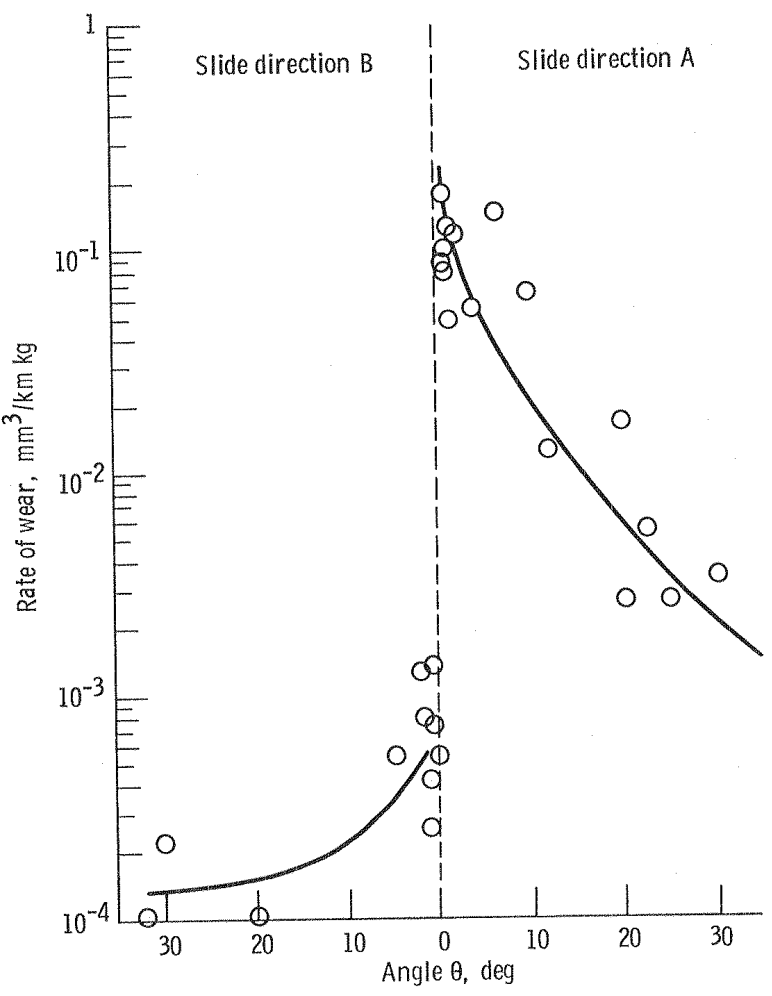

Figure 30(b). - Rate of wear of $\mathrm{Al}_{2} \mathrm{O}_{3}$ as a function of angle $\theta$ Slide directions $A$ and $B$ and angle $\theta$ are defined in figure 30 (a). Load: $0.65 \mathrm{n} ; \mathrm{H}_{2} \mathrm{O}$ lubricated; sliding speed: 100-140 $\mathrm{m} / \mathrm{minute}$; circular track experiments. (Duwell, 1967).) 


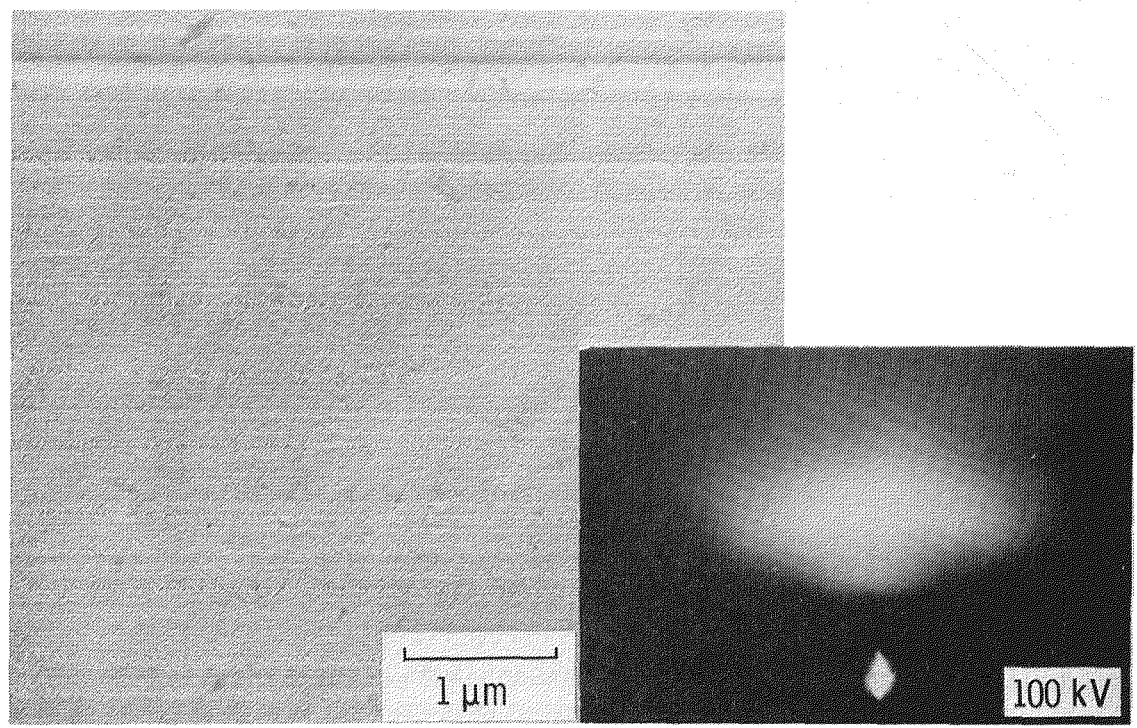

(a) Wear surface.

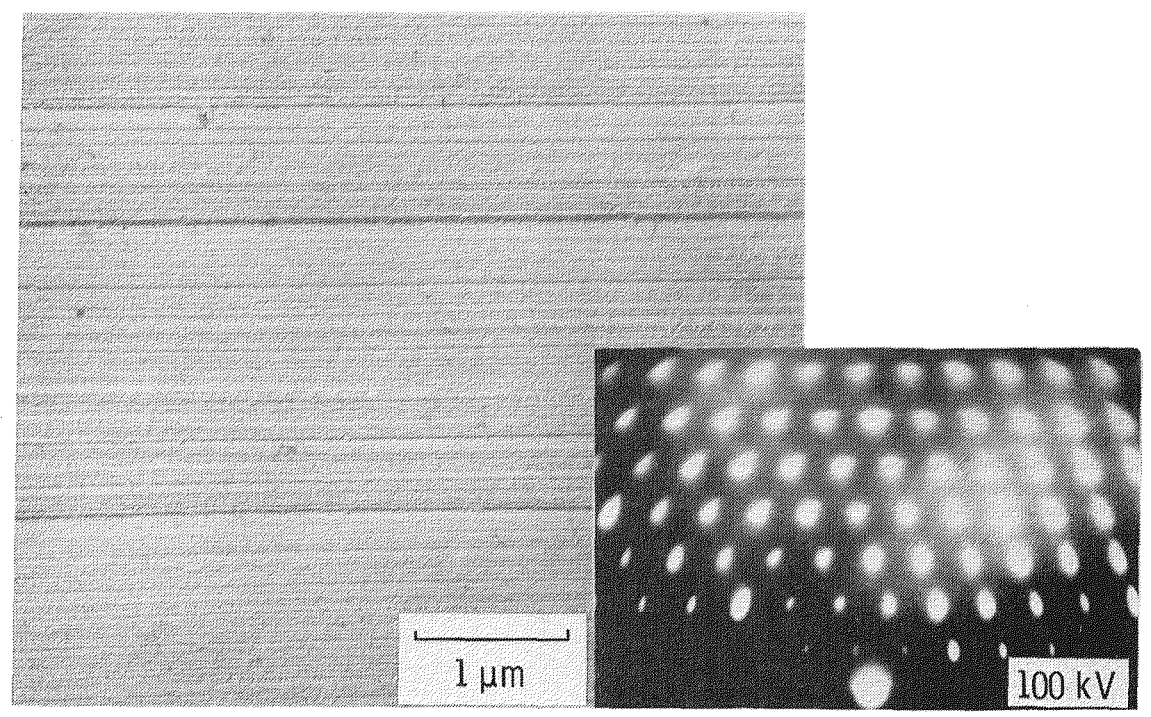

(b) Etched surface (etching depth: few hundreds $\AA$ ).

Figure 31. - Wear surface of Mn- Zn ferrite in sliding contact with a $\mathrm{\gamma Fe}_{2} \mathrm{O}_{3}$ magnetic tape. Sliding surface, $\{110\}$; sliding direction, $\langle 110\rangle$; sliding velocity, $11 \mathrm{~m} / \mathrm{s}$; laboratory air; room temperature. 


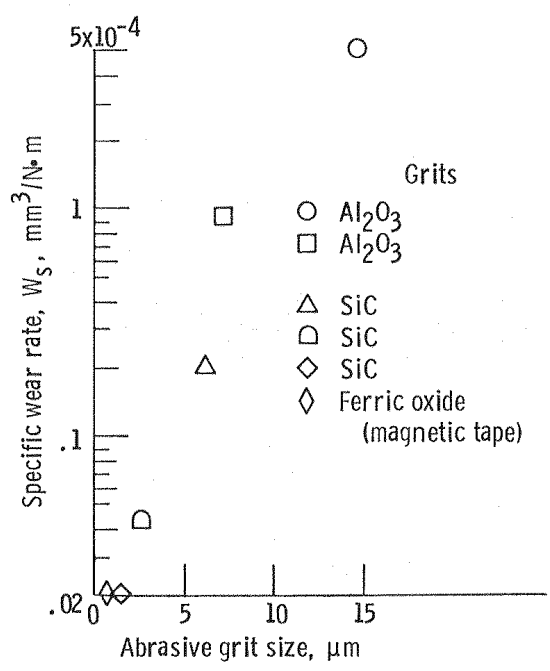

Figure 32. - Specific wear rates (abrasiveness) for various lapping tapes in lapping process of drum ferrite specimen. Initial tape tension, $2 \mathrm{~N}$; rotation speed of drum, $0.5 \mathrm{~m} / \mathrm{s}$ tape speed, $0.02 \mathrm{~m} / \mathrm{s}$; wrap angle, $\pi / 2$; laboratory air; room temperature.

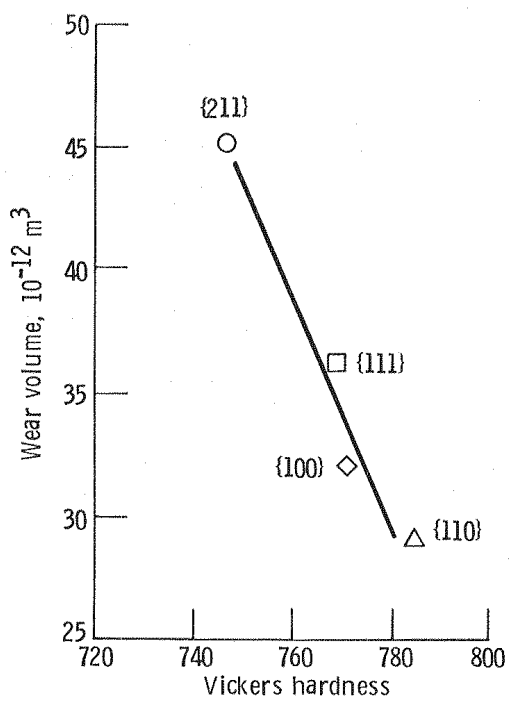

Figure 33. - Anisotropy of wear for $\{100\},\{110\},\{111\}$, and $\{211\}$ planes of $\mathrm{Mn}-\mathrm{Zn}$ ferrite as a function of Vickers hardness. Sliding direction, $\langle 110\rangle$; lapping-tape, $\mathrm{Al}_{2} \mathrm{O}_{3}$ number 2000 ; sliding velocity, $11 \mathrm{~m} / \mathrm{s}$; laboratory air; room temperature; Vickers hardness measuring load, $0.25 \mathrm{~N}$. 

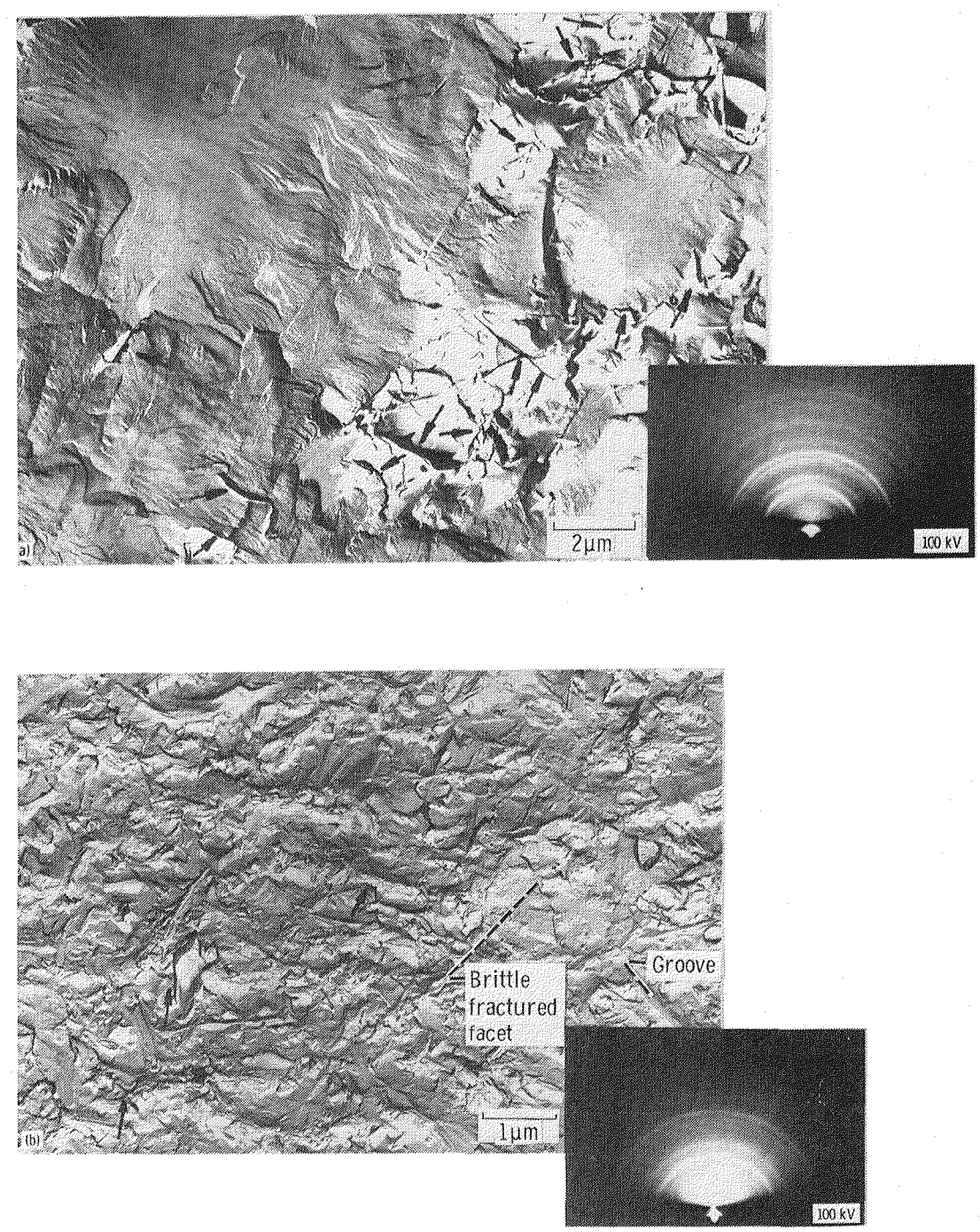

Figure 34. - Replication electron photomicrographs of abraded surfaces of $\mathrm{Mn}-\mathrm{Zn}$ ferrite (single-crystal $\mathrm{Mn}-\mathrm{Zn}$ ferrite $\{100\}$ plane; abrasion direction, $\langle 01 \mathrm{\rangle}\rangle$; lapping machine; lapping disk, cast iron;

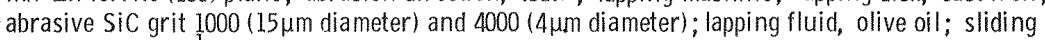
velocity, $0.5 \mathrm{~m} \mathrm{~s}^{-1}$; abrasive: fluid ratio, $27 \mathrm{wt}$ \%; arrows denote cracks): (a) abraded surface on $15 \mu \mathrm{m}$ $\mathrm{SiC}$ grits (apparent contact pressure, $3 \mathrm{~N} \mathrm{~cm}^{-2}$ ); (b) abraded surface on $4 \mu \mathrm{m} \mathrm{SiC}$ grits (apparent contact pressure, $8 \mathrm{~N} \mathrm{~cm}^{-2}$ ). 


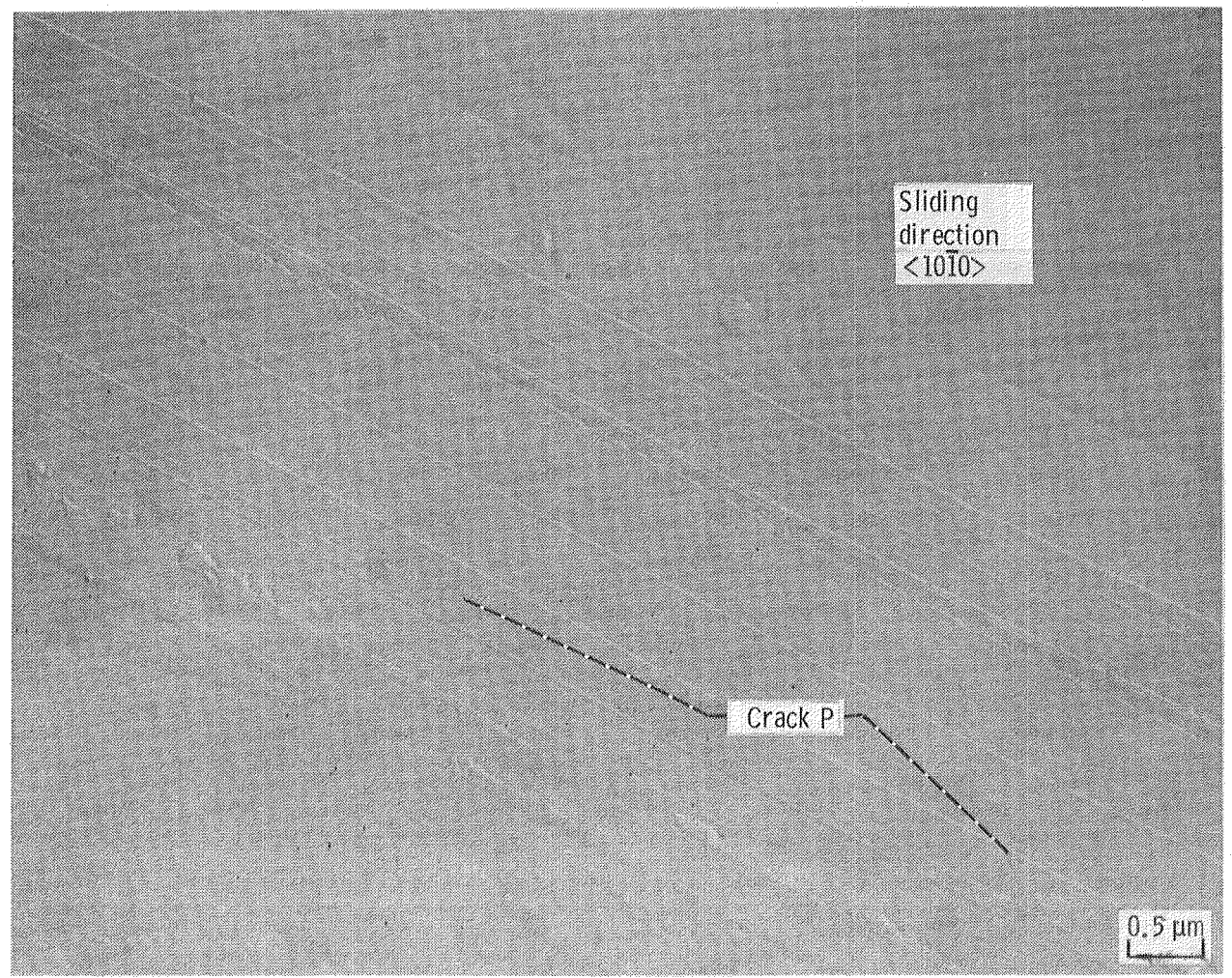

(a) Load, 30 grams.

Figure 35. - Replication electron micrographs of wear track on single-crystal silicon carbide (0001) surface. Single pass of spherical rider of radius $0.02 \mathrm{~mm}$; sliding direction, $\langle 1010\rangle$; sliding velocity, $3 \mathrm{~mm} / \mathrm{min}$; temperature, $25^{\circ} \mathrm{C}$ in argon at atmospheric pressure. 


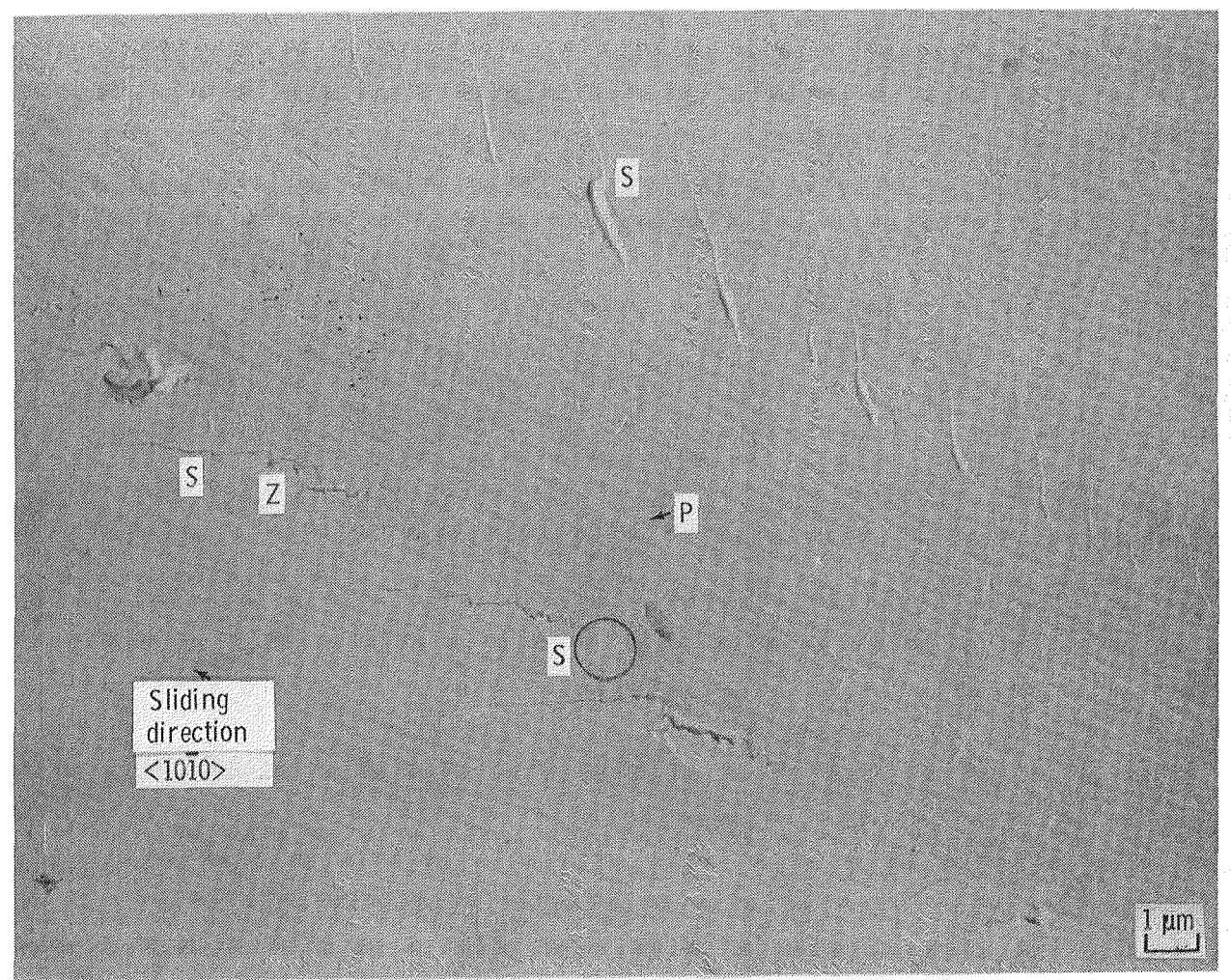

(b) Load, 40 grams.

Figure 35. - Concluded. 


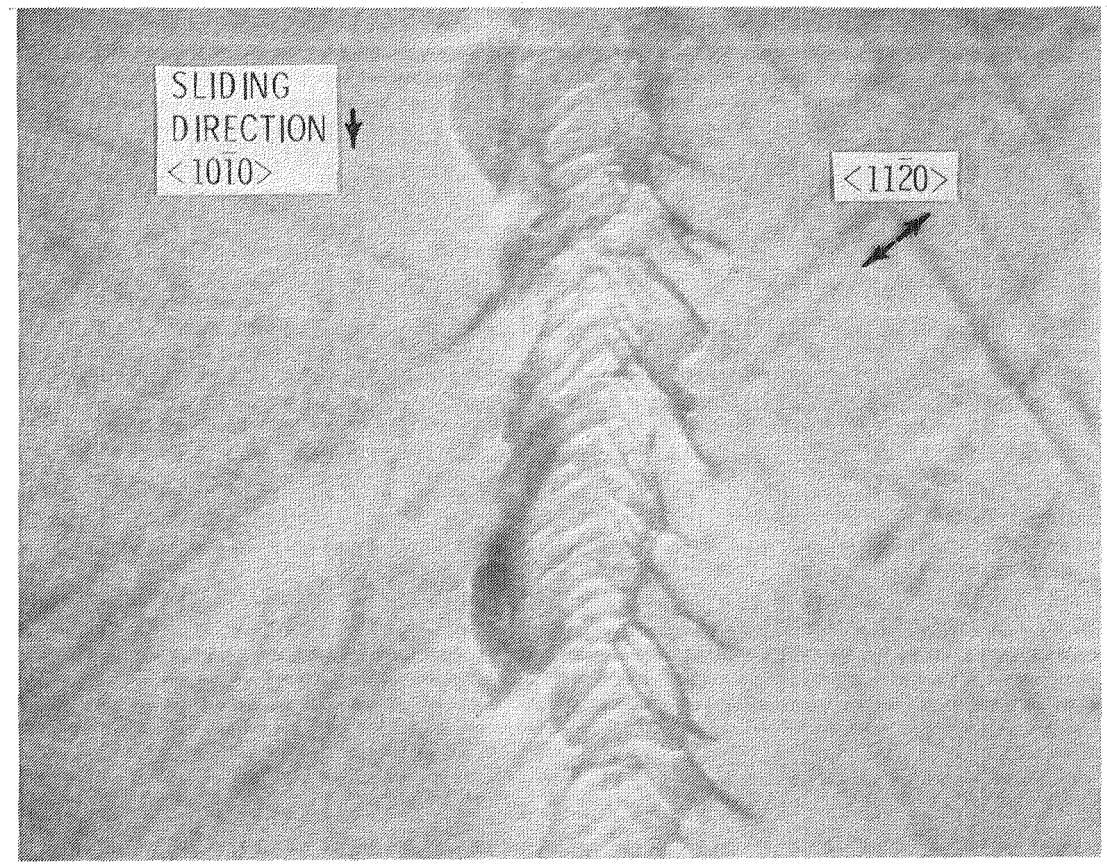

(a) Load, 30 grams.

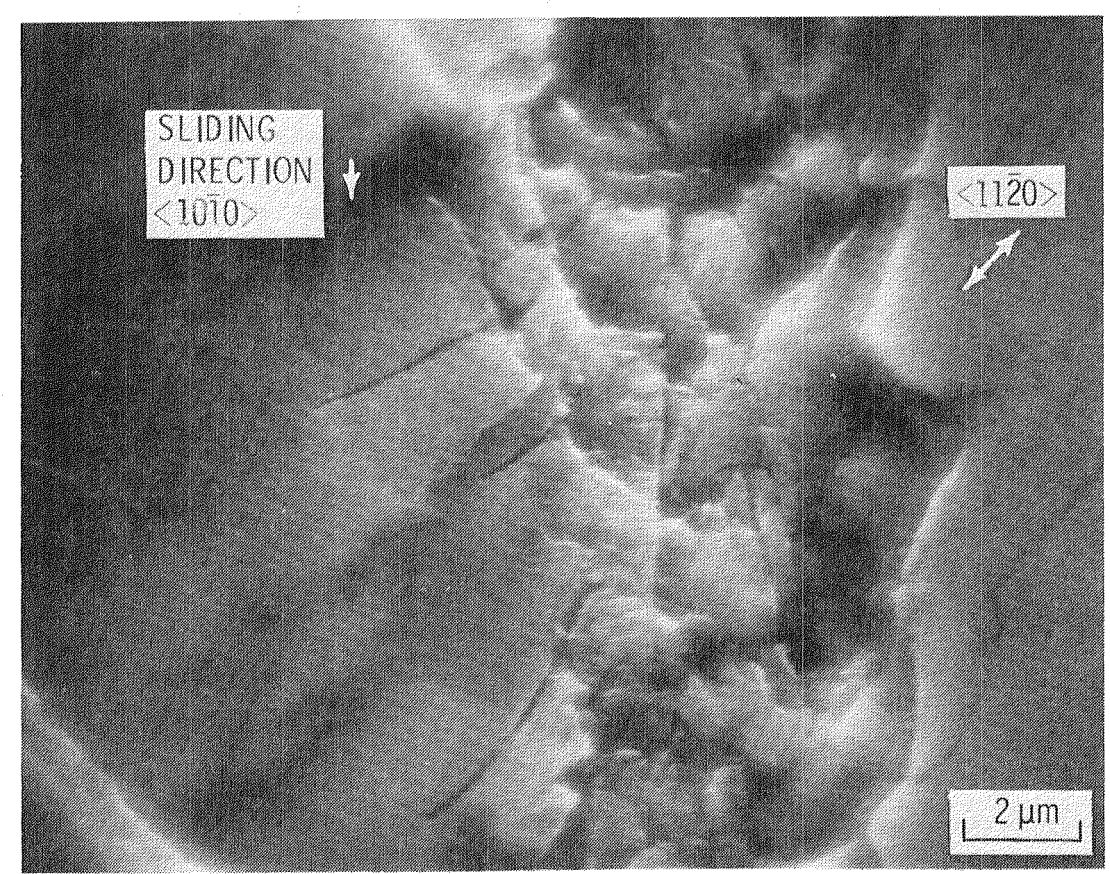

(b) Load, 50 grams.

Figure 36. - Scanmina electron microciraphs of wear track on single-crystal silicon carbide (0001) surface (etched with molten salt (1 $\mathrm{NaF}+2 \mathrm{KCO}_{3}$ ) at 700 to $800^{\circ} \mathrm{Cl}$. Single pass of conical diamond rider; sliding direction, $\langle 1010\rangle$; sliding velocity, $3 \mathrm{~mm} / \mathrm{min}$; temperature, $25^{\circ} \mathrm{C}$ in argon at atmospheric pressure. 

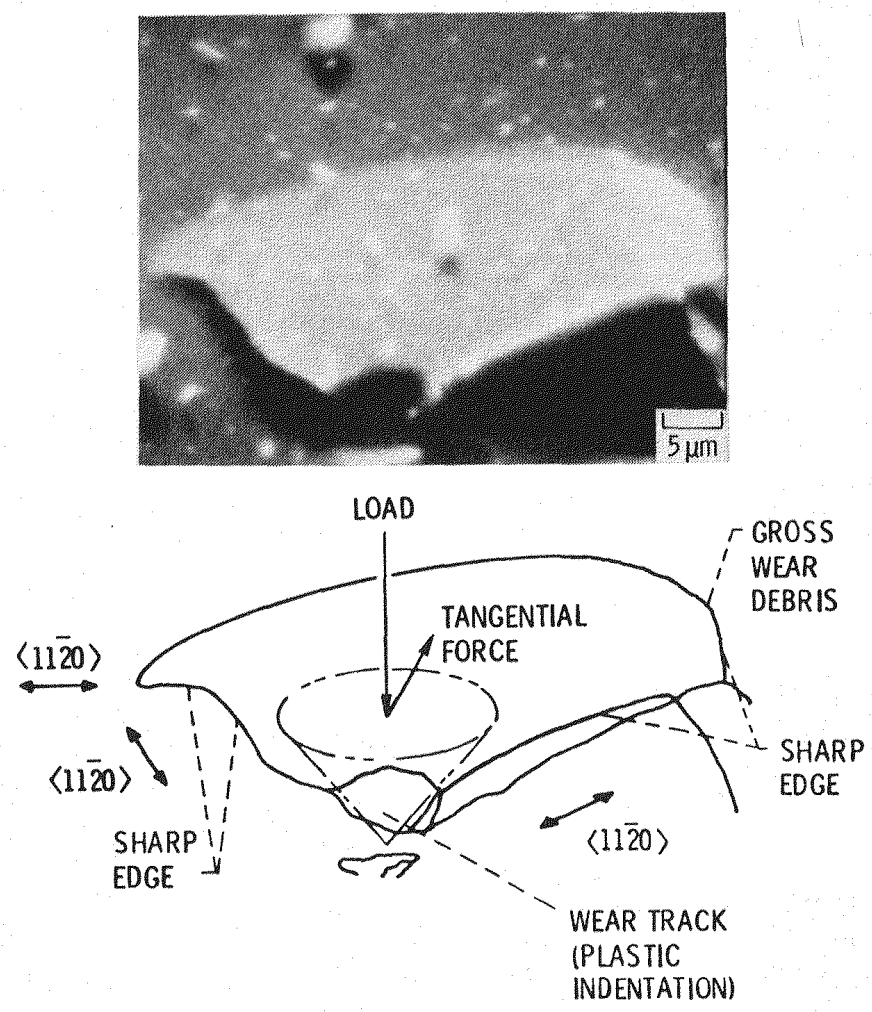

(a) First stage (before gross sliding).

Figure 37. - Mechanism of fracture. Single pass of conical diamond rider; sliding surface, (0001); sliding direction, $<1010>$; sliding velocity, $3 \mathrm{~mm} / \mathrm{min}$; load, 30 grams; temperature, $25^{\circ} \mathrm{C}$ in argon at atmospheric pressure. 

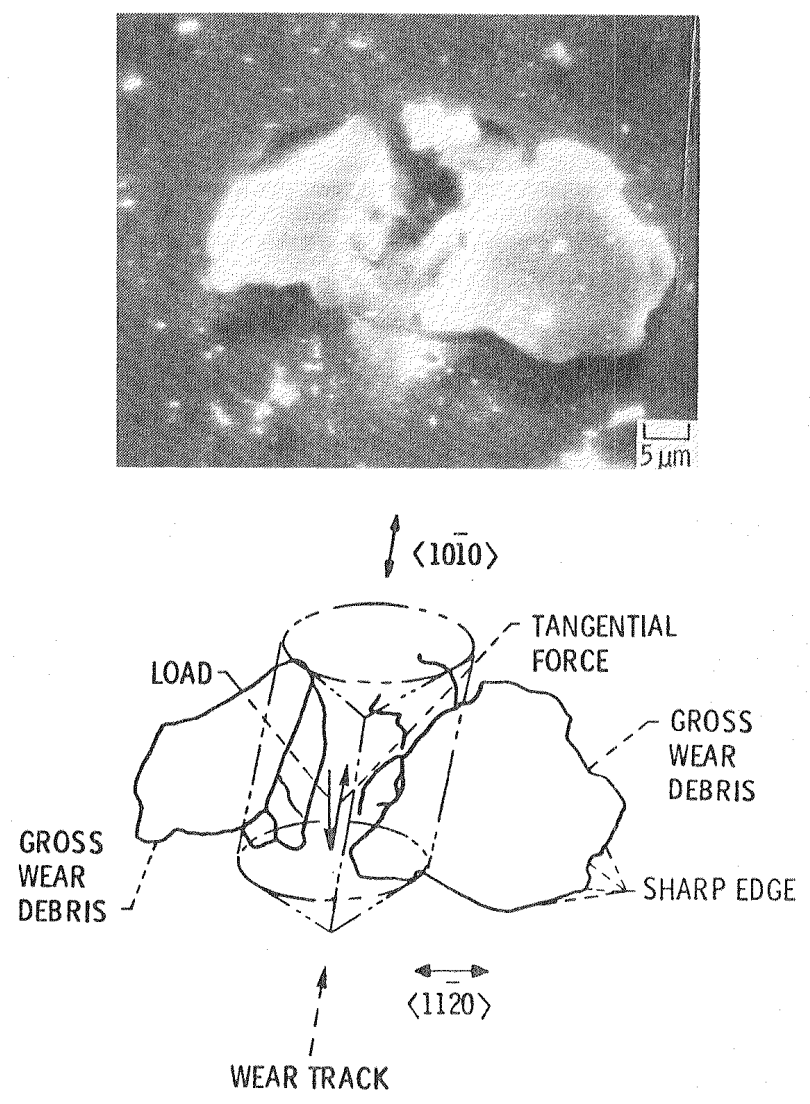

(b) Second stage (after gross sliding).

Figure 37. - Continued.

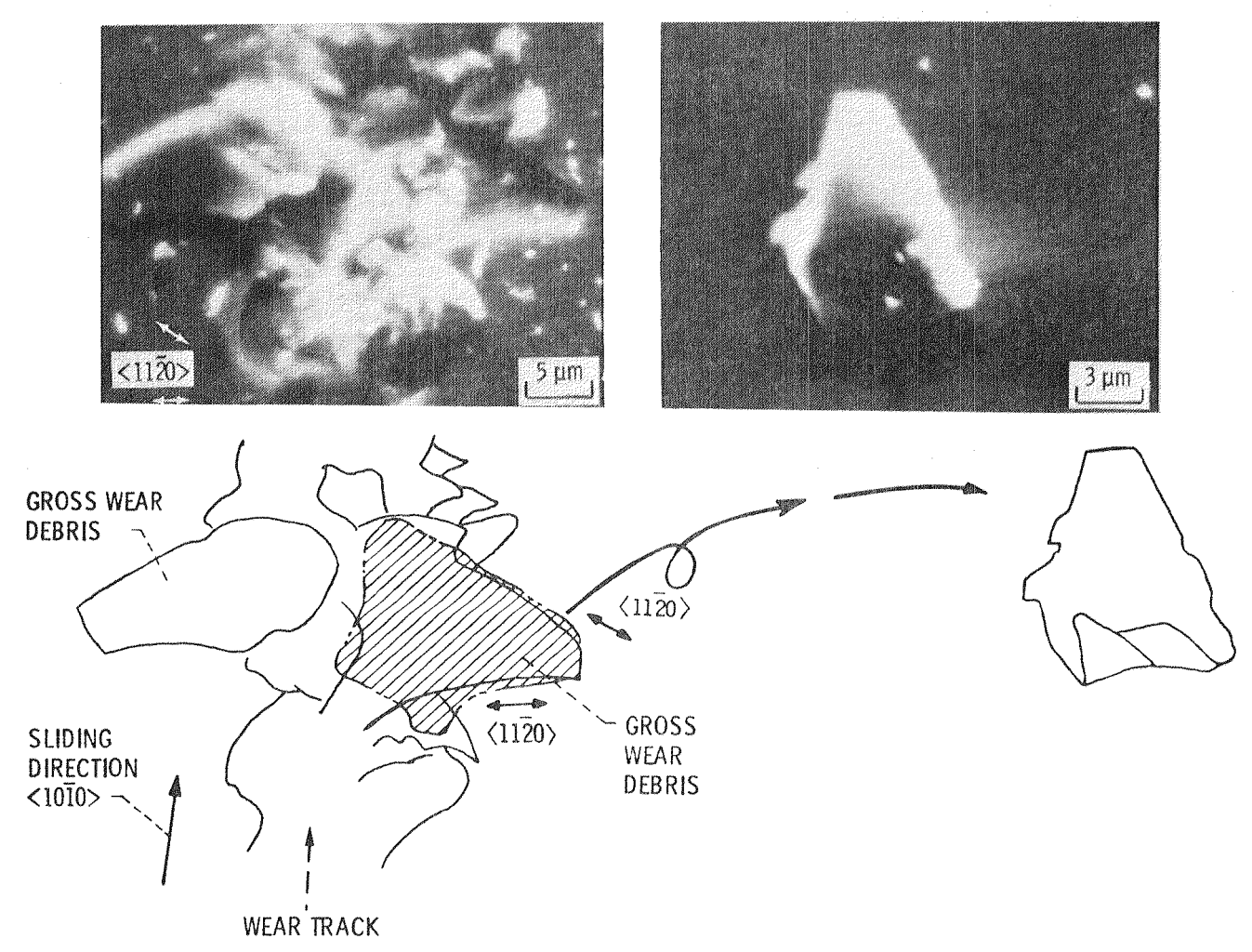

(c) Third stage.

Figure 37. - Concluded. 


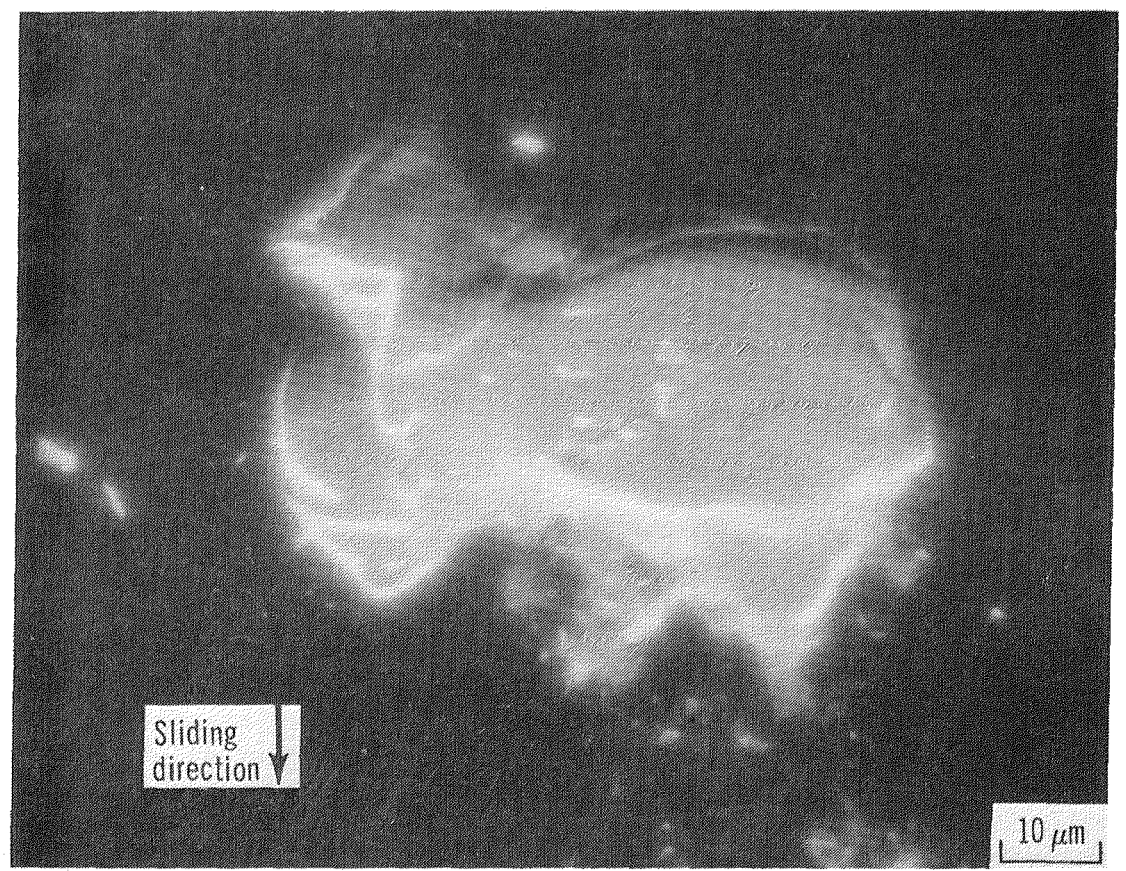

Figure 38. - Large fracture pit of single-crystal silicon carbide in contact with 8.12 atomic percent Ti-Fe alloy as a result of ten passes of rider in vacuum $\left(10^{-8} \mathrm{~Pa}\right)$. A scanning electron micrograph of wear track on silicon carbide (0001) surface. Sliding velocity, $3 \times 10^{-3}$ meter per minute; load, 0.2 newton; room temperature. 


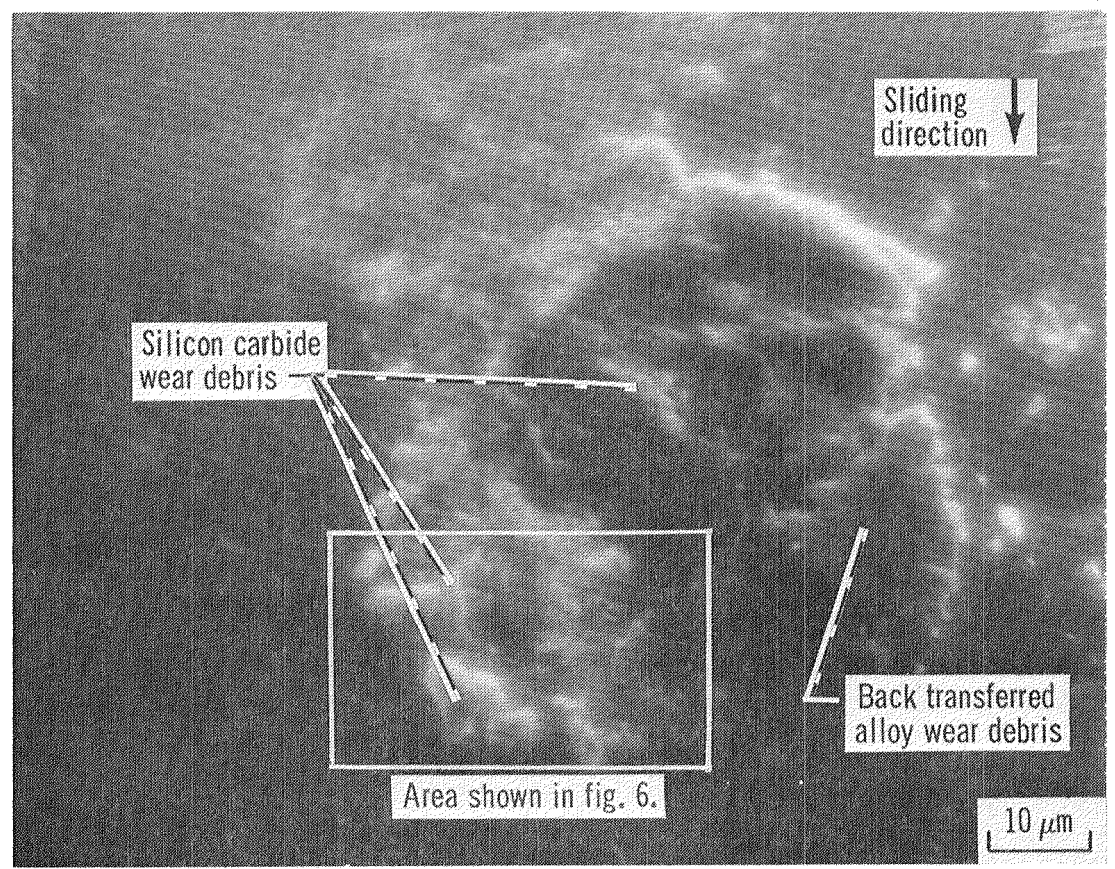

(a) Silicon carbide wear debris.

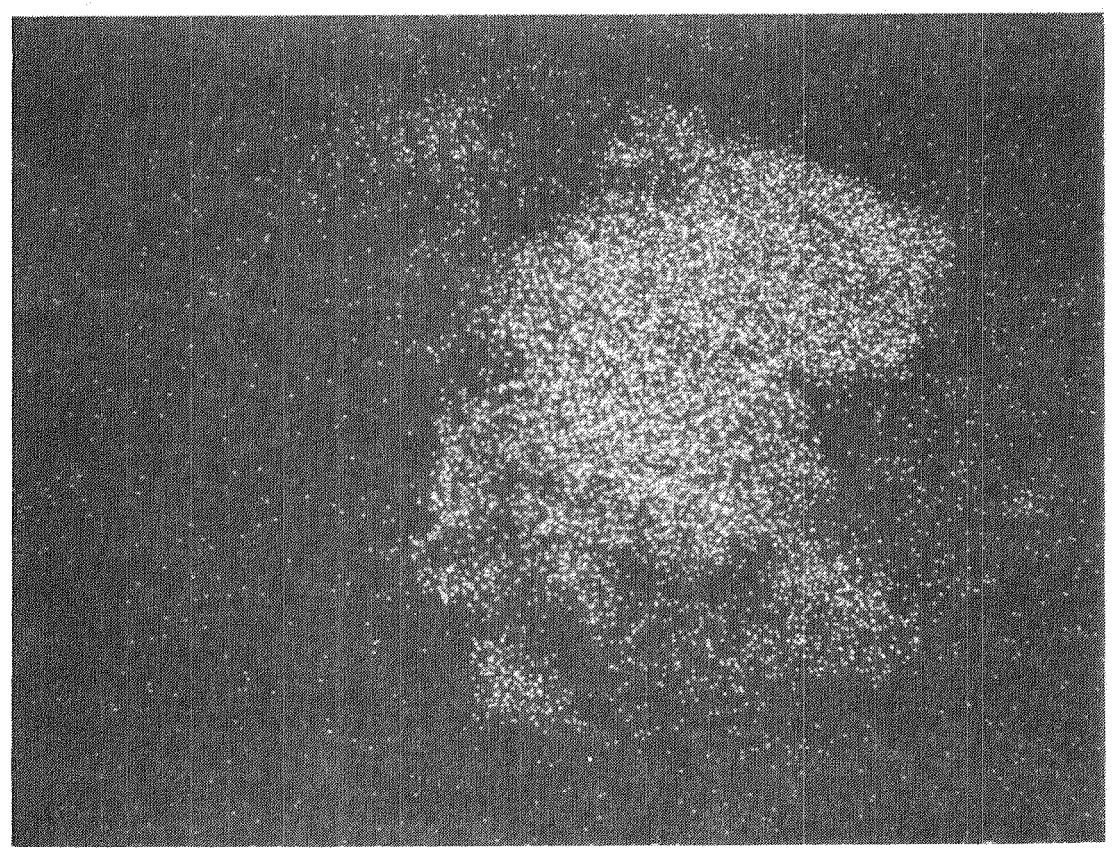

(b) Silicon $\mathrm{K}_{\alpha} \mathrm{X}$-ray map of 8.12 atomic percent Ti-Fe alloy rider; $1 \times 10^{4}$ counts.

Figure 39. - Silicon carbide wear debris on alloy as a result of ten passes of rider in vacuum $\left(10^{-8} \mathrm{~Pa}\right)$. Scanning electron micrograph and an $X \cdot$ ray dispersive analysis of wear scar on alloy rider. Sliding velocity, $3 \times 10^{-3}$ meter per minute; load, 0.2 newton; room temperature. 


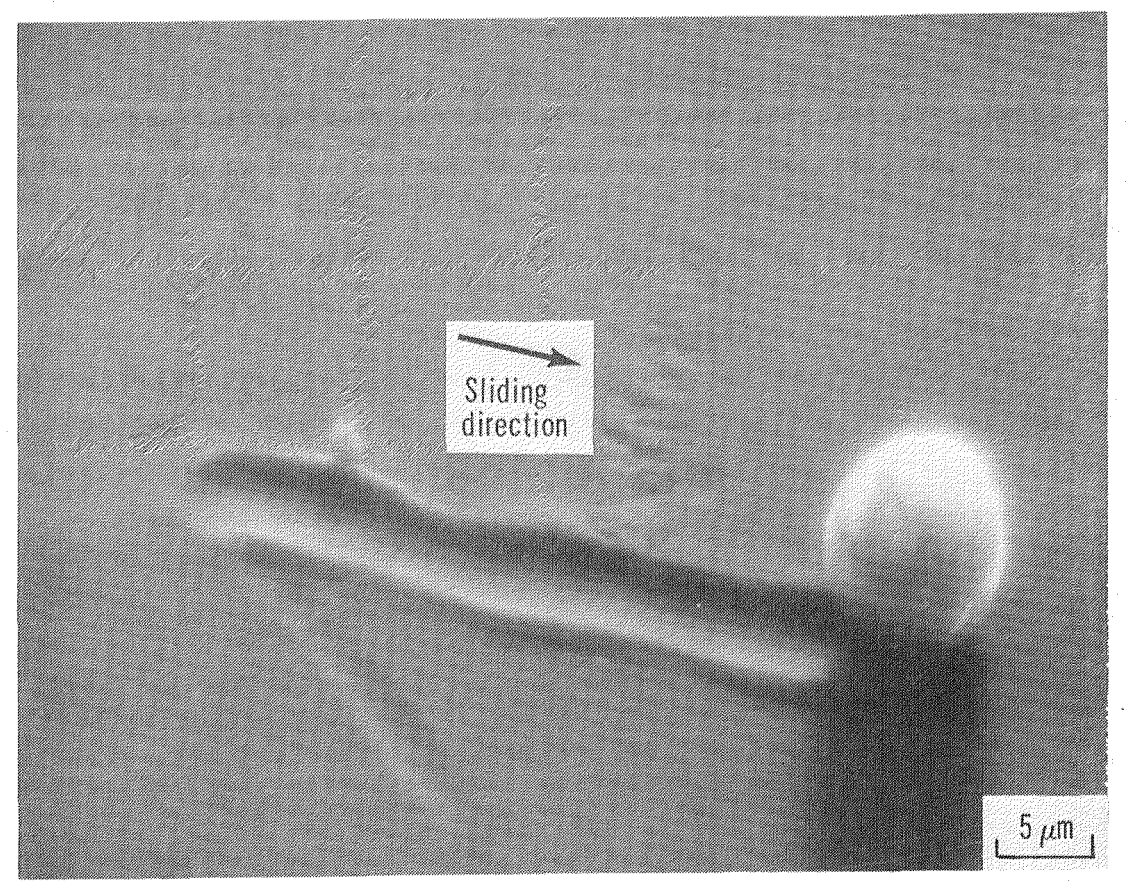

(a) Spherical wear particle and groove.

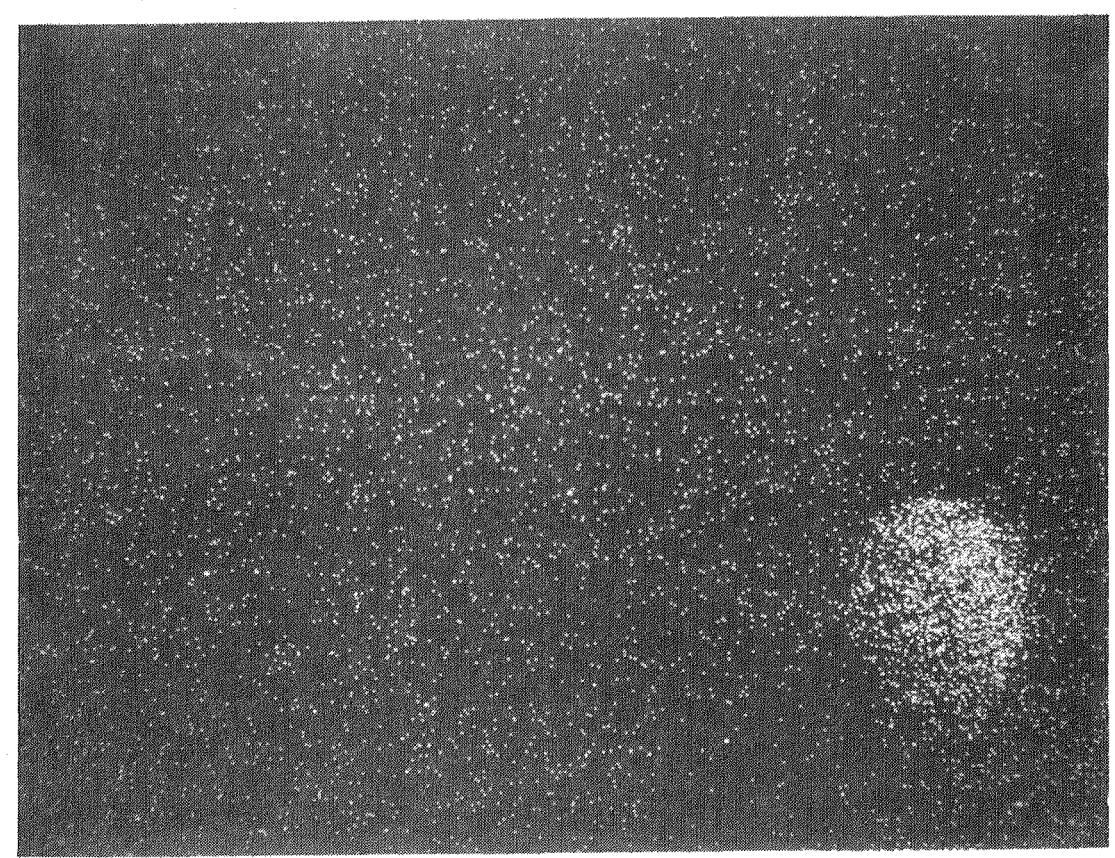

(b) Silicon, $K_{\alpha} X$-ray map of 1.02 at \% Ti-Fe alloy rider; $1 \times 10^{4}$ counts.

Figure 40. - Spherical wear particle on alloy as a result of ten passes of rider in vacuum $\left(10^{-8} \mathrm{~Pa}\right)$. Scanning electron micrograph and an $\mathrm{X}$-ray dispersive analysis of wear scar on alloy rider. Sliding velocity, $3 \times 10^{-3}$ meter per minute; load, 0.2 newton; room temperature. 


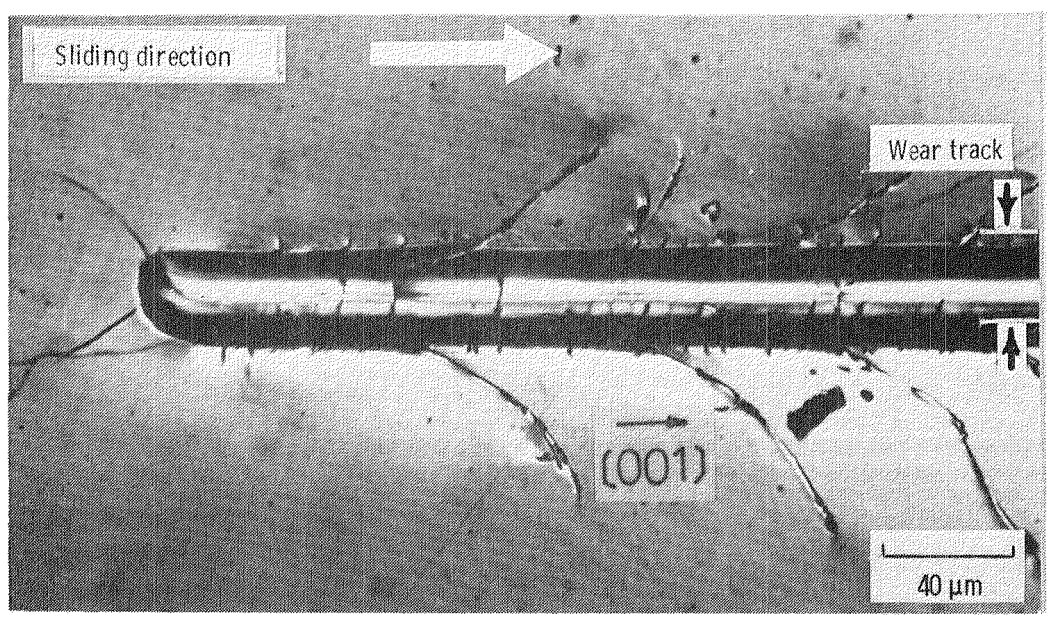

(a) In air

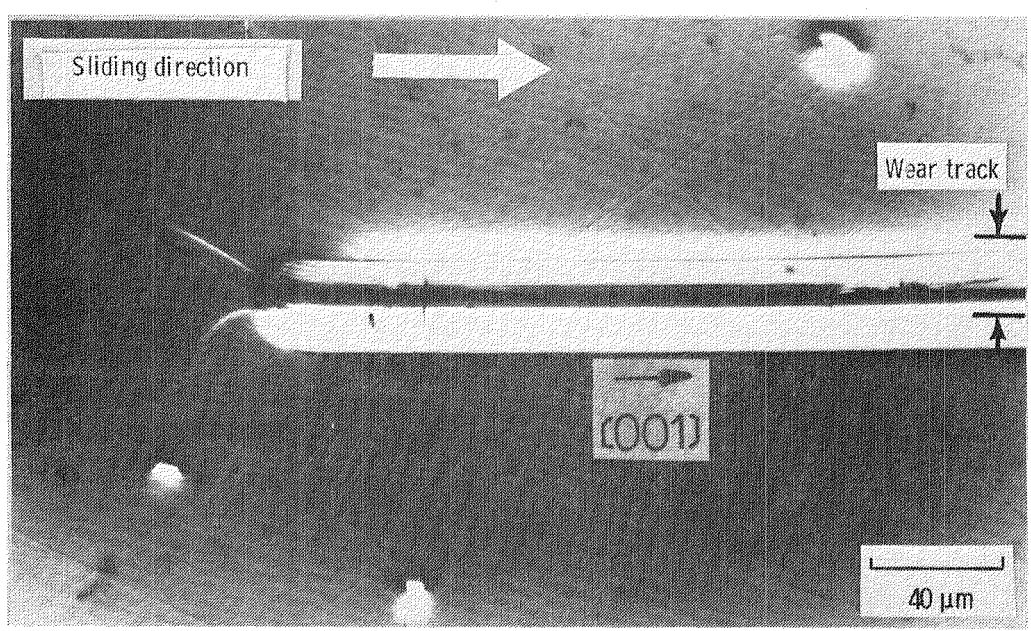

(b) In lubricant.

Figure 41. - Diamond rider sliding on a single crystal Mn-Zn ferrite (001) surface both in air (a) and lubricated with oil (b). 


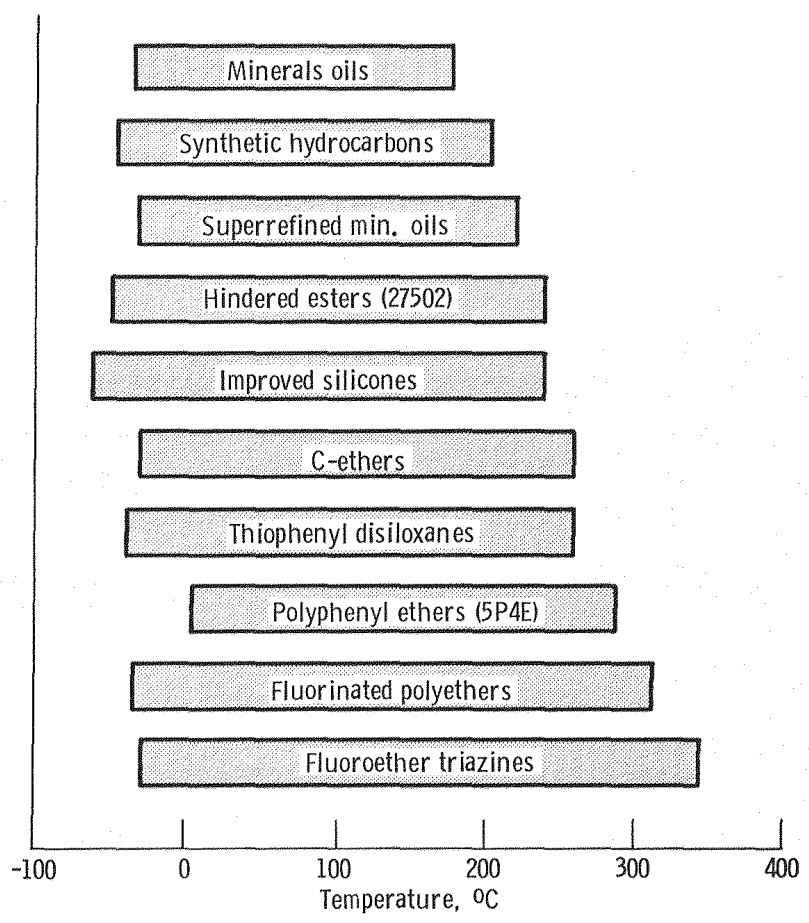

Fiqure 42. - Operating temperature range for classes of high temperature liquid lubricants. (Loomis, 1984).)

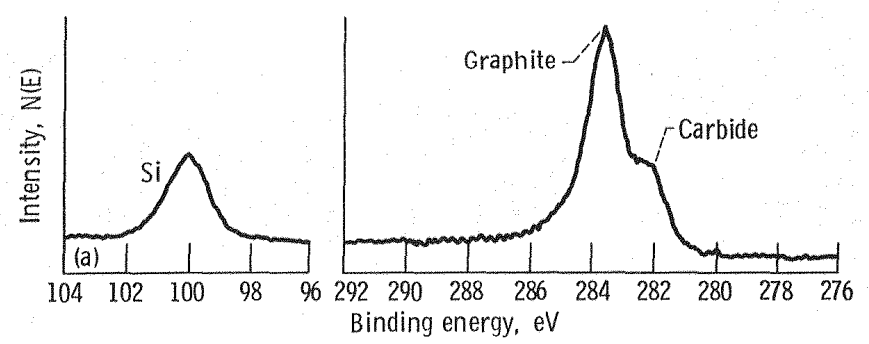

$$
\mathrm{Si}_{2 p} \text { XPS peak } \quad C_{1 S} \text { XPS peaks }
$$

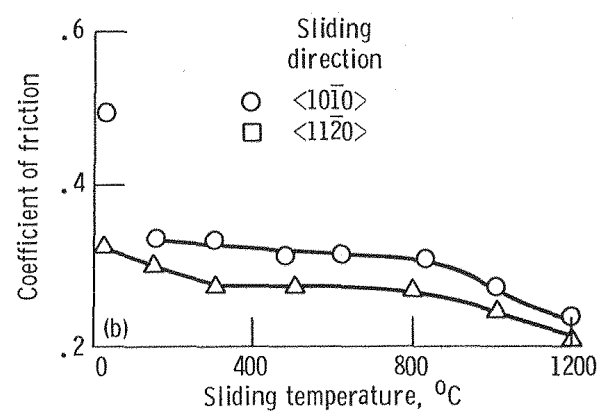

Figure $43 .-$ XPS spectra of silicon carbide surface heated to $1500^{\circ} \mathrm{C}$ and measured friction coefficients on that surface to $1200^{\circ} \mathrm{C}$ after graphitization. 


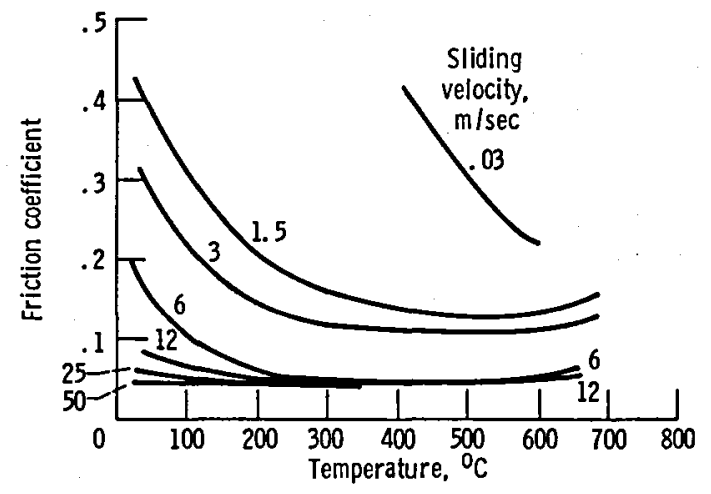

Figure 44 - Effect of sliding velocity and temperature on friction coefficient of bonded $\mathrm{PbO}-\mathrm{SiO}_{2} 0.03 \mathrm{~mm}$ thick; load: $9.8 \mathrm{~N}$ (Sliney, 1958).
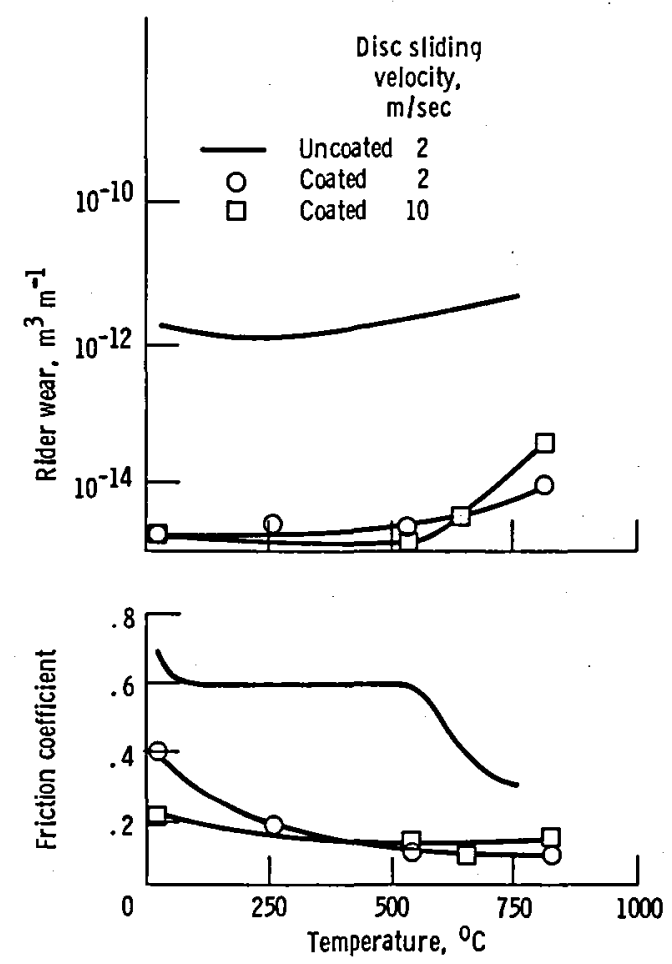

Figure 45. - Lubricating properties of $0.03 \mathrm{~mm}$ thick fused fluoride coating composition in air. Load: $4.9 \mathrm{~N}$ (Sliney, et al; 1965). 


\begin{tabular}{|c|c|c|}
\hline $\begin{array}{l}\text { 1. Report No. } \\
\text { NASA TM-87105 }\end{array}$ & 2. Government Accession No. & 3. Recipient's Catalog No. \\
\hline \multirow{2}{*}{\multicolumn{2}{|c|}{$\begin{array}{l}\text { 4. Title and Subtitle } \\
\text { Tribological Properties of Structural Ceramics }\end{array}$}} & $\begin{array}{l}\text { 5. Report Date } \\
\text { September } 1985\end{array}$ \\
\hline & & $\begin{array}{l}\text { 6. Performing Organization Code } \\
506-33-2\end{array}$ \\
\hline \multirow{2}{*}{\multicolumn{2}{|c|}{$\begin{array}{l}\text { 7. Author(s) } \\
\text { Donald H. Buckley and Kazuhisa Miyoshi }\end{array}$}} & $\begin{array}{l}\text { 8. Performing Organization Report No. } \\
\text { E-2649 }\end{array}$ \\
\hline & & 10. Work Unit No. \\
\hline \multirow{2}{*}{\multicolumn{2}{|c|}{$\begin{array}{l}\text { 9. Performing Organization Name and Address } \\
\text { National Aeronautics and Space Administration } \\
\text { Lewis Research Center } \\
\text { Cleveland, Ohio } 44135\end{array}$}} & \multirow{2}{*}{ 11. Contract or Grant No. } \\
\hline & & \\
\hline \multirow{2}{*}{\multicolumn{2}{|c|}{$\begin{array}{l}\text { 12. Sponsoring Agency Name and Address } \\
\text { National Aeronautics and Space Administration } \\
\text { Washington, D.C. } 20546\end{array}$}} & $\begin{array}{l}\text { 13. Type of Report and Period Covered } \\
\text { Technica } 1 \text { Memorandum }\end{array}$ \\
\hline & & 14. Sponsoring Agency Code \\
\hline \multicolumn{3}{|c|}{$\begin{array}{l}\text { 15. Supplementary Notes } \\
\text { To be published as a chapter in Structural Ceramics edited by John B. Wachtman, } \\
\text { Jr., Academic Press. }\end{array}$} \\
\hline \multicolumn{3}{|c|}{$\begin{array}{l}\text { 16. Abstract } \\
\text { The tribological and lubricated behavior of both oxide and non-oxide ceramics are } \\
\text { reviewed in this chapter. Ceramics are examined in contact with themselves, } \\
\text { other harder materials and metals. Elastic, plastic and fracture behavior of } \\
\text { ceramics in solid state contact is discussed. The contact load necessary to } \\
\text { initiate fracture in ceramics is shown to be appreciably reduced with tangential } \\
\text { motion. Both friction and wear of ceramics are anisotropic and relate to crystal } \\
\text { structure as has been observed with metals. Grit size effects in two- and three- } \\
\text { body abrasive wear are observed for ceramics. Both free energy of oxide forma- } \\
\text { tion and the d valence bond character of metals are related to the friction and } \\
\text { wear characteristics for metals in contact with ceramics. Surface contaminants } \\
\text { affect friction and adhesive wear. For example, carbon on silicon carbide and } \\
\text { chlorine on aluminum oxide reduce friction while oxygen on metal surfaces in } \\
\text { contact with ceramics increases friction. Lubrication increases the critical } \\
\text { load necessary to initiate fracture of ceramics both in indentation and with } \\
\text { sliding or rubbing. Ceramics compositions both as coatings and in composites are } \\
\text { described for the high temperature lubrication of both alloys and ceramics. }\end{array}$} \\
\hline \multirow{2}{*}{\multicolumn{3}{|c|}{\begin{tabular}{l|l} 
17. Key Words (Suggested by Author(s)) & 18. Distribution Statement \\
Adheston; Friction; Wear; & Unclassified - un limited \\
Lubrication; Tribology & STAR Category 27
\end{tabular}}} \\
\hline & & \\
\hline $\begin{array}{l}\text { 9. Security Classiff (of this report) } \\
\text { Unc lass if ied }\end{array}$ & $\begin{array}{l}\text { 20. Security Classiff. (of this page) } \\
\text { Unc las if ied }\end{array}$ & 21. No. of pages \\
\hline
\end{tabular}

*For sale by the National Technical Information Service, Springfield, Virginia 22161 
End of Document 